$$
\text { البحث الثانى عشـر : }
$$

دور التفطيط الإستراتيجي في تحقيق الميزة التنافسية لجاهمة

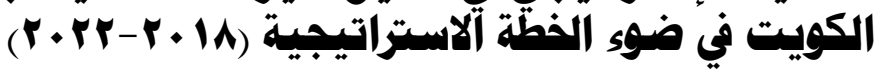

$$
\begin{aligned}
& \text { : إلحافاك } \\
& \text { د. فيصل فهد الرشيليدي } \\
& \text { دكتوراه يِّ أصول التربيت والتخطيط التربوي } \\
& \text { دولت الكويت }
\end{aligned}
$$





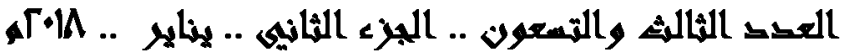

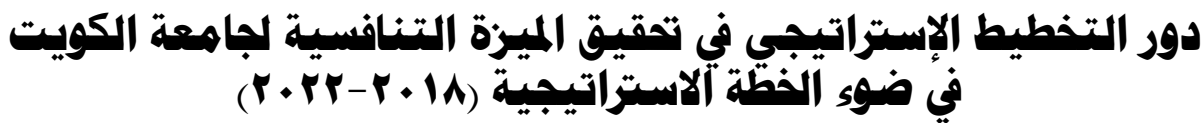

د. فيصل فهد الربشيلي التئي

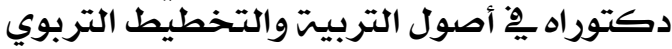

دولت الكويت

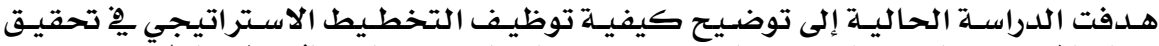

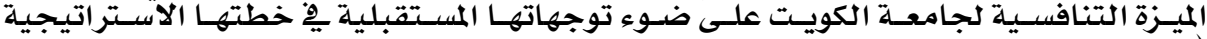

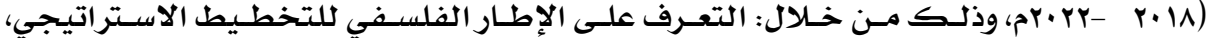

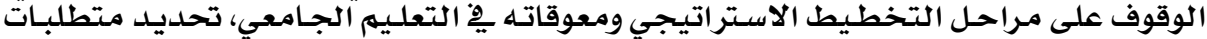

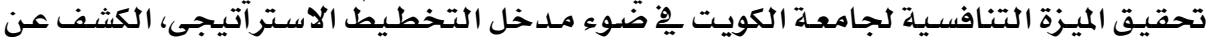

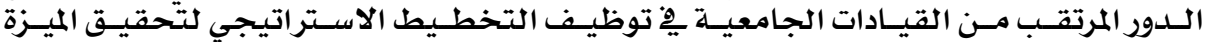

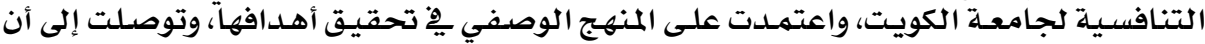

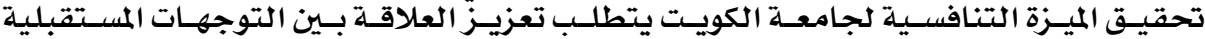

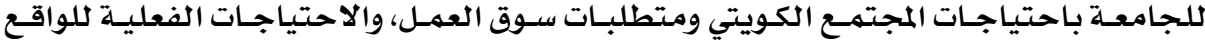

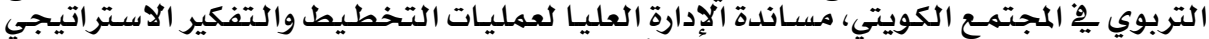

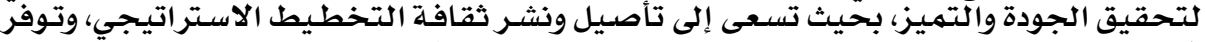

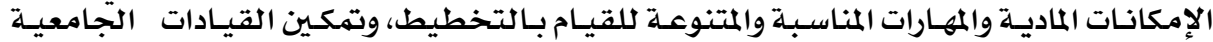

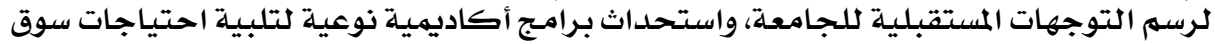

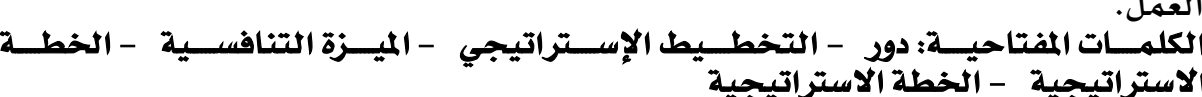

The Role of Strategic Planning in Achieving the Competitive Advantage of Kuwait University in the Light of the Futuristic s of Strategic Plan (2018-2021)

Dr. Faisal Fahad El-Rashidi

Abstract:

The current study aimed to clarify how to use strategic planning in achieving the competitive advantage of Kuwait University in the light of the futuristic orientations of its strategic plan (2018-2021) through acknowledging the philosophical framework of the strategic planning, defining the phases of strategic planning and its obstacles in university education, and determining the requirements needed for achieving the competitive advantage of Kuwait University in the light of strategic planning.The study depended on the Descriptive Method to achieve its objectives and reached some results including; supporting the relationship between the strategic intents of the university with the expectations and needs of the Kuwaiti society and labor market, support of academic for processs and activities of strategic planning in order to achieve quality and excellence, spreading the quality culture and providing resources and convievent skils an developing the academic programs to satisfy the requirements of wpork labor.

Key Words: Role- Strategic planning-competitive advantage-plan 


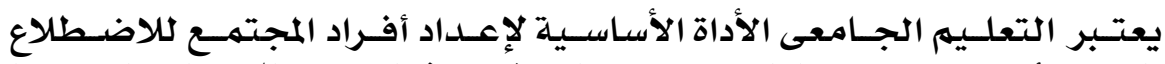

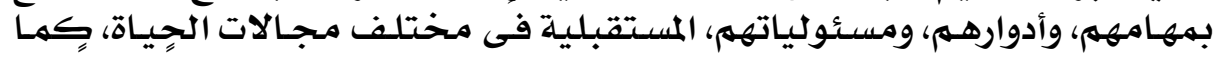

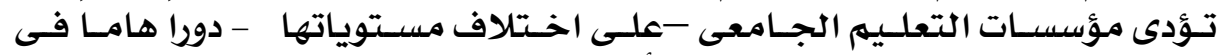

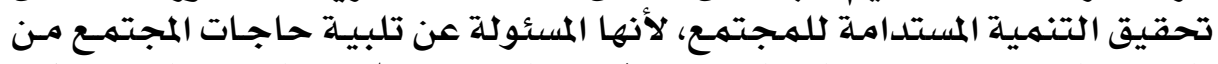

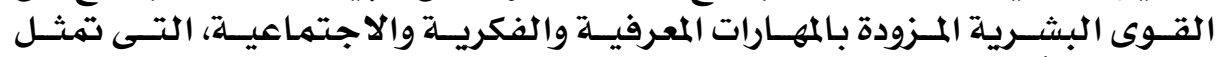

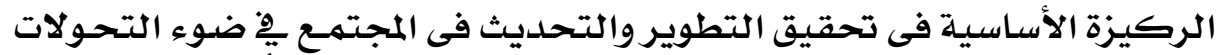

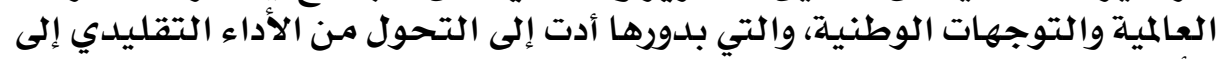

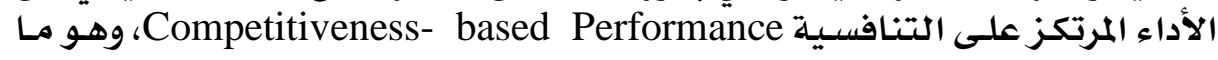

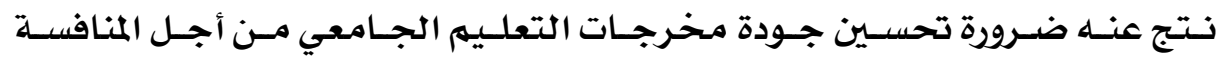

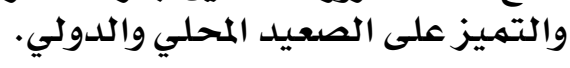

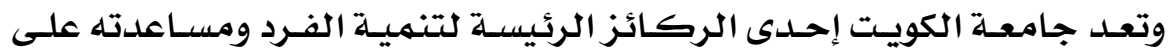

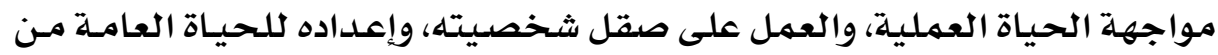

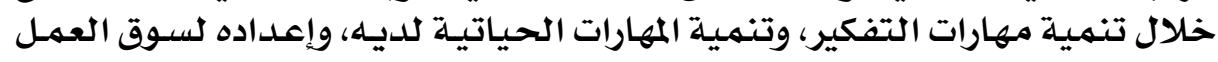

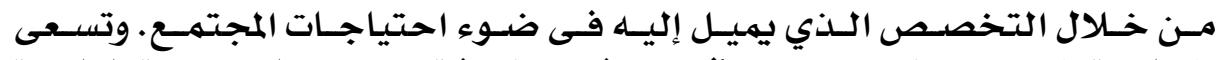

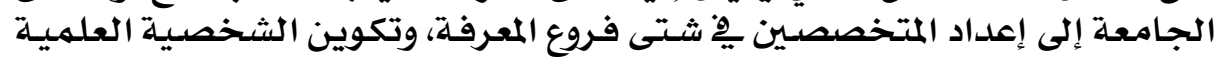

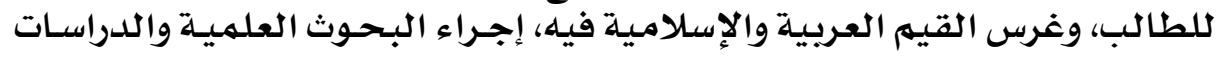

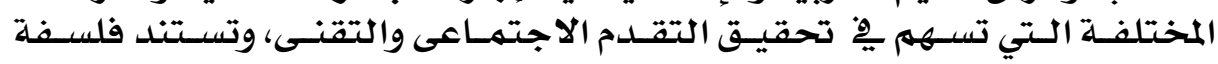

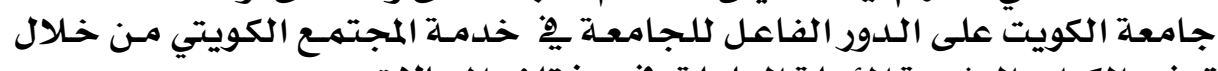

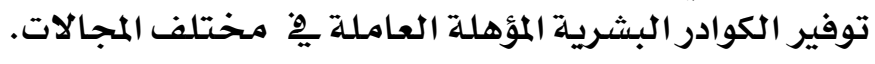

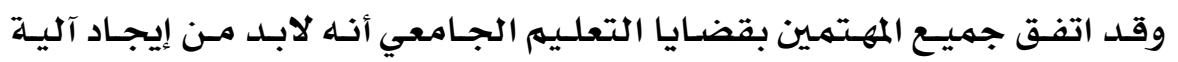

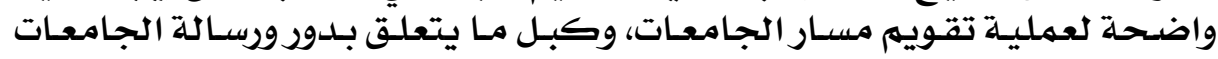

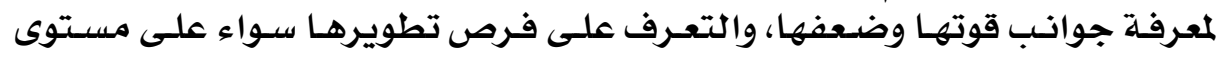

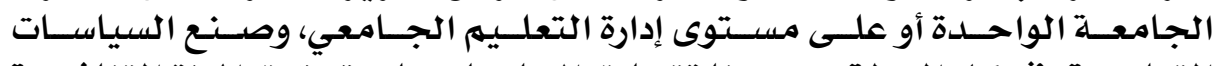

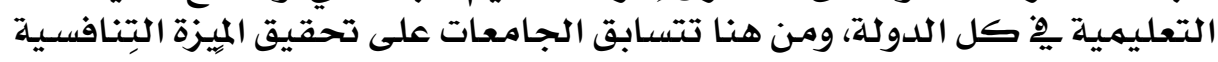

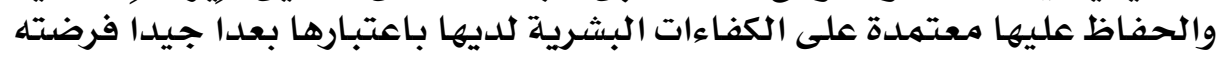

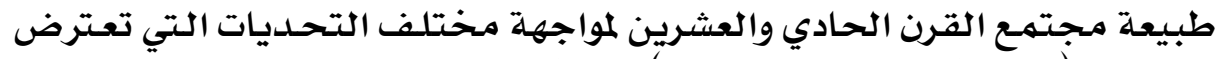

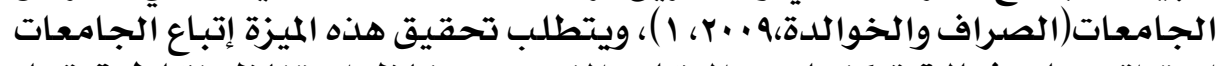

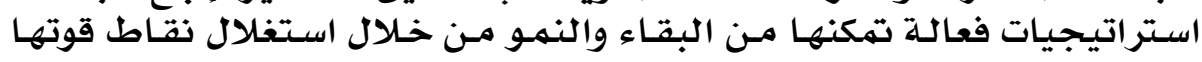

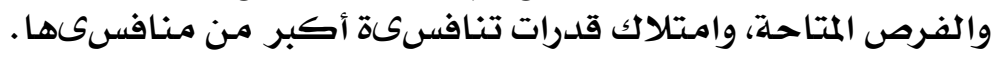

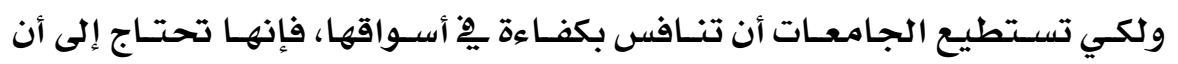

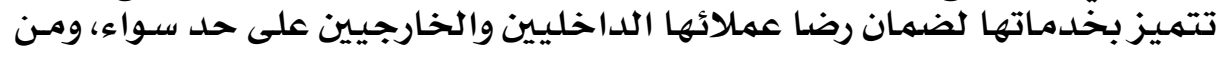

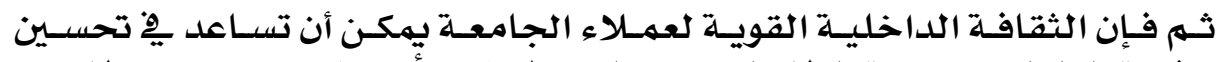

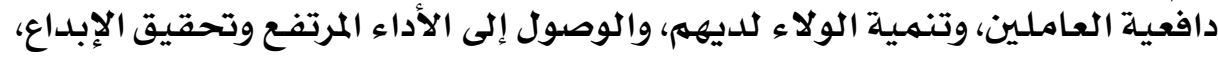

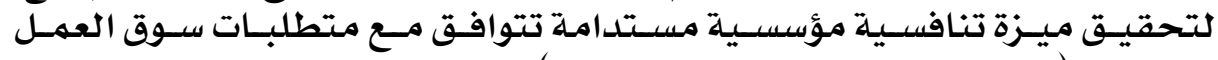

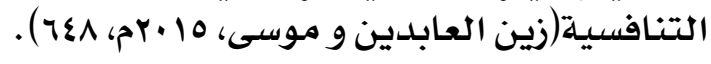




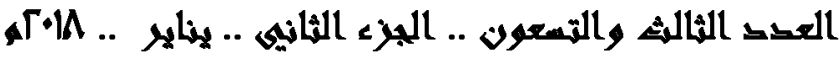

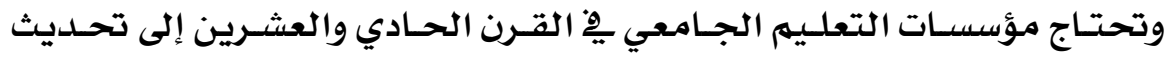

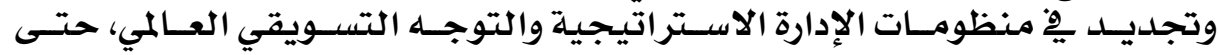

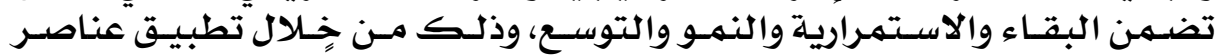

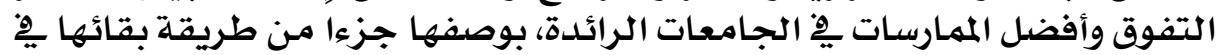

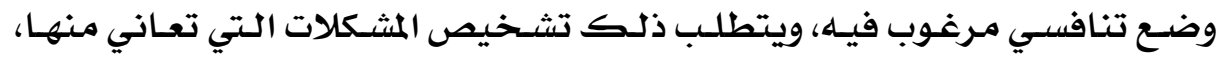

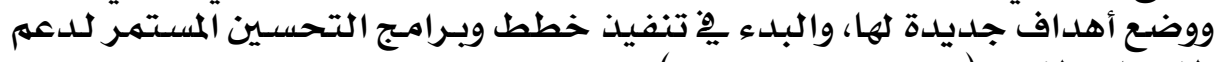

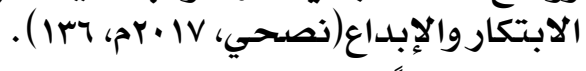

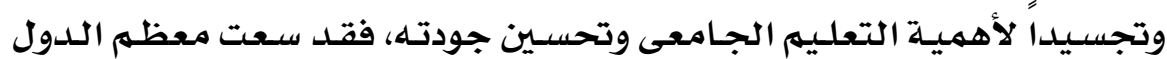

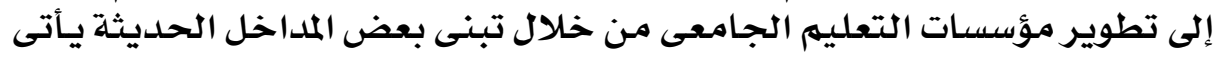

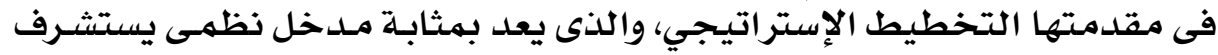

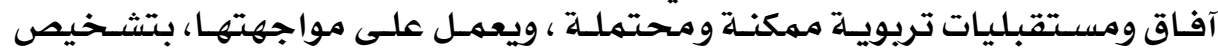

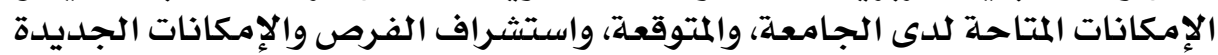

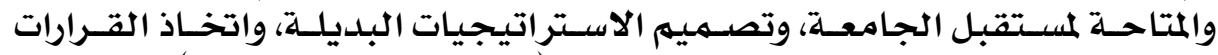

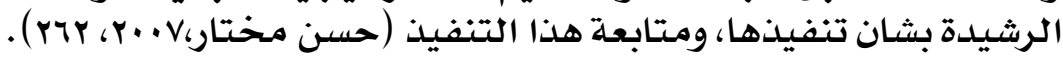

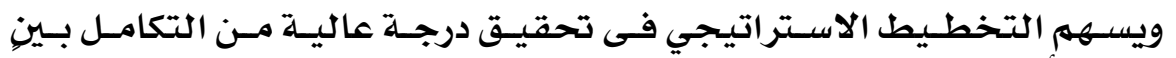

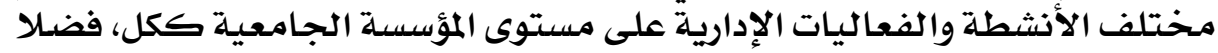

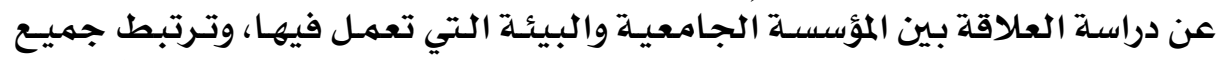

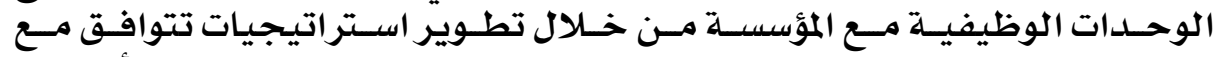

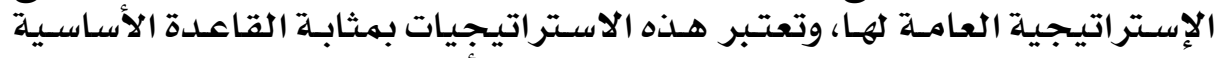

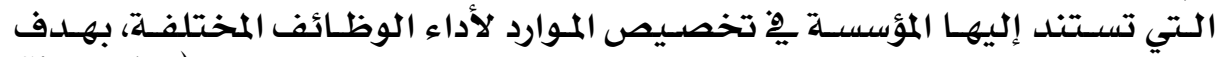

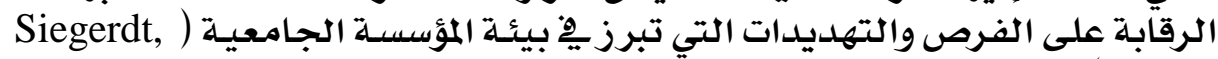
. (2006,8

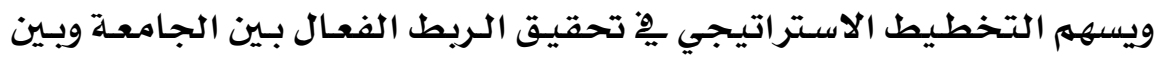

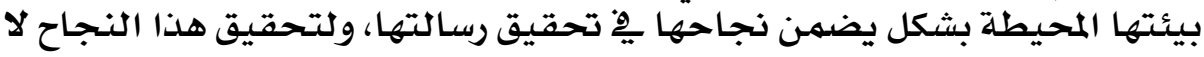

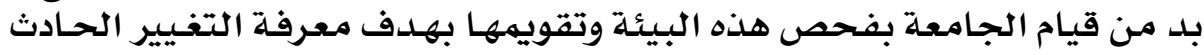

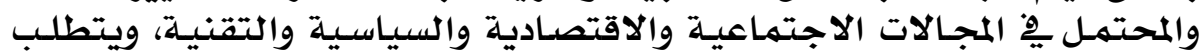

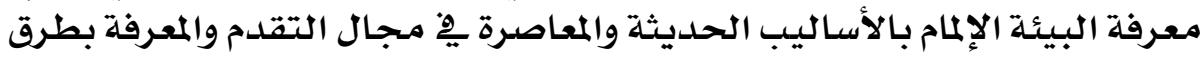

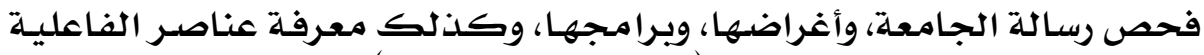

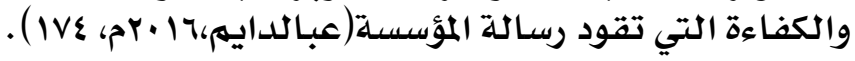

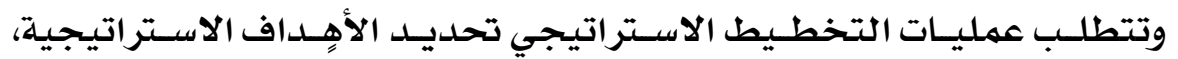

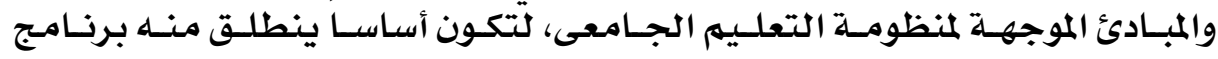

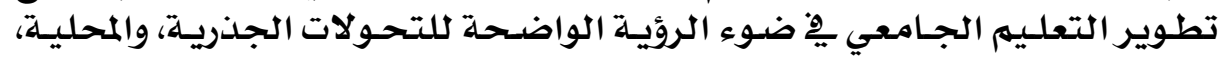

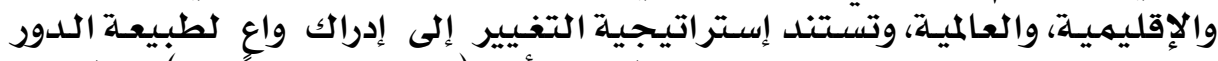

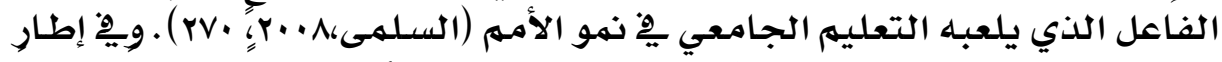

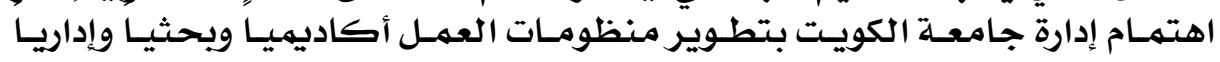




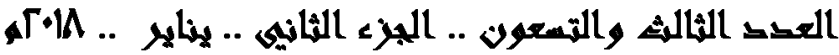

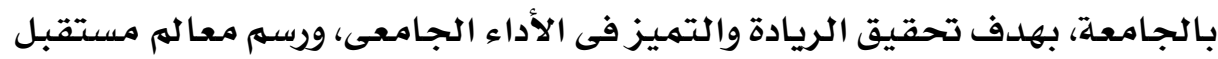

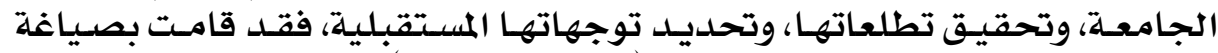

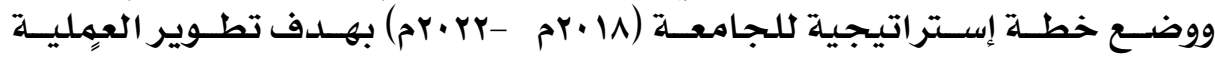

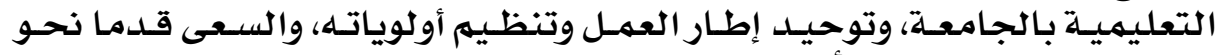

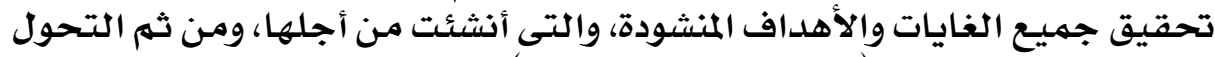

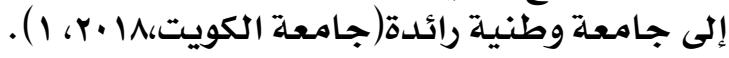

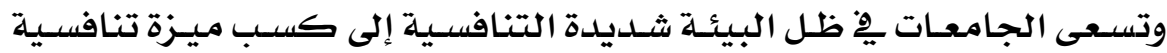

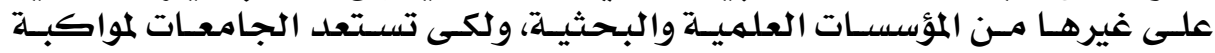

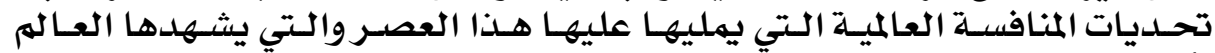

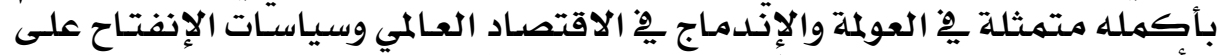

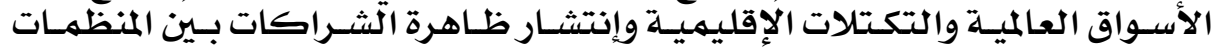

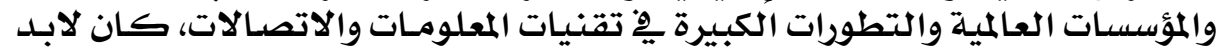

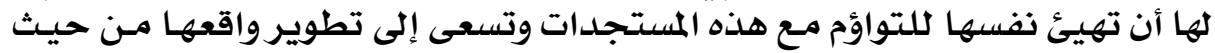

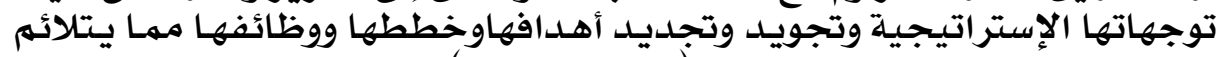

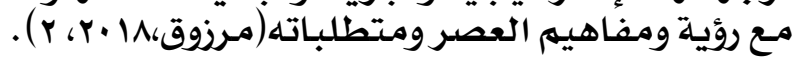

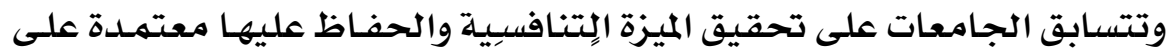

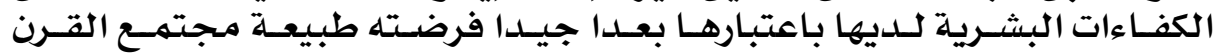

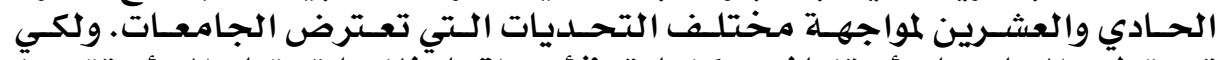

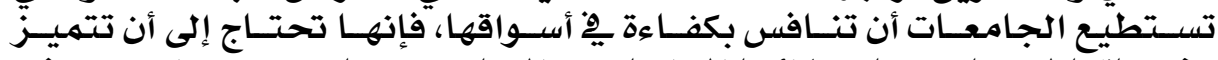

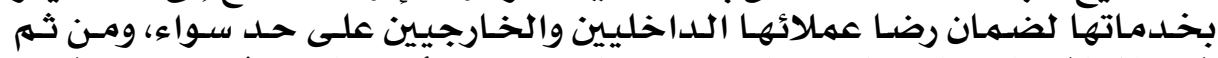

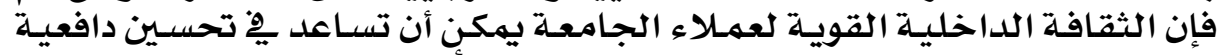

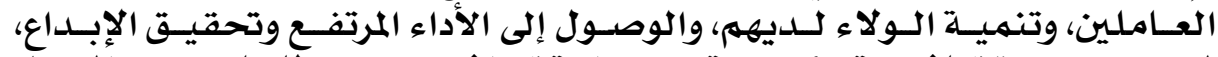

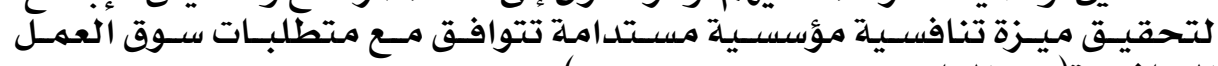

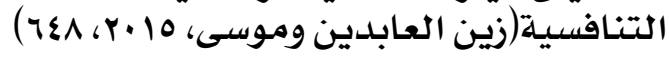

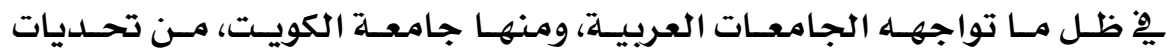

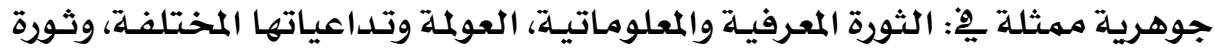

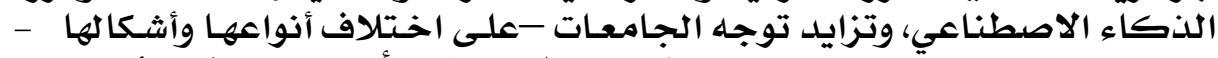

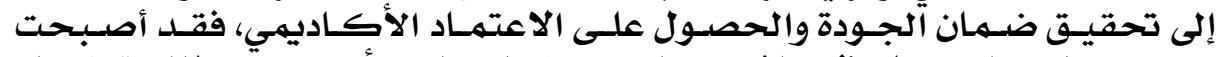

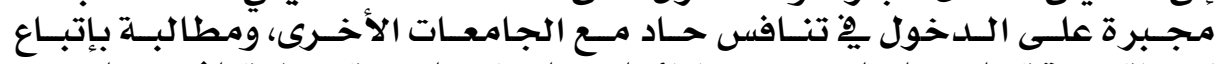

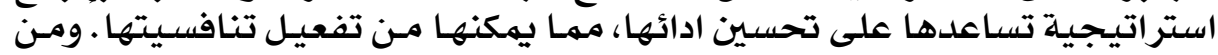

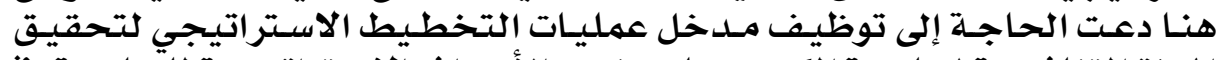

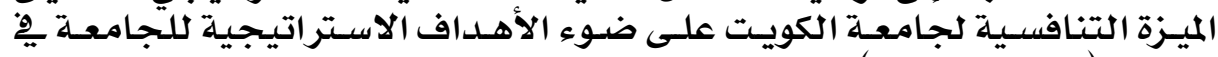

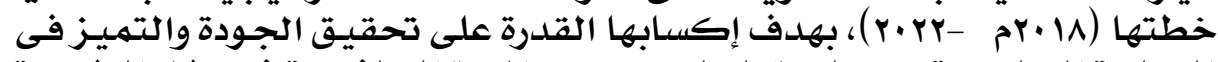

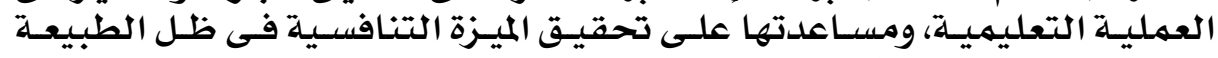

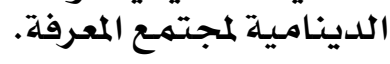

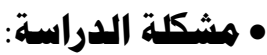

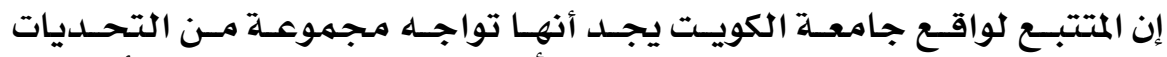

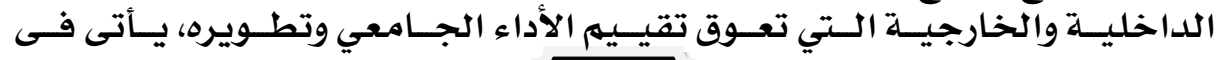

\section{$\varepsilon 7 \varepsilon$}




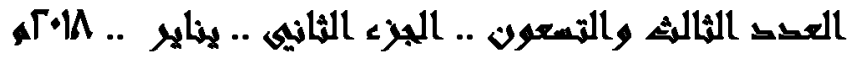

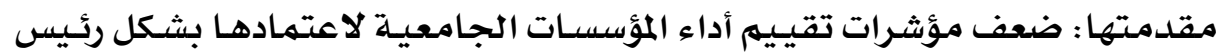

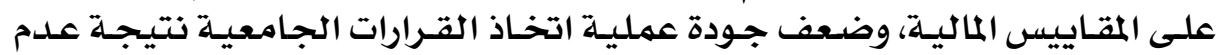

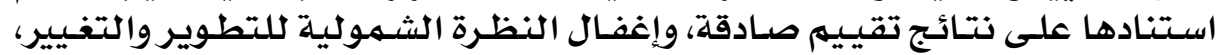

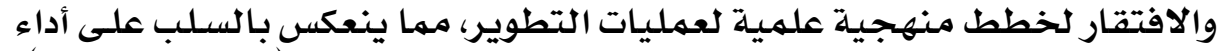

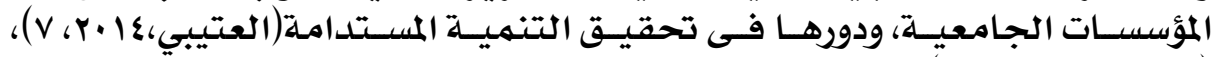

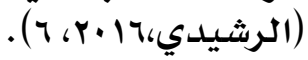

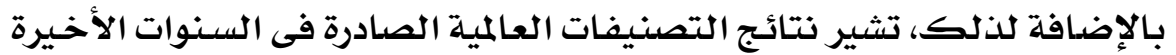

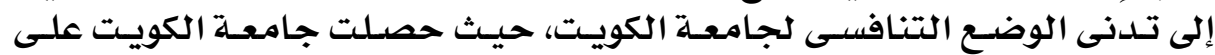

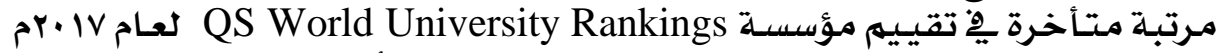

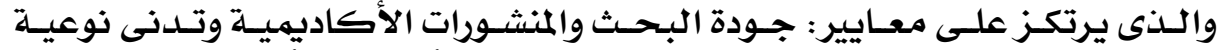

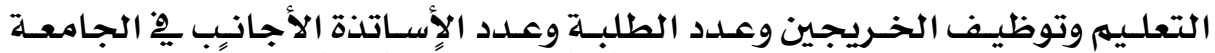

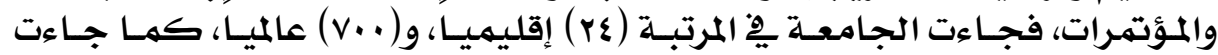

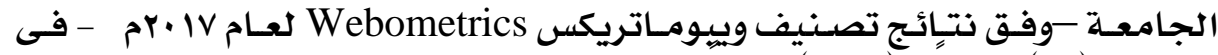

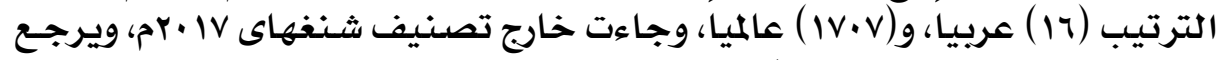

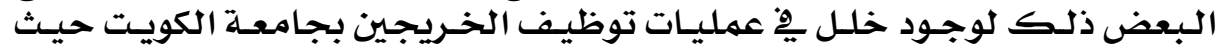

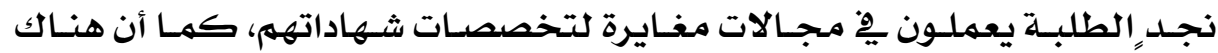

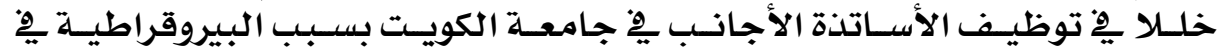

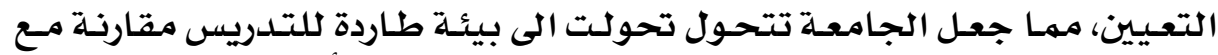

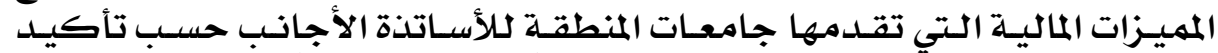

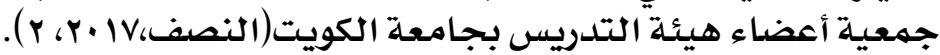

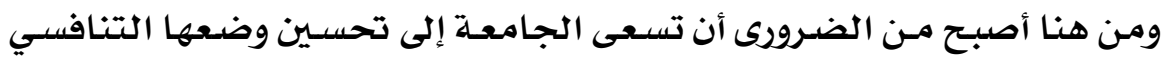

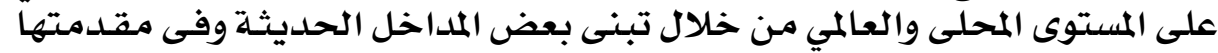

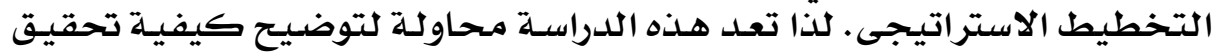

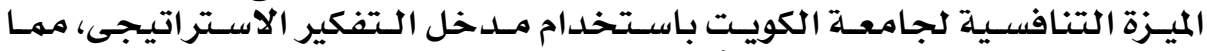

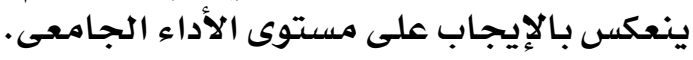

واستتادا إلى مـا سبق، يهكن صياغة مشكلة الدراسة فى السؤال الرئيس التالى:

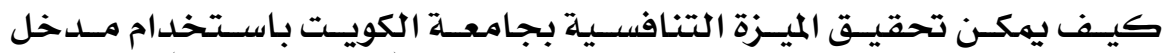

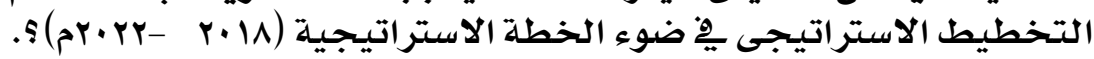
وتتطلب الإجابة عن هذا السؤال الإجابـة عن الأسئلة الآتيـة:

14 ما الإطار الفلسفي للتخطيط الاستراتيجي ومعوقاته يِ إنتعليه الجامعي؟.

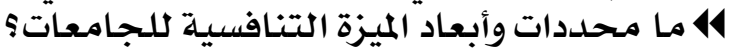

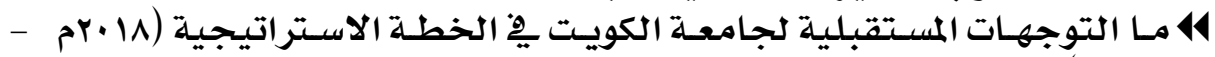
.

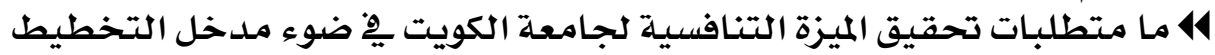

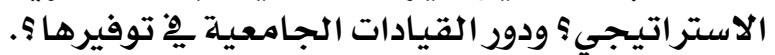




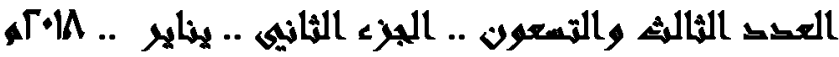

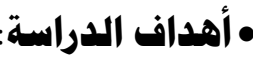

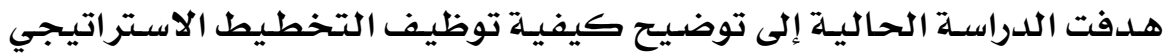

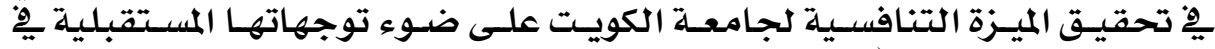

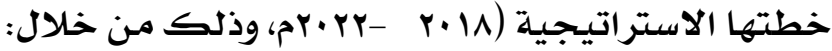

14 التعرف على الإطار الفلسفي للتخطيط الاستراتيـي.

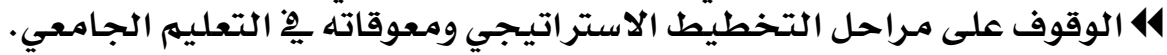

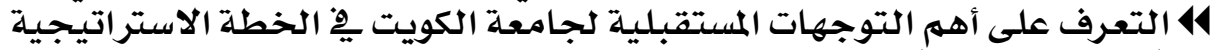

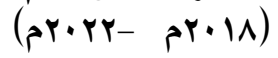

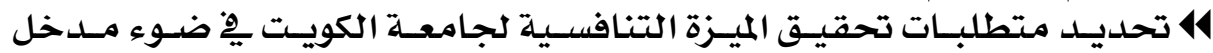

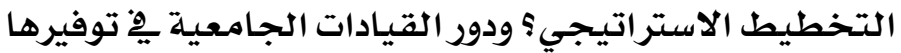

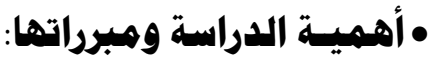

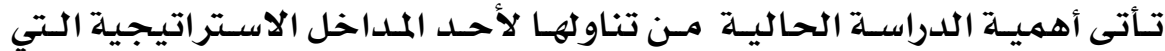

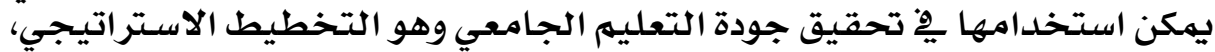

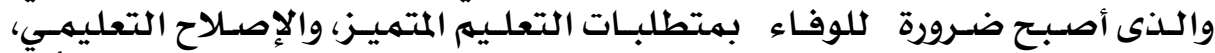

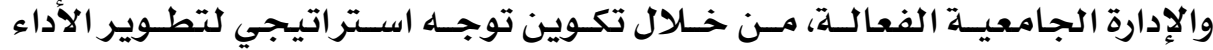

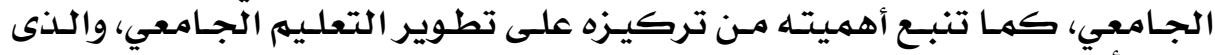

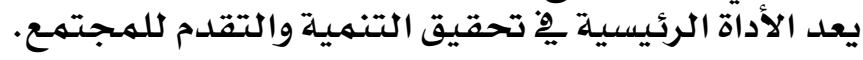

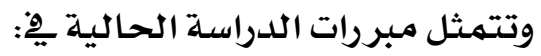

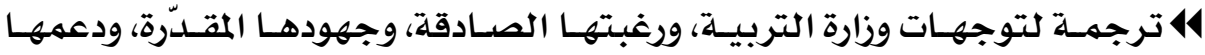

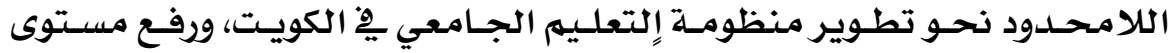

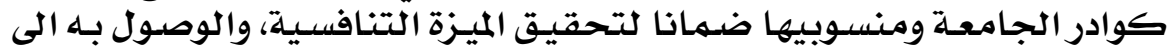
المستوى العالمي.

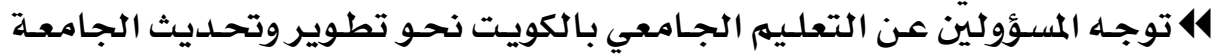

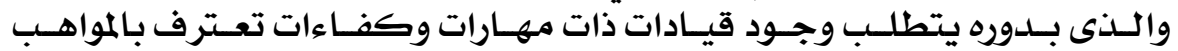

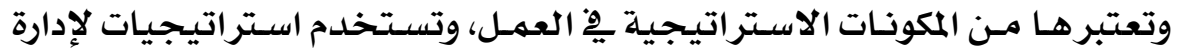

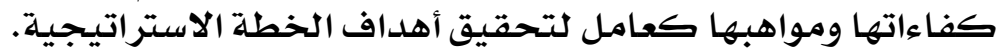

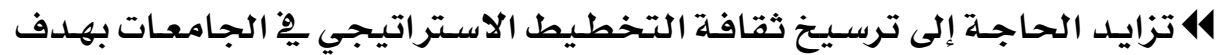

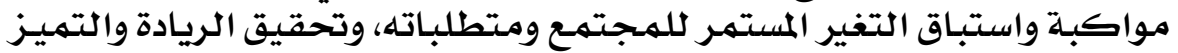

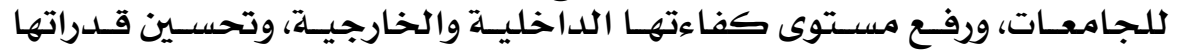

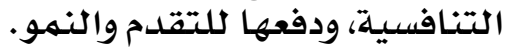

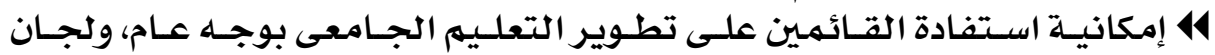

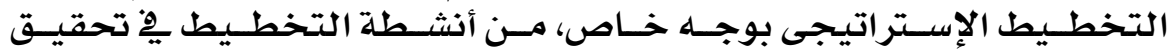
التتنافسيـة التعليهـيـة.

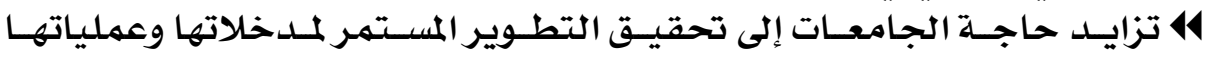

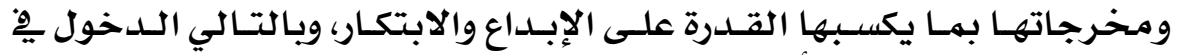
تنافسية مـ الجـامعات الأخرى. 


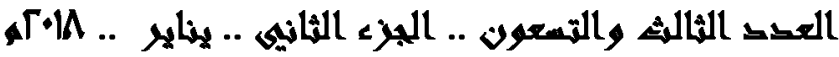

• منهج الدراسسة:

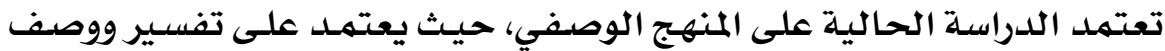

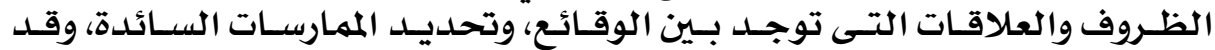

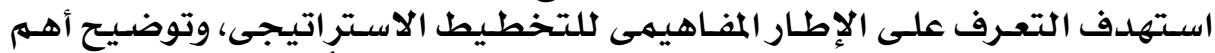

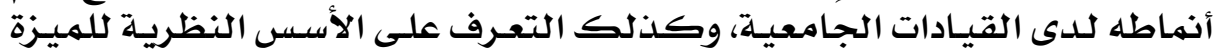

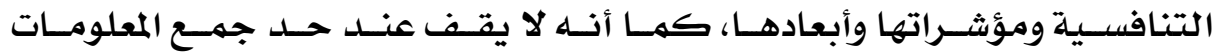

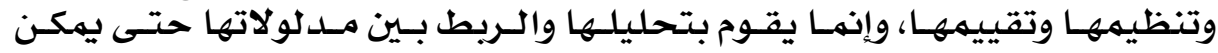

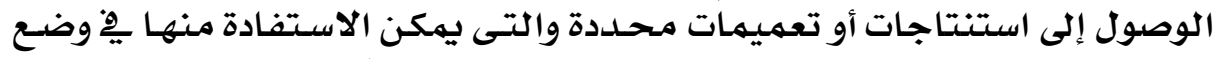

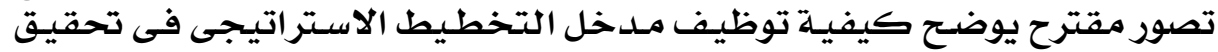

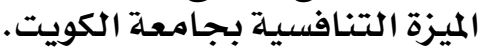

• مصطات الدمات الدراسة:

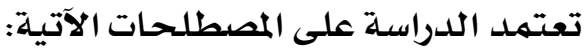

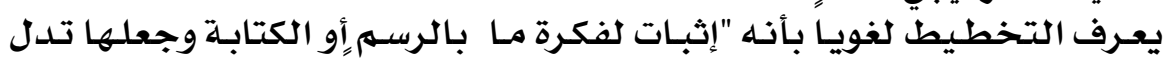

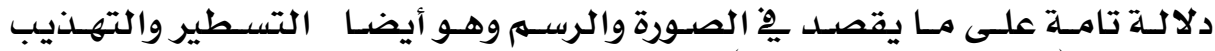

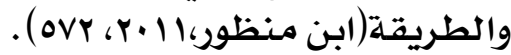

ويعرف التخطيط الإستراتيجىى بأنه منهج نظامى يستشـرف آفاق المستقتبليات

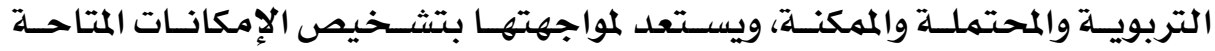

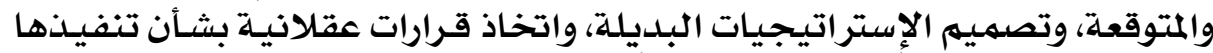

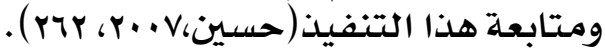

كما يعرف التخطيط الإستراتيجى بأنه جهد مـنظم يهـدف إلى اتخـاذ قـرارات

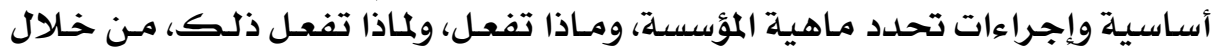

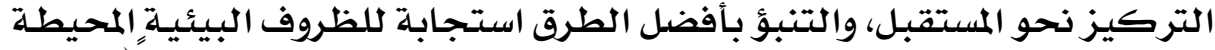

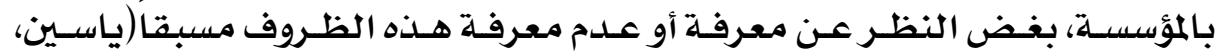
. (ro r. r. q

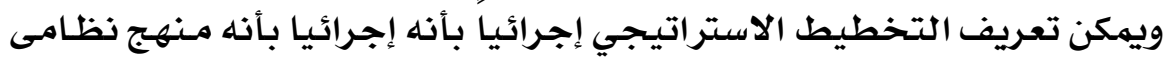

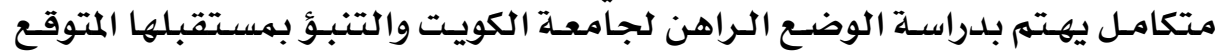

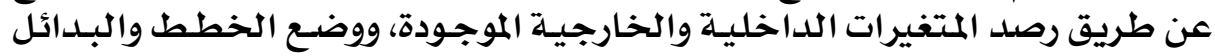

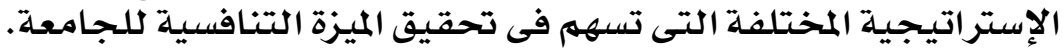

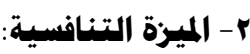

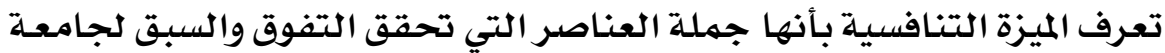

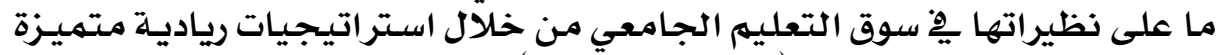

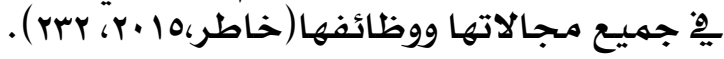

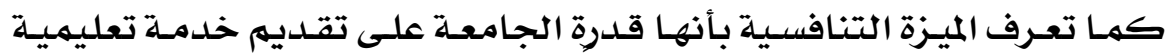

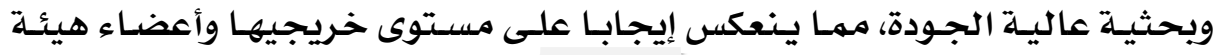




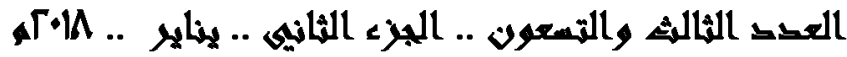

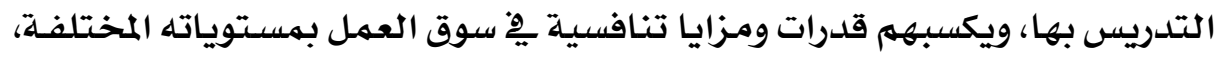

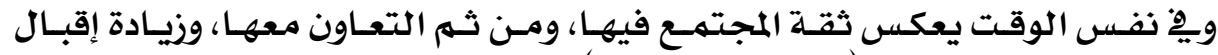

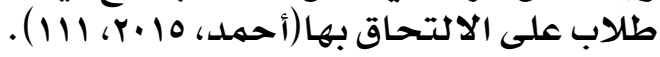

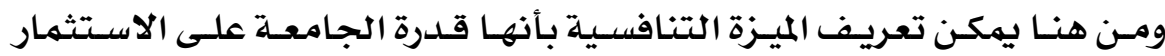

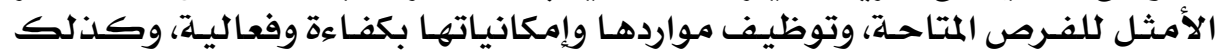

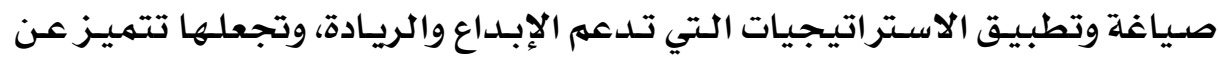

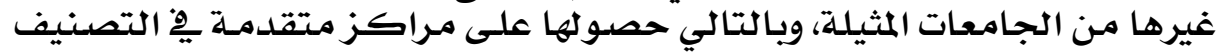

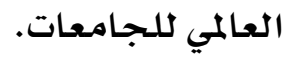

\section{• الدراسات السابقة:}

ويمكن تقسيه الدراسـات السابقة على السيق النحو الآتي:

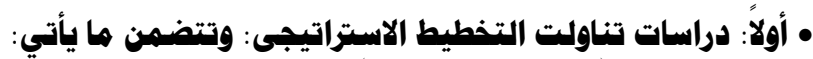

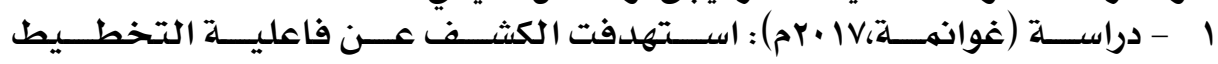

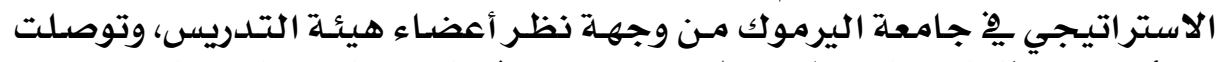

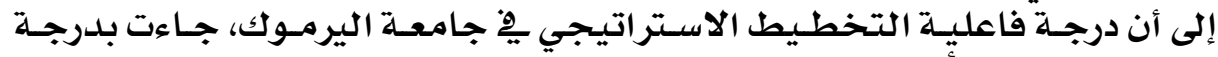

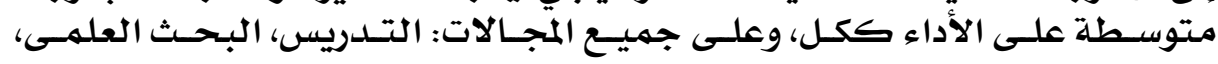

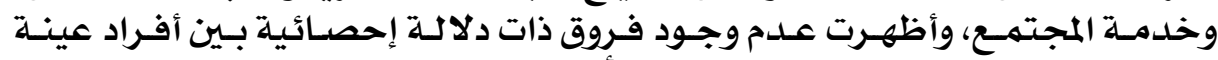

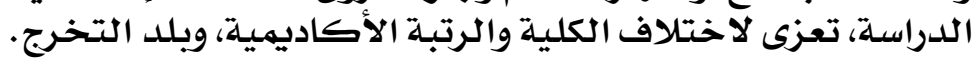

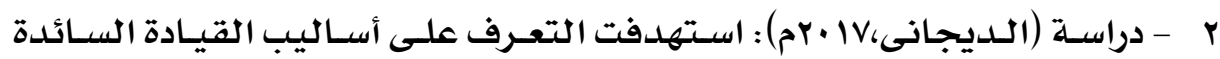

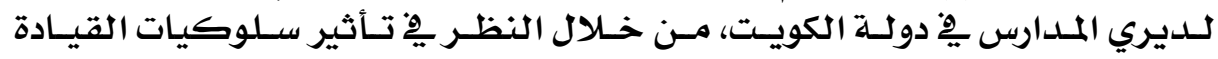

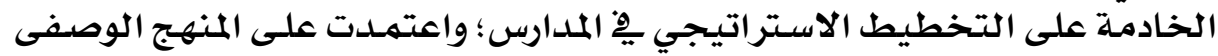

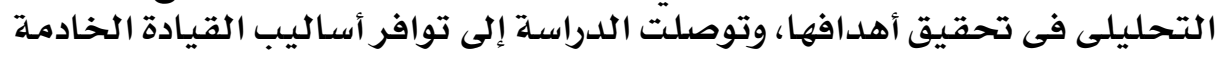

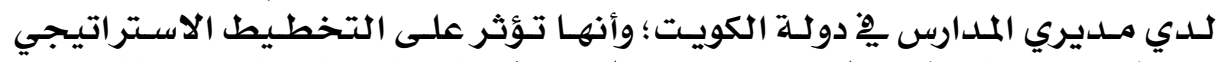

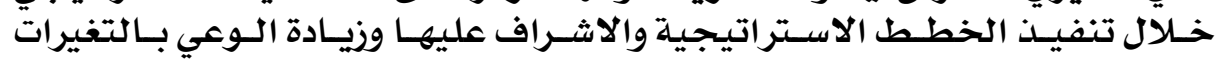

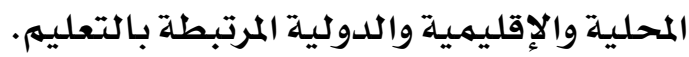

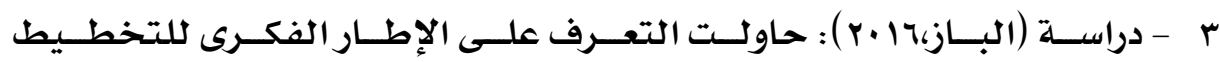

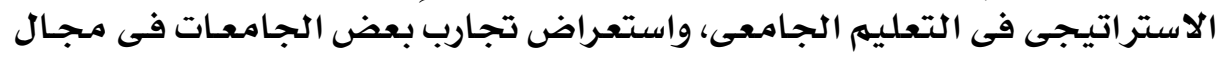

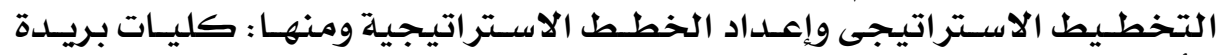

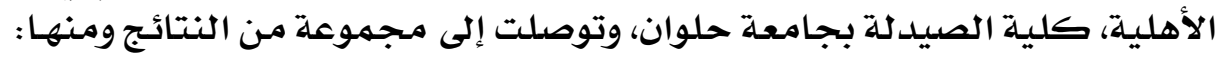

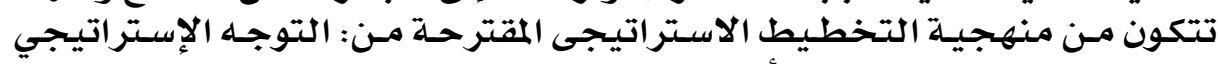

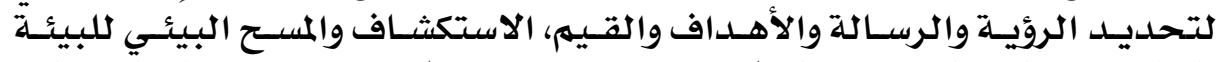

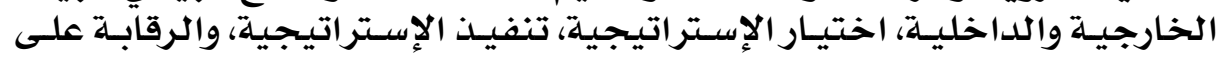

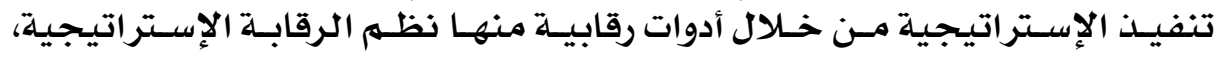
والقياس المقارن.

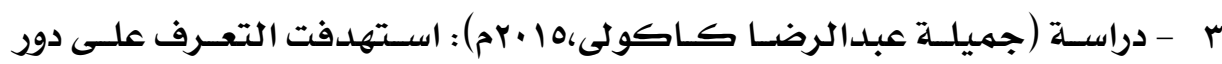

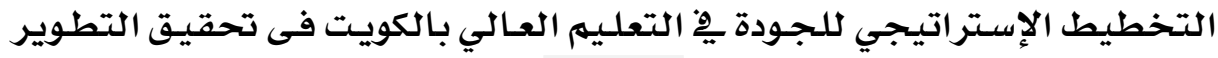

\section{$\varepsilon 7 \wedge$}




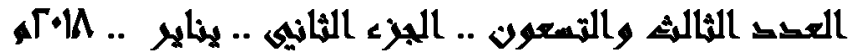

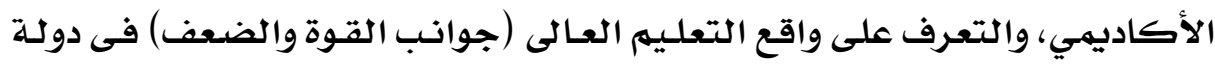

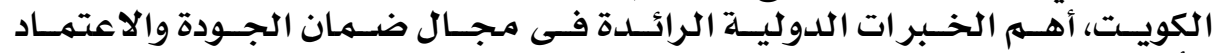

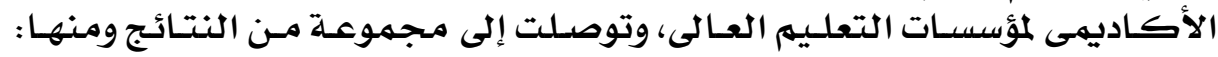

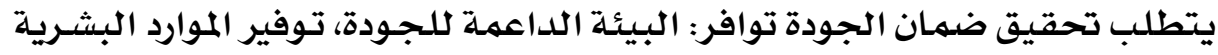

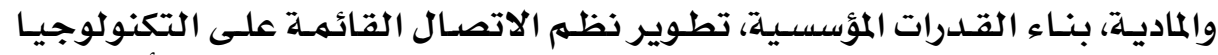

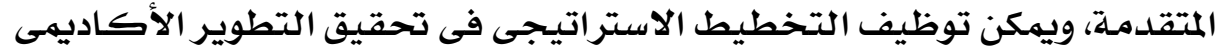

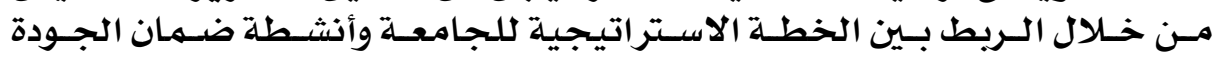

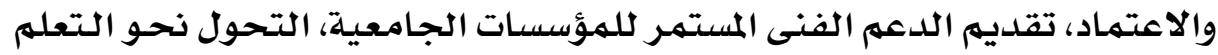
التنظيهى.

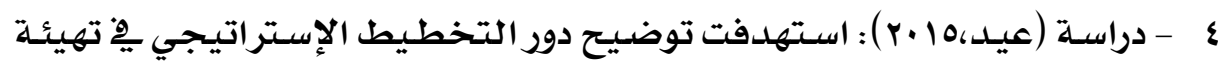

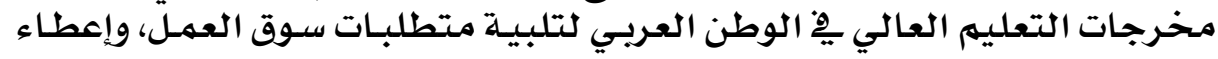

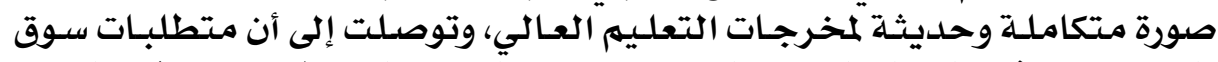

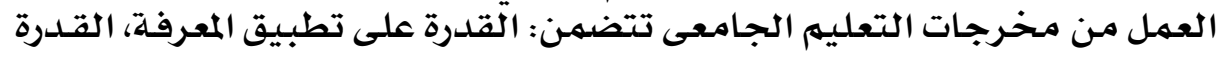

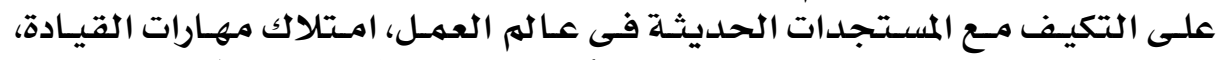

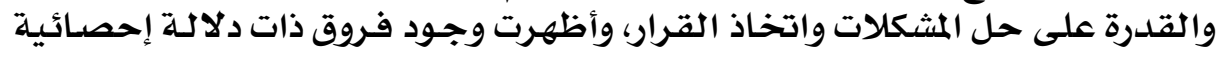

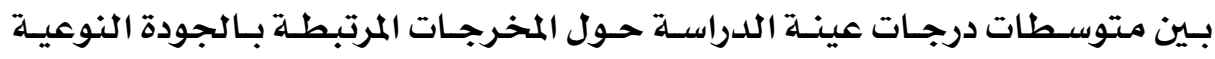

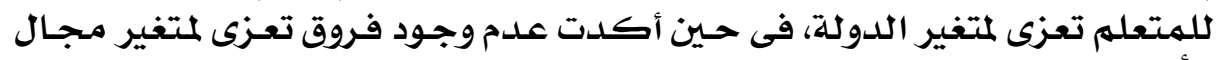

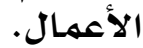

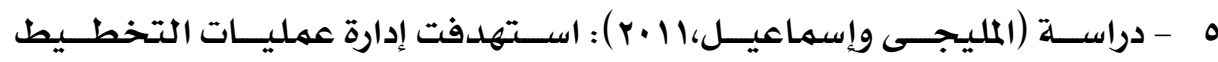

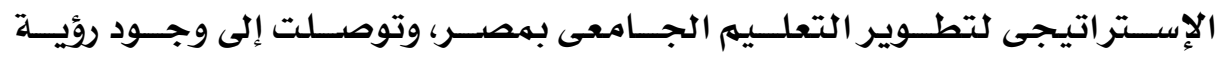

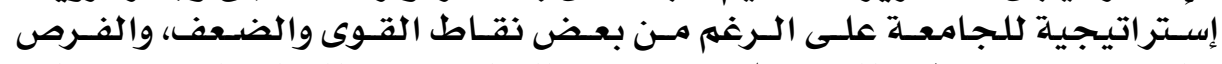

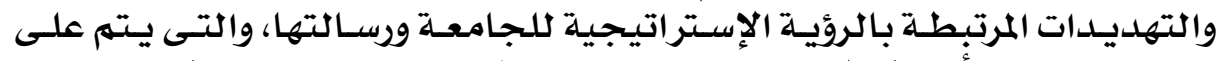

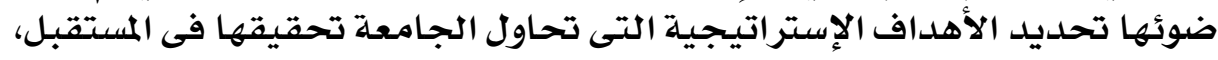

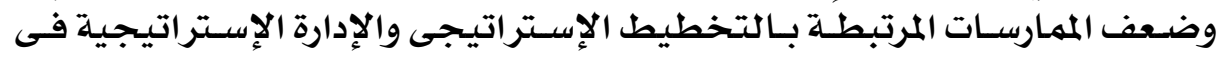

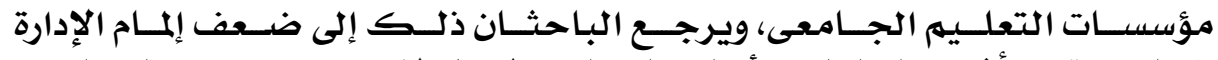

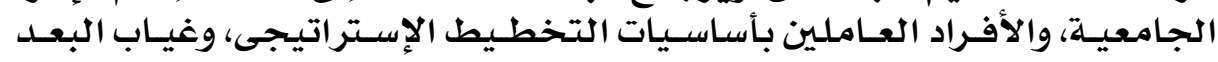

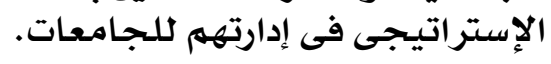

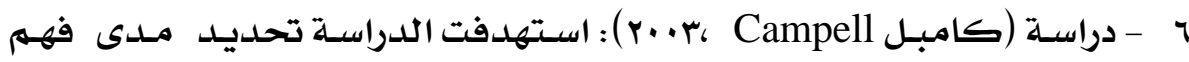

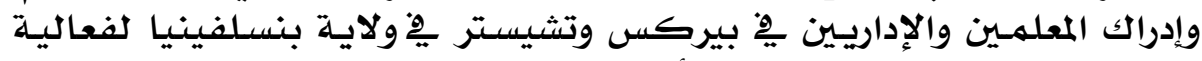

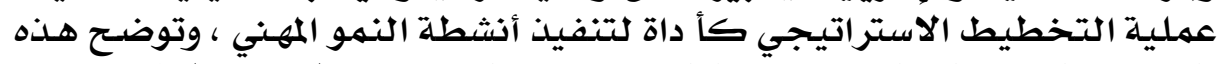

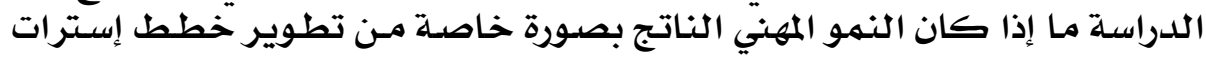

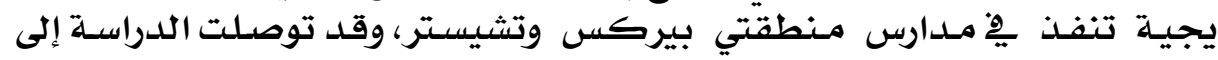

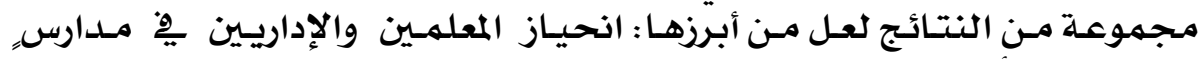

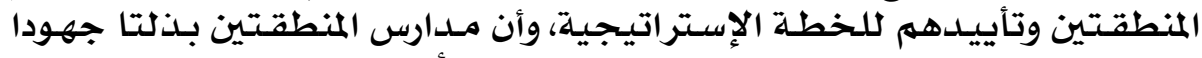

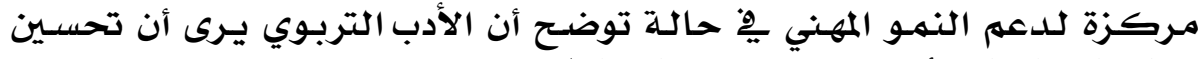

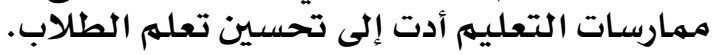

\section{9}




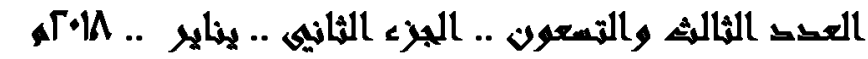

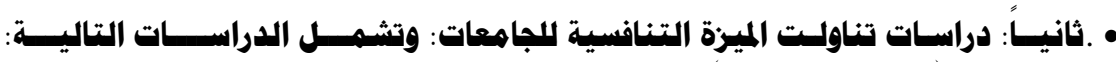

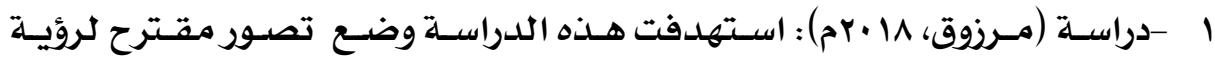

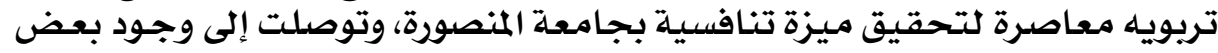

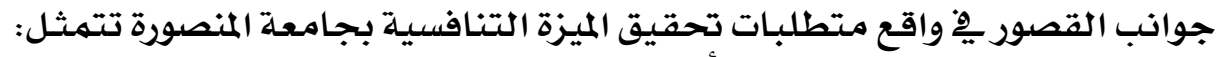

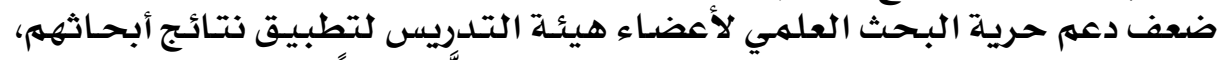

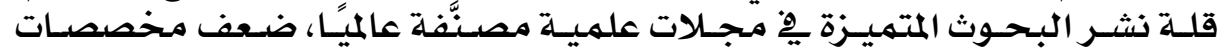

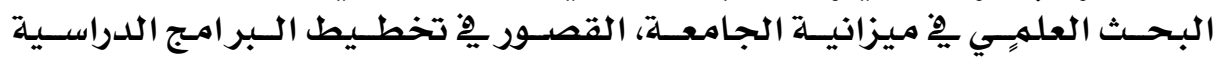

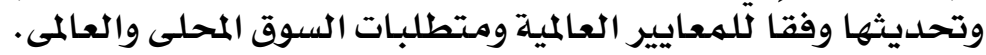

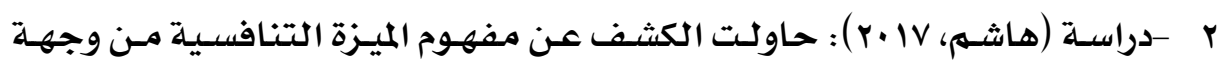

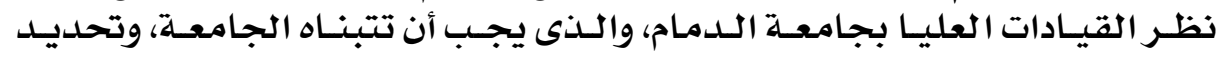

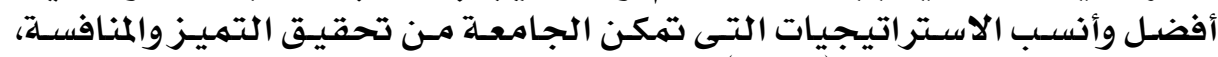

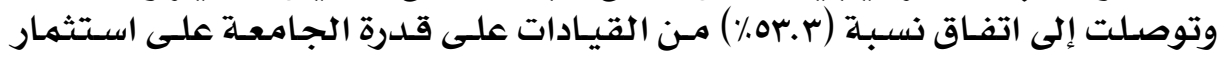

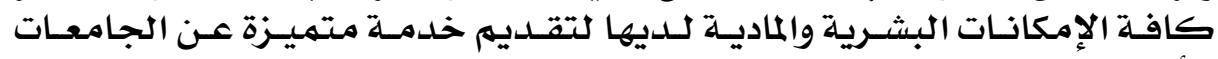

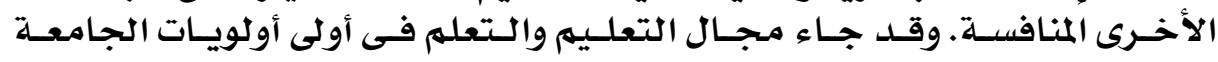

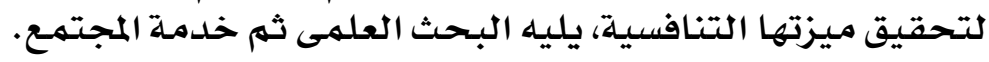

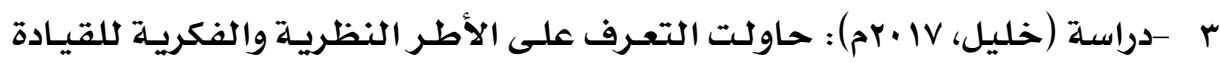

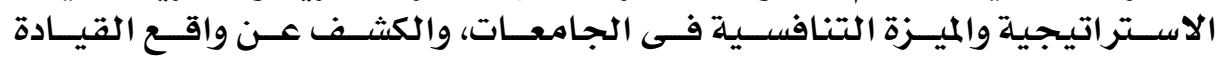

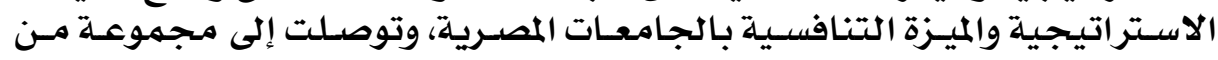

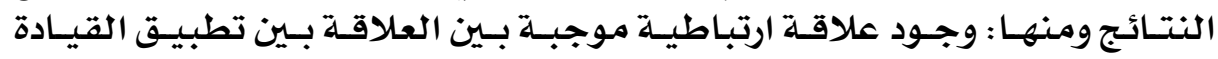

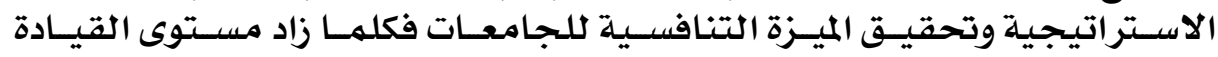

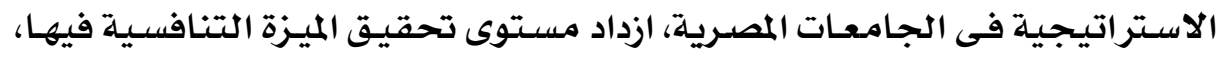

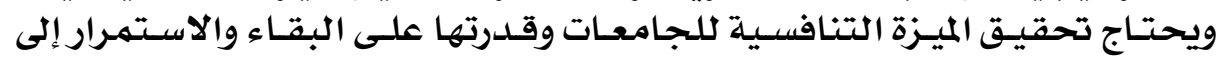

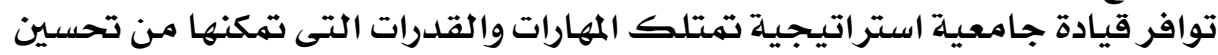
الوضع التنافسى لثها.

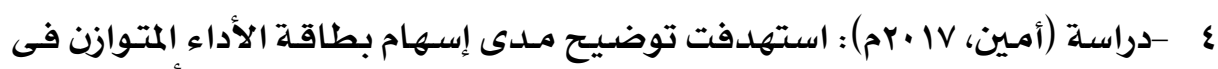

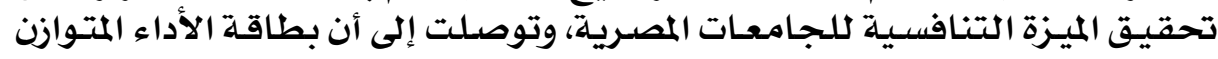

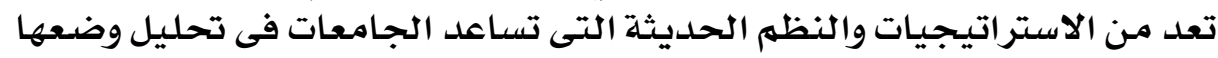

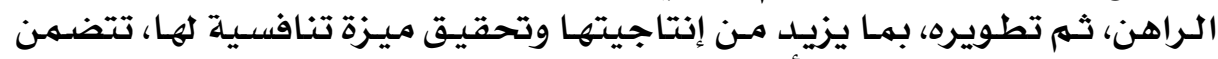

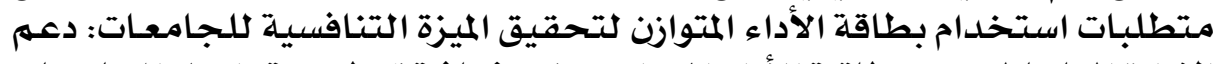

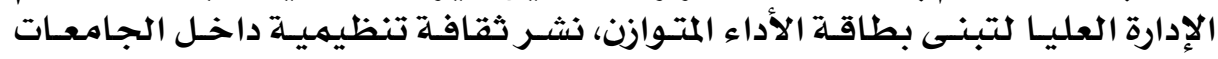

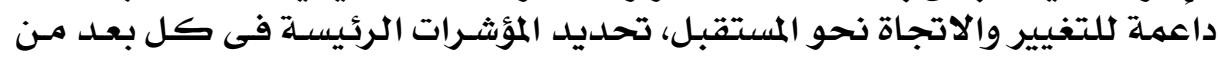

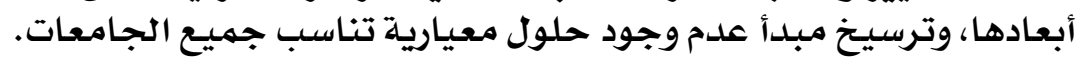

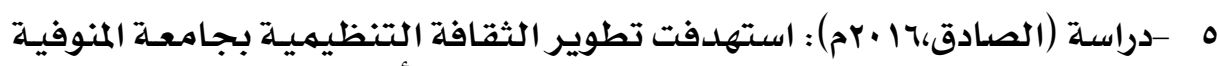

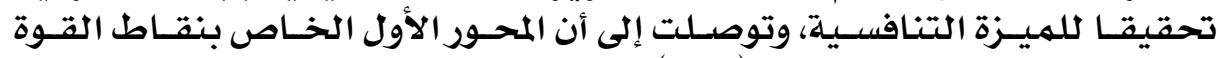

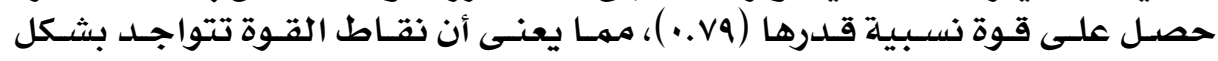

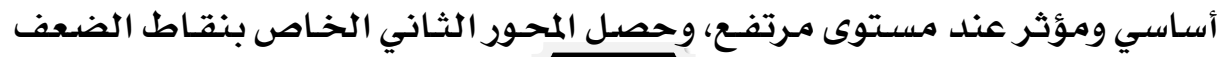

\section{$\varepsilon \vee$}




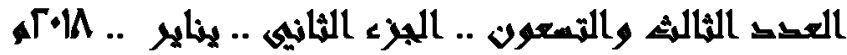

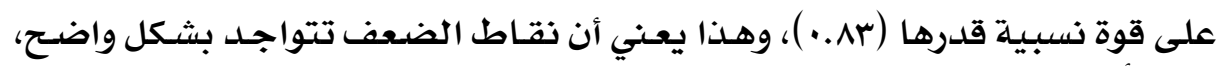

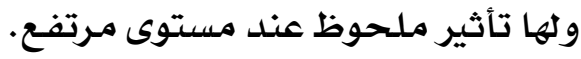

Y - دراسة (أحمد، 10 ·rم) : حاولت التعرف على درجة توافر متطلبـات تطبيق سـتة

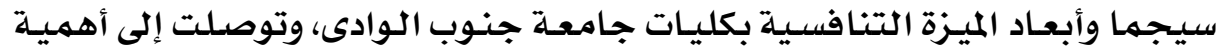

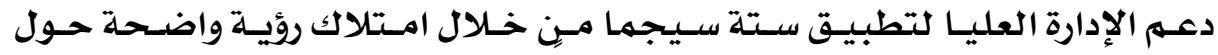

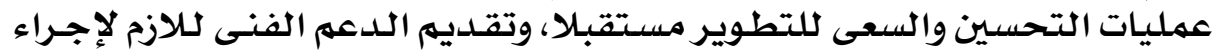

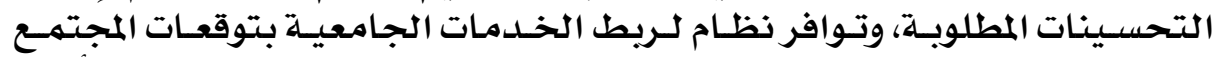

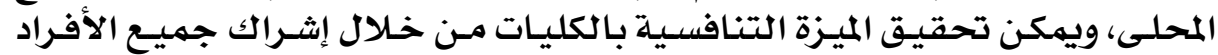

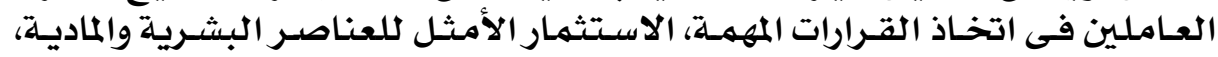

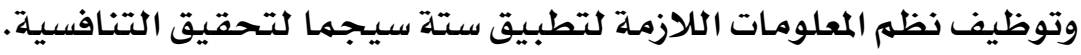

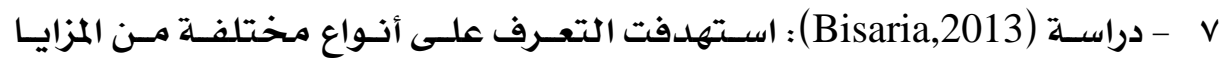

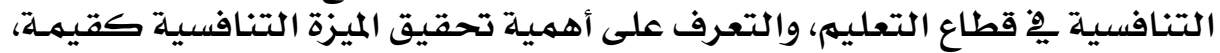

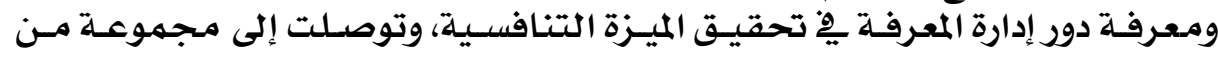

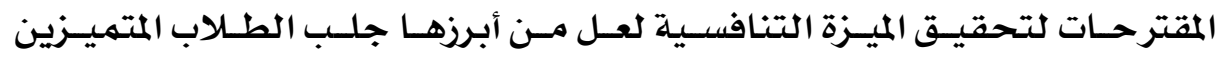

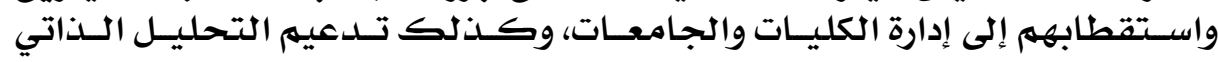

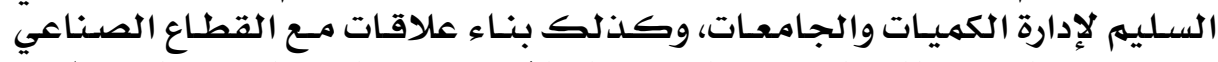

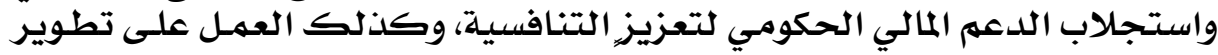

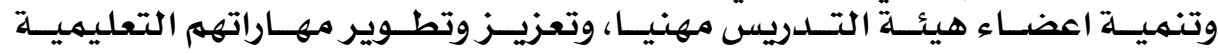

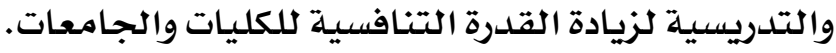

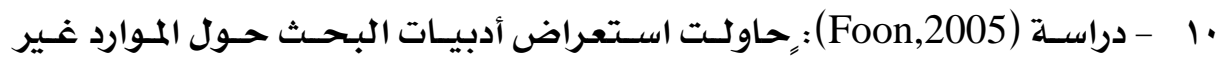

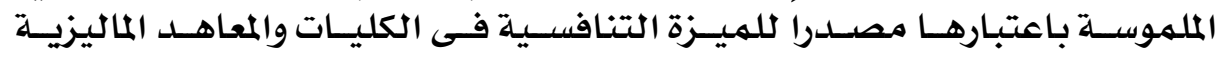

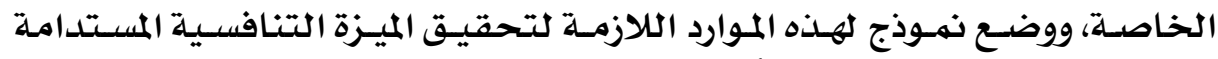

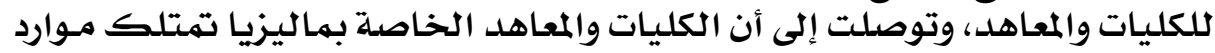

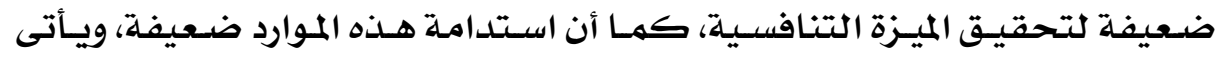

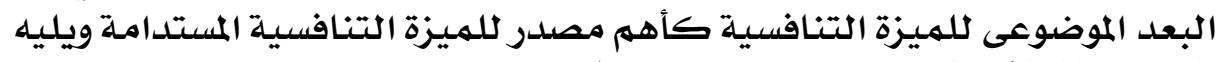

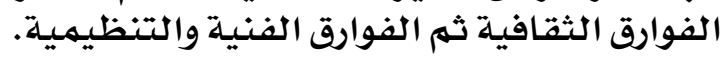

وبعد استعراض الدراسـات السـابقة التى تناولت التخطيط الاستر اتيـجى والميزة

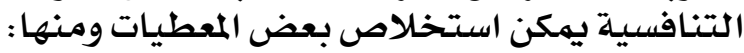

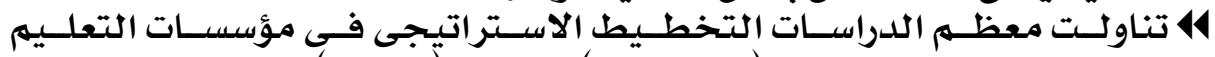

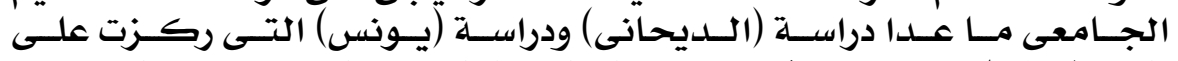

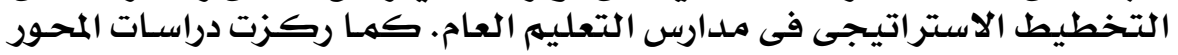

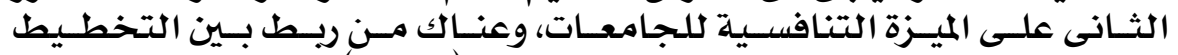

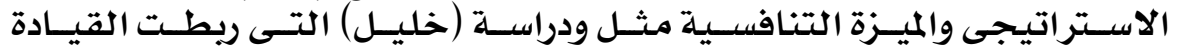

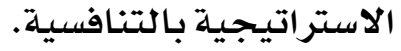

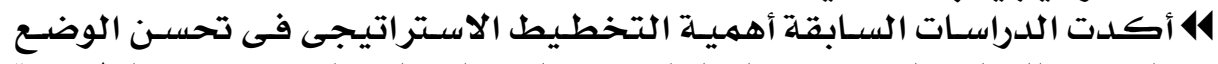

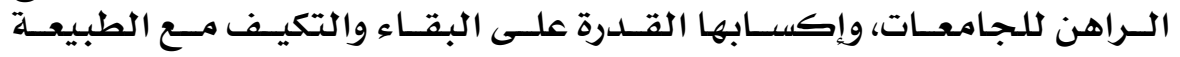




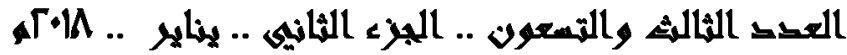

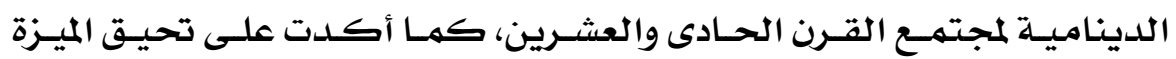

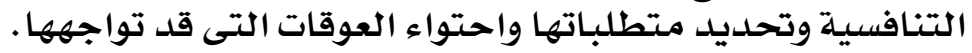

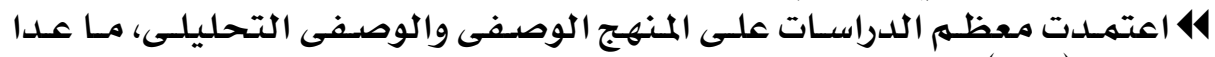

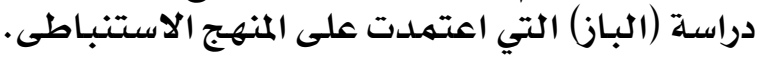

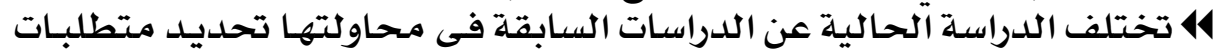

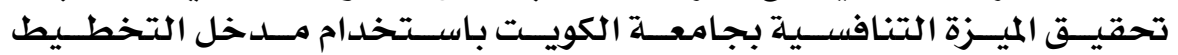

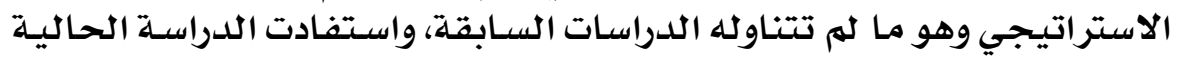

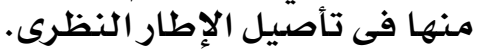

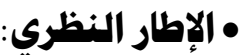

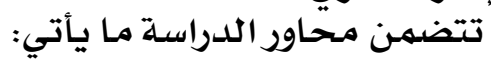

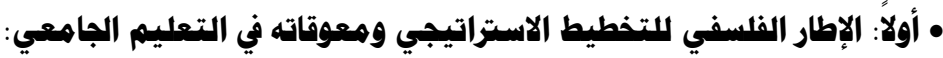

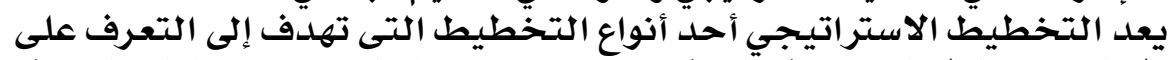

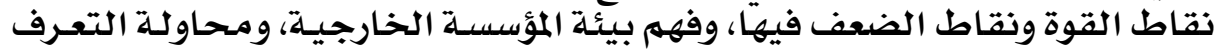

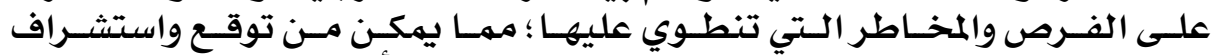

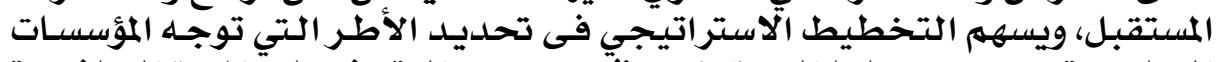

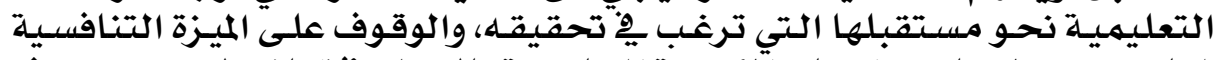

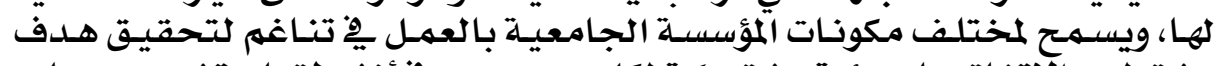

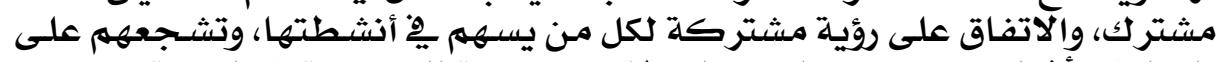

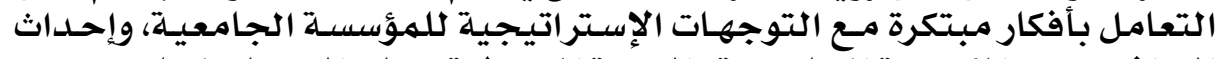

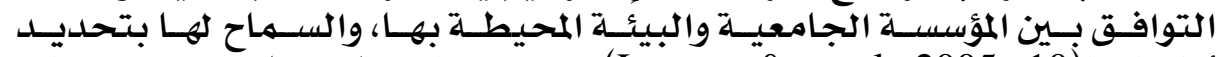

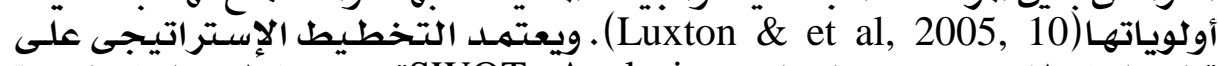

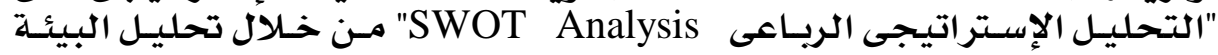

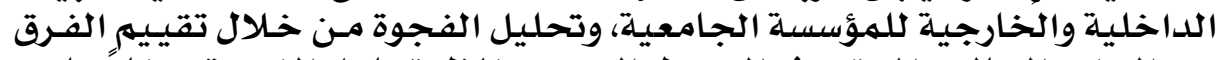

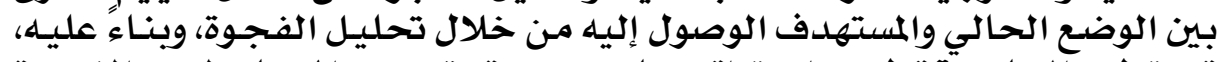

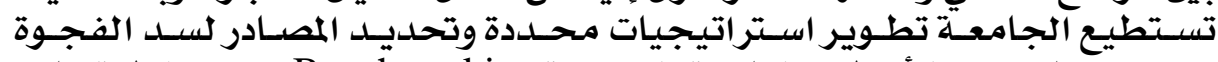

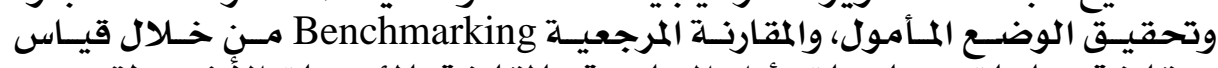

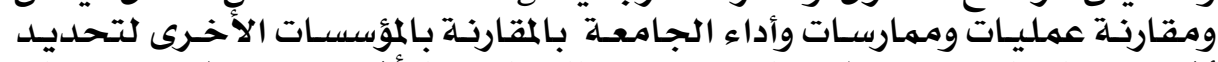

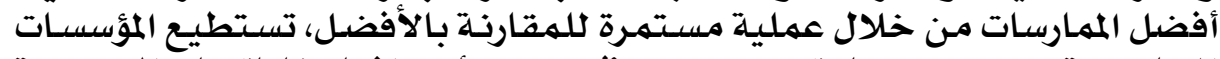

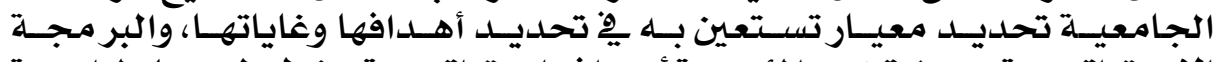

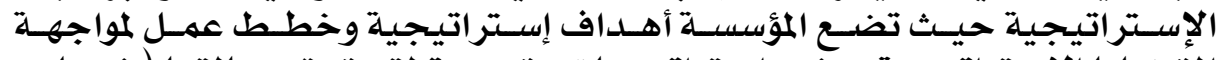

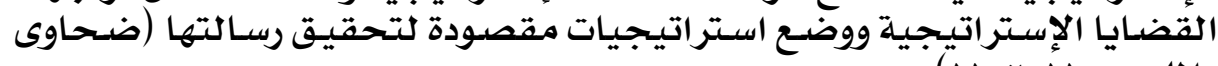

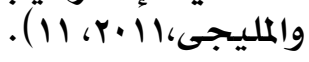

ويمكـن تنـاول أسـاسـيات التخطـيط الإســراتيجي فـى التعلـيهم الجــامعى مـن

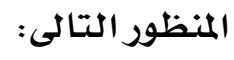

ا - هفهوم التخطيط الإستراتيجى فئ التعليم الجاهعى:

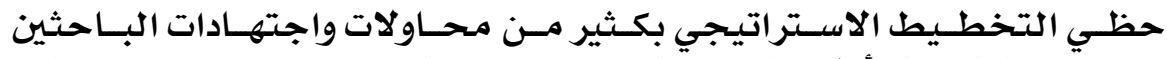

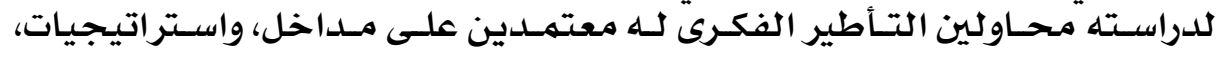




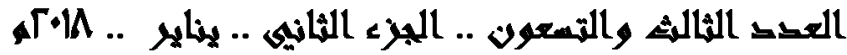

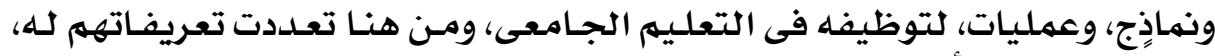

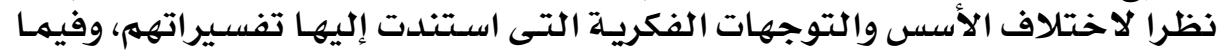
يلى عرض لبعض هذه التعريفات:

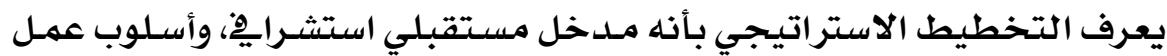

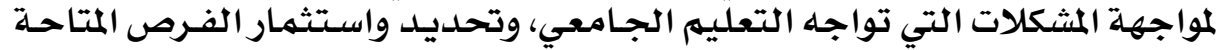

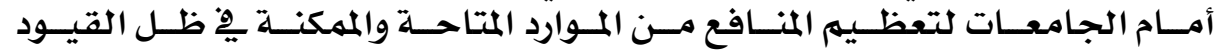

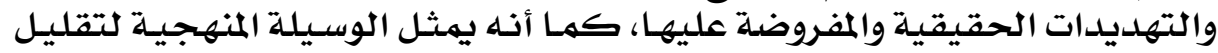

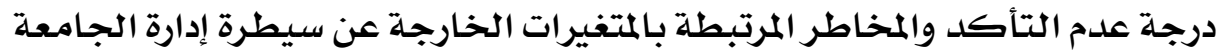
.(Johnson, 2004, 16)

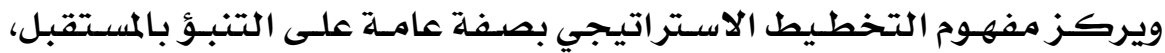

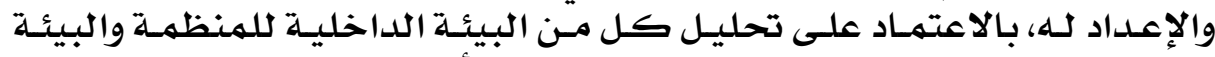

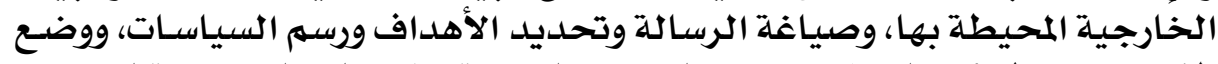

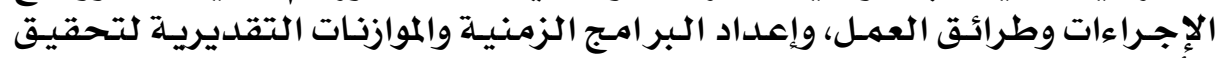

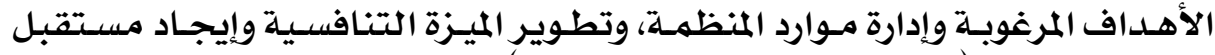

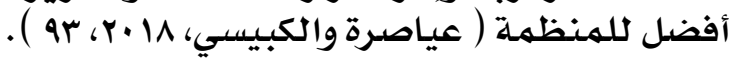

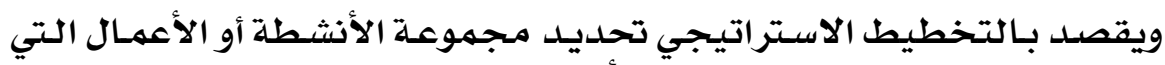

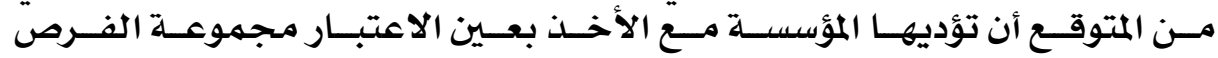

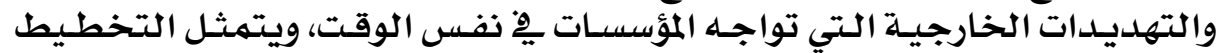

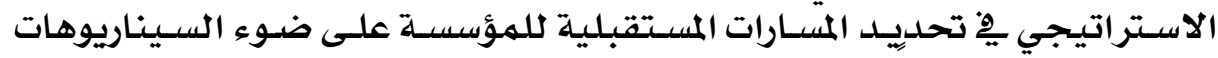

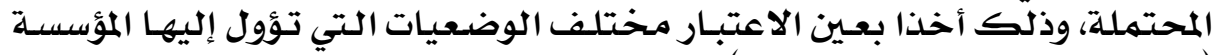

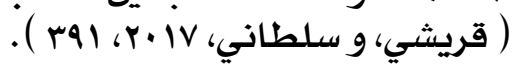

كما يعرف التخطيط الاستراتيـي بأنه مفهوم إداري يتضهن تحليل ودراسـة

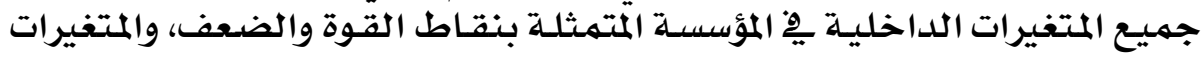

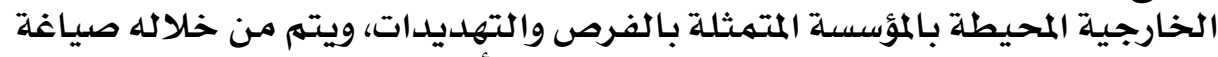

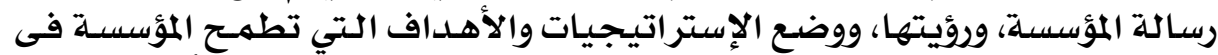

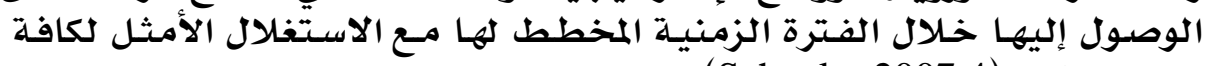
الموارد المتاحة (Schueler,2007,4).

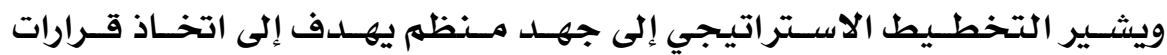

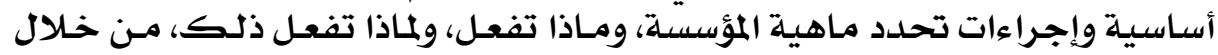

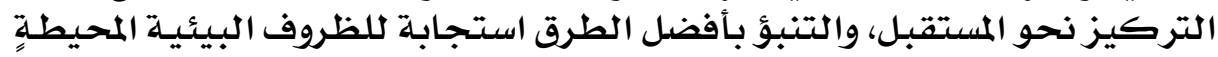

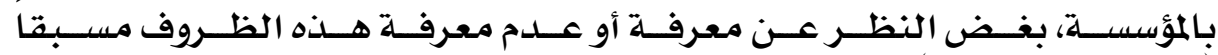

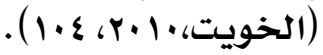

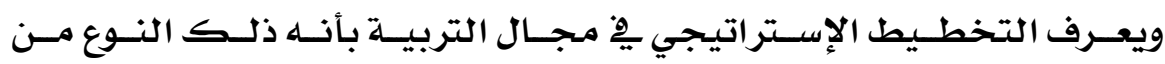

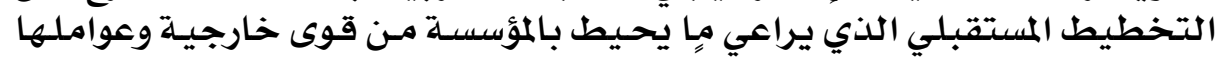

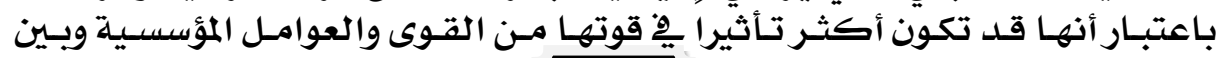




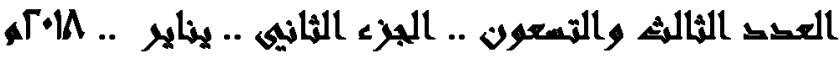

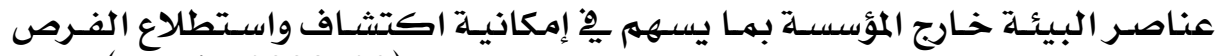

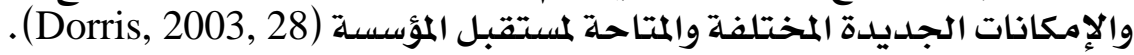

ويشير التخطيط الإستراتيـجي إلى عمليـة وضـع الأهـداف التتظيهيـة، وتحلديد

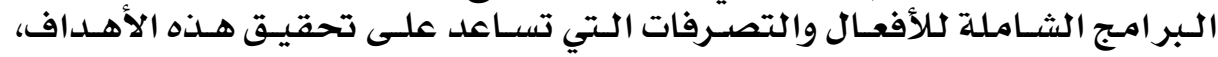

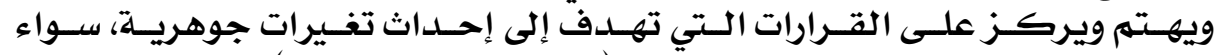

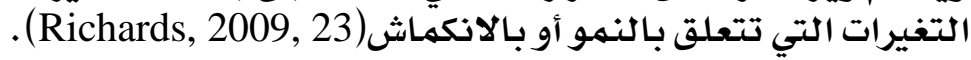

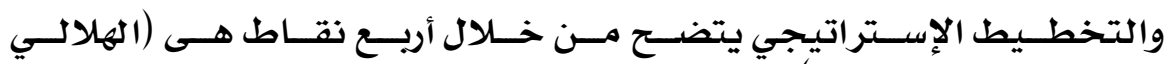

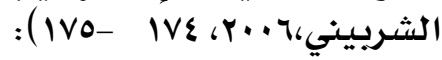

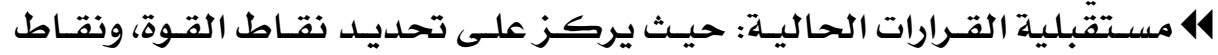

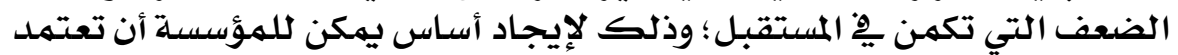

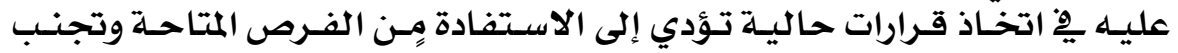

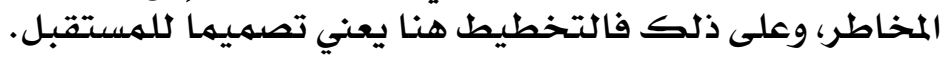

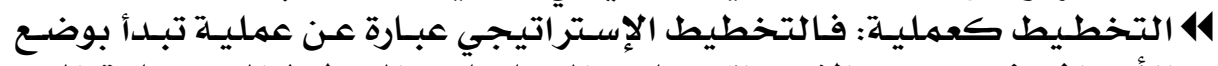

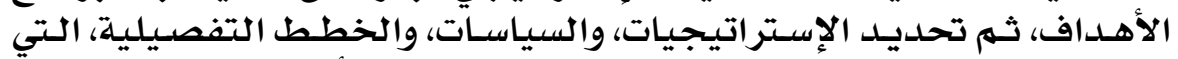

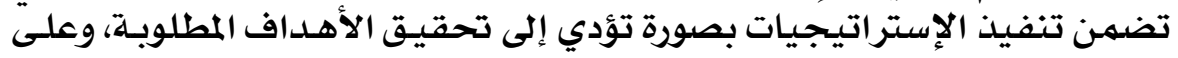

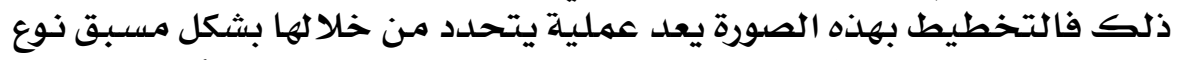

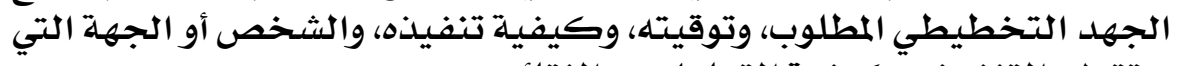

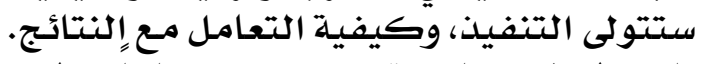

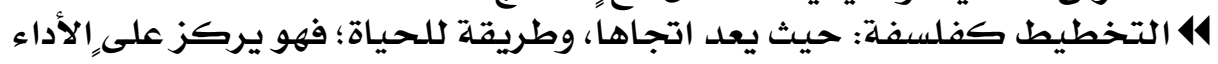

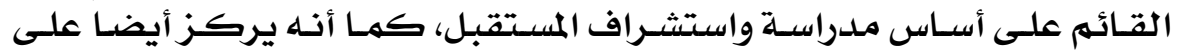

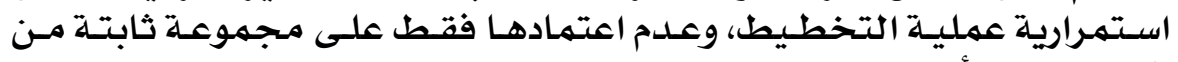

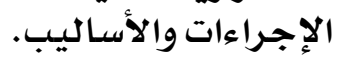

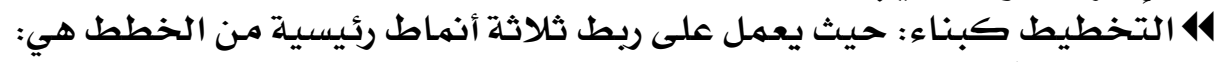

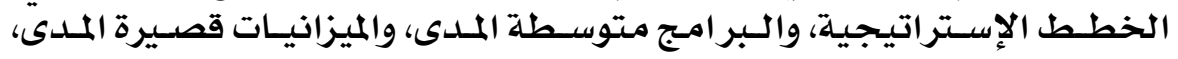

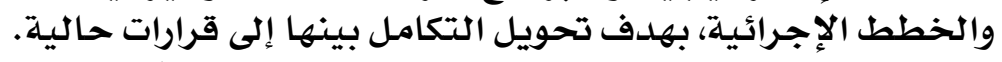

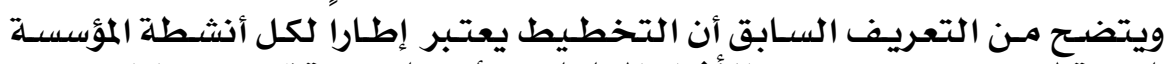

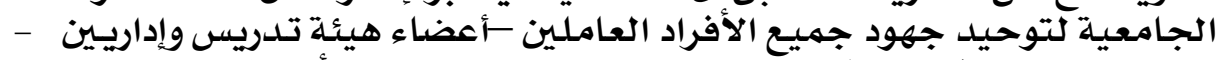

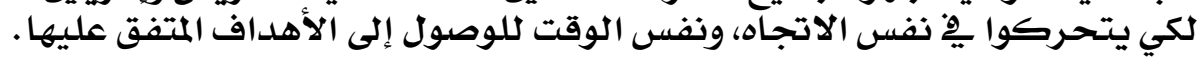

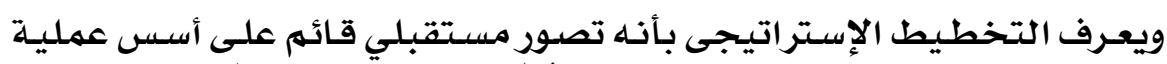

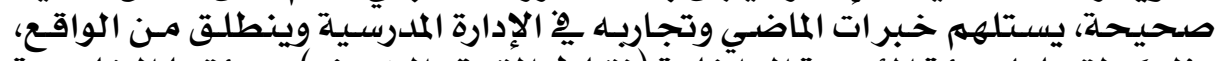

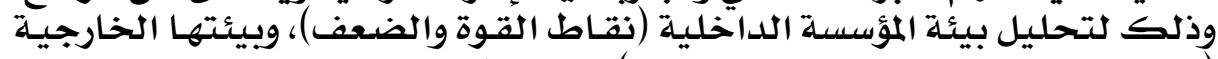

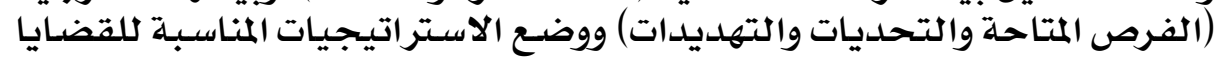

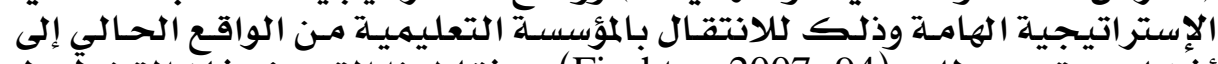

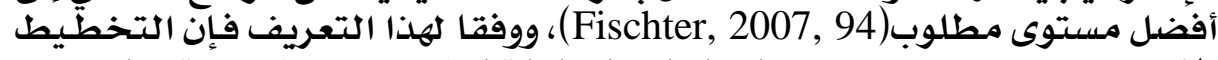

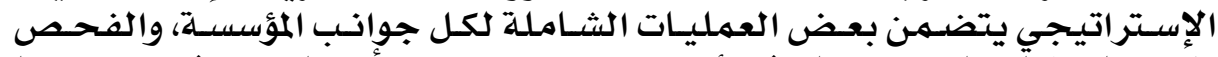

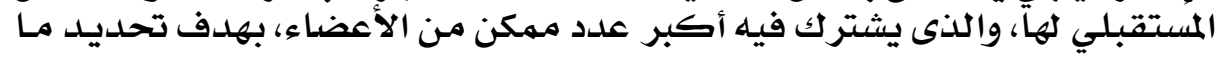




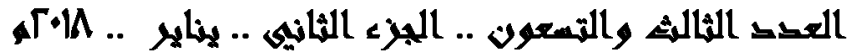

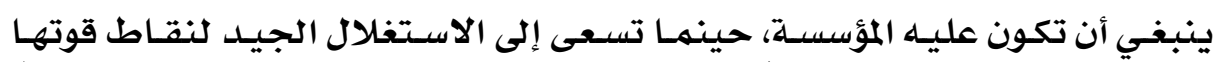

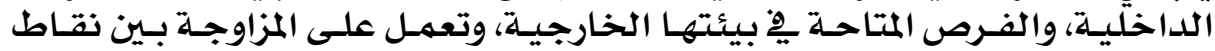
القوة والضعف هذه بشكل يقود إلى أفضل النتائج.

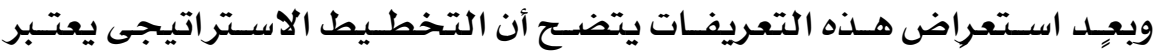

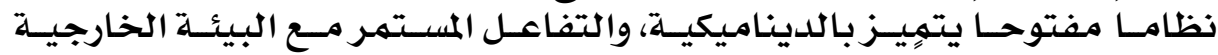

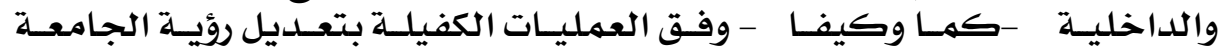

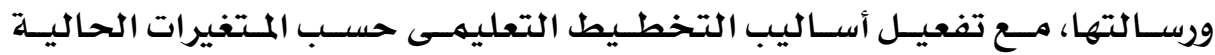

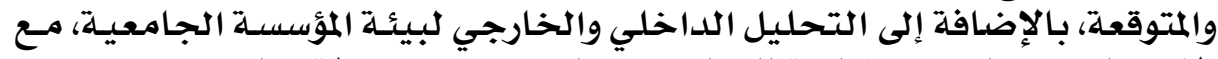

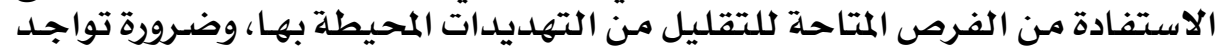

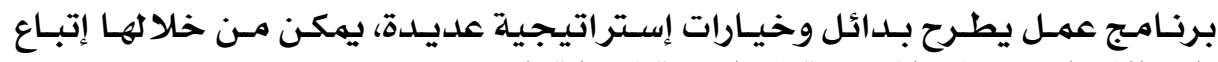

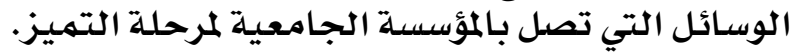

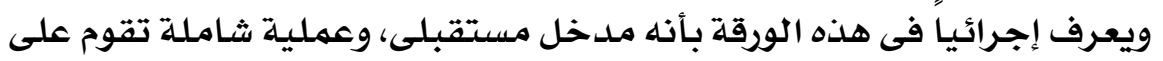

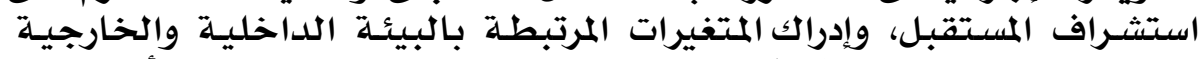

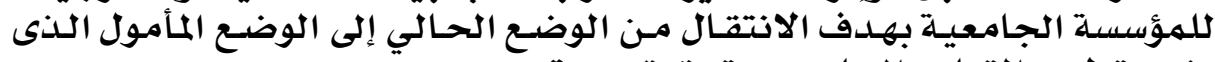

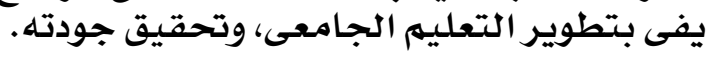

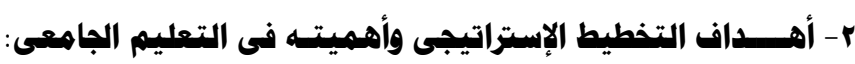

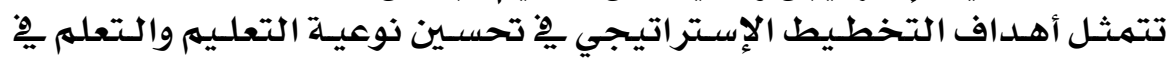

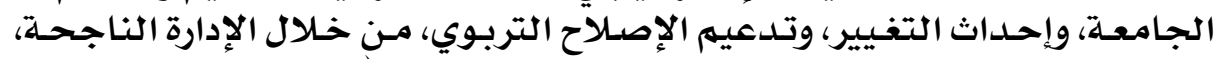

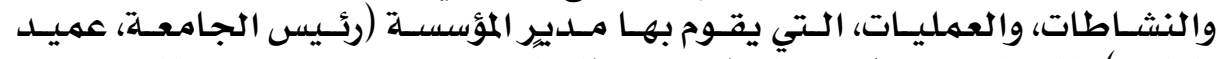

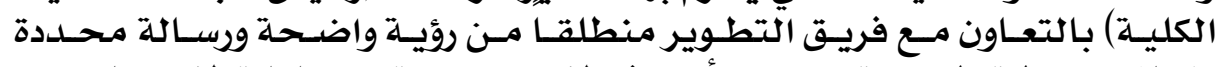

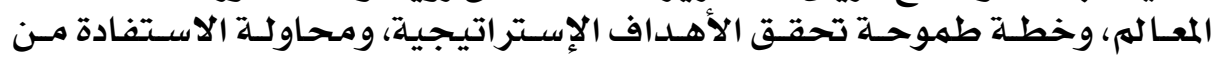

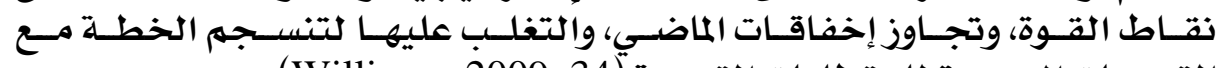
التوجهات الجديدة للمتطلبات التربوية (Williams, 2009, 34).

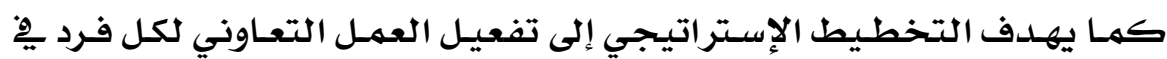

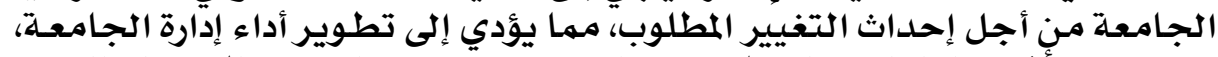

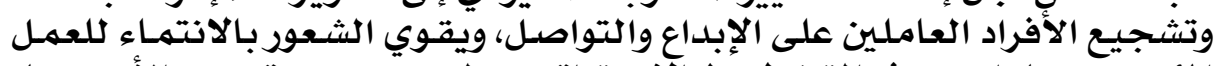

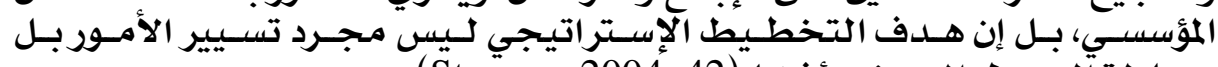
محاولة ألوصول إلى وضع أفضل (Stevens, 2004, 42).

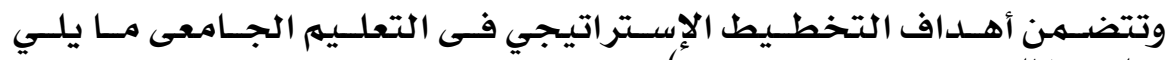

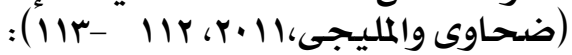

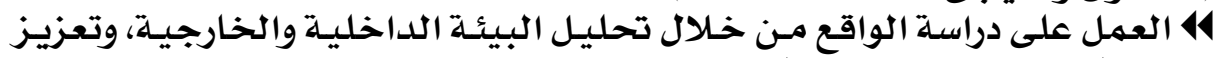

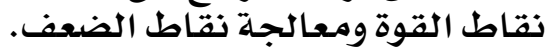

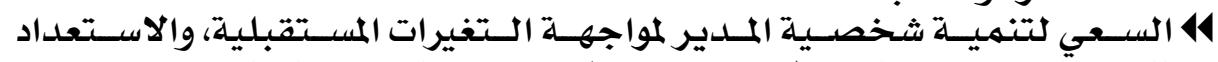

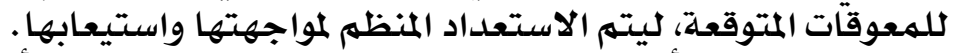

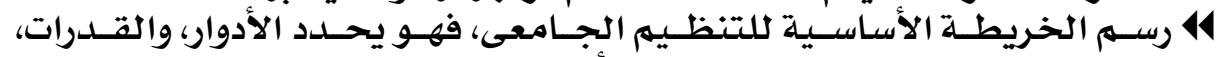

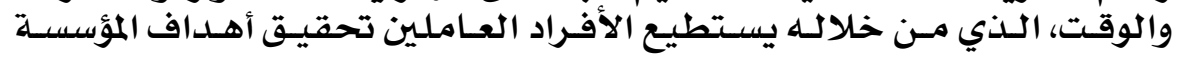

\section{\& V०} الجامعيلة. 


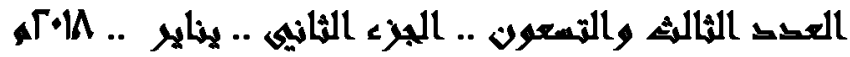

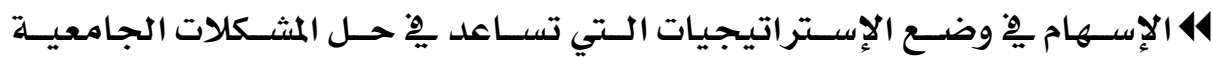

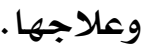

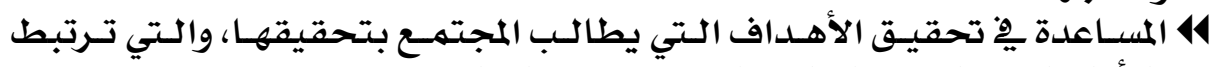

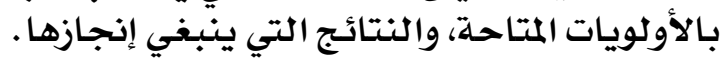

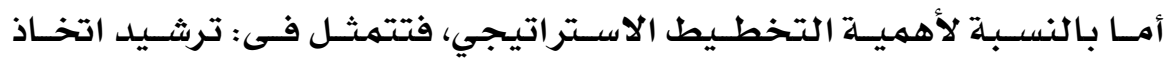

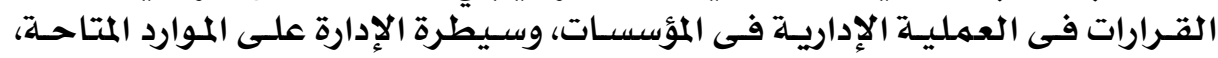

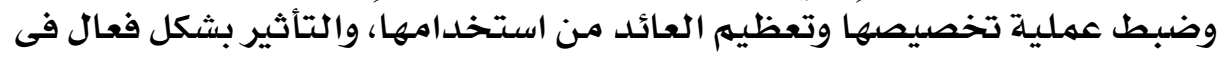

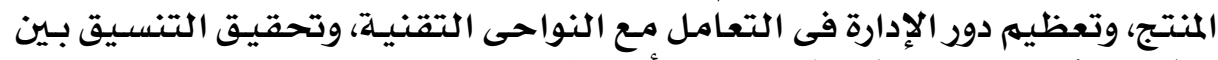

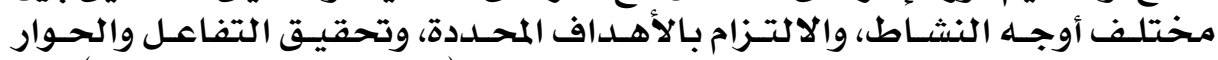

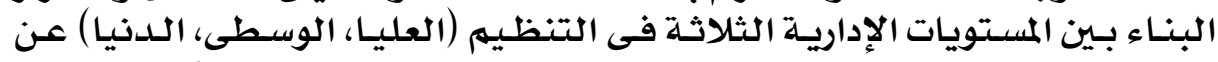

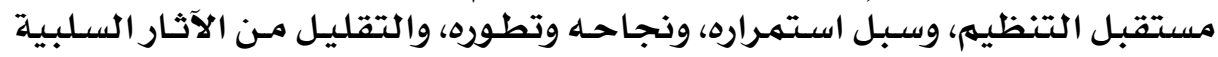

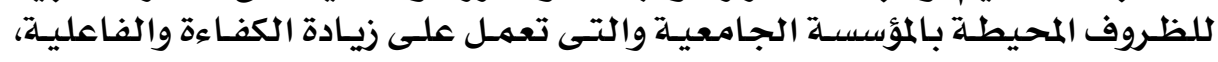

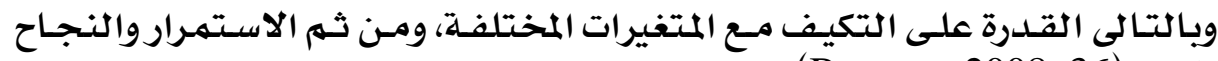

الدائم(Burgess, 2008, 36).

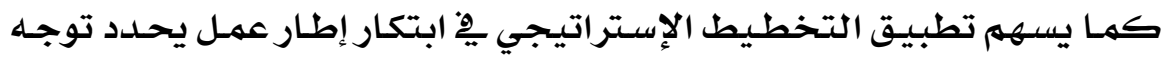

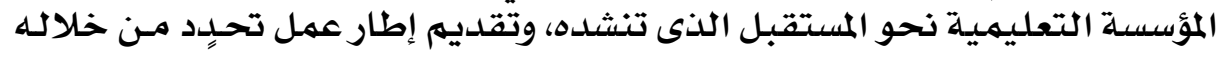

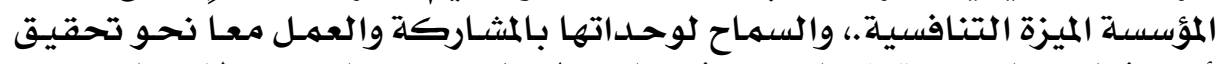

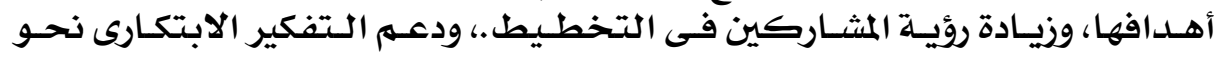

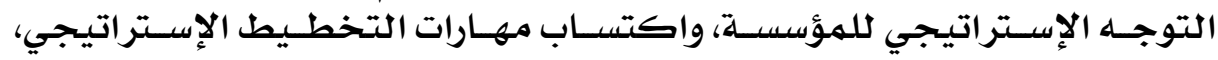

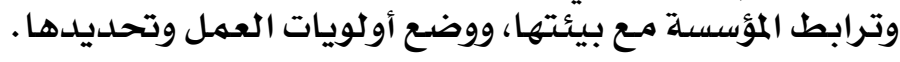

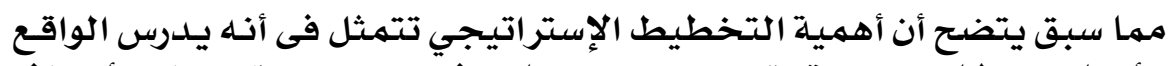

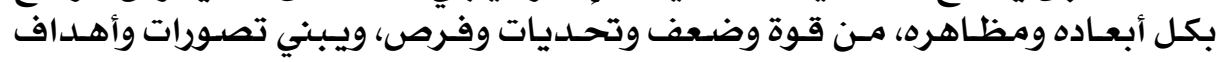

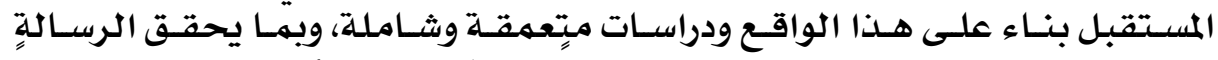

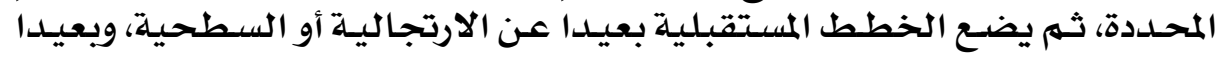

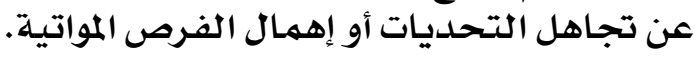

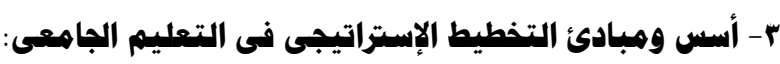

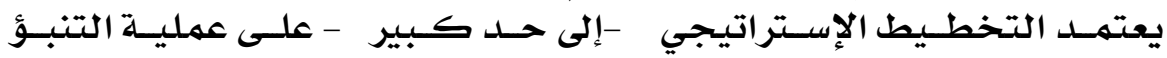

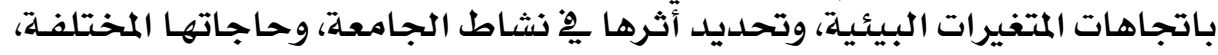

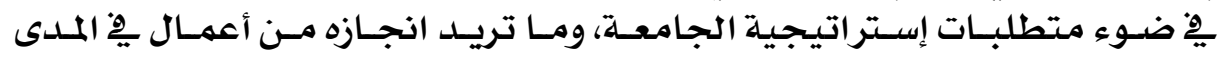

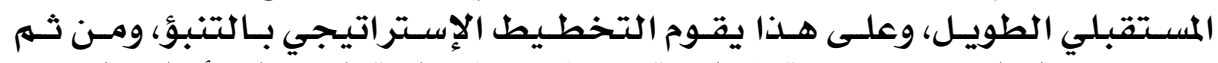

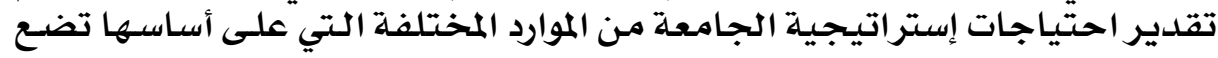

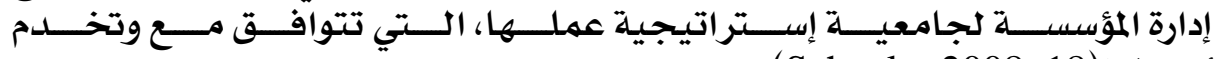
أهدافها (Schueler,2008, 18).

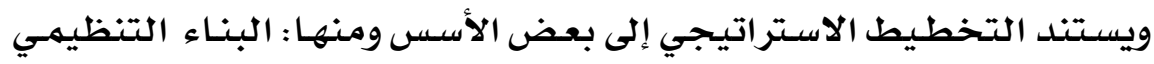

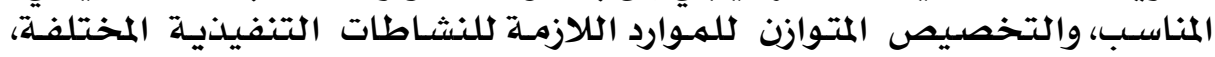




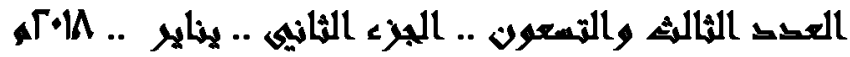

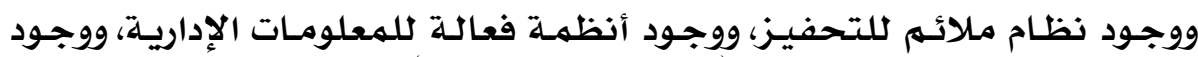

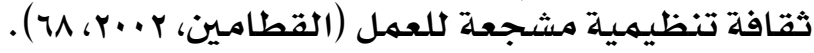

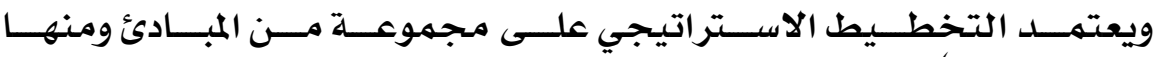
: (Prusha,2006,9) 14 يسعى التخطيط الاستراتيـجي إلى الاسـتجابـة الإسـتراتيـجية للظـروف الحساديـة

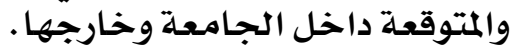

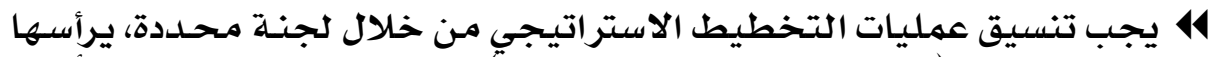

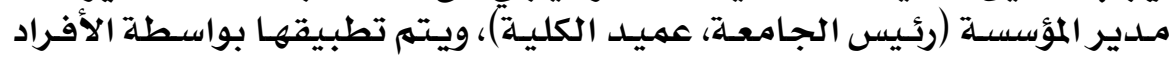

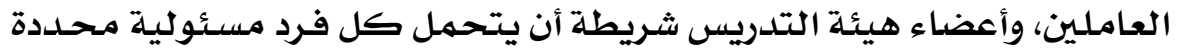

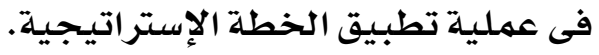

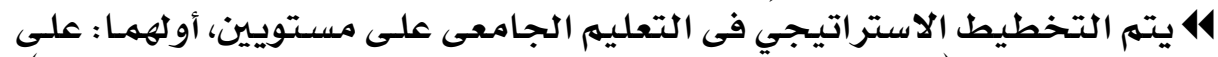

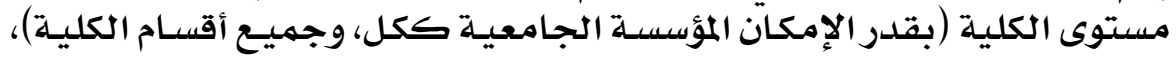

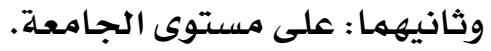

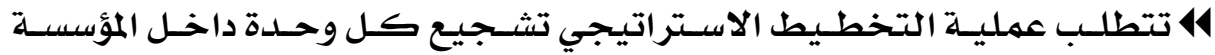

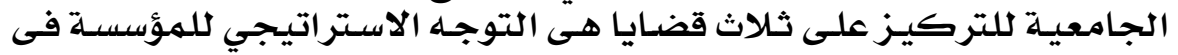

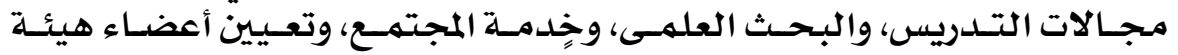

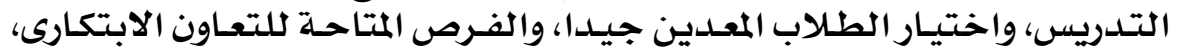

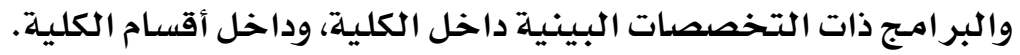

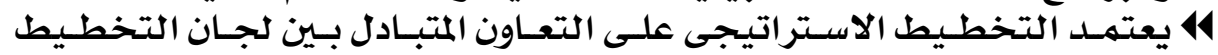

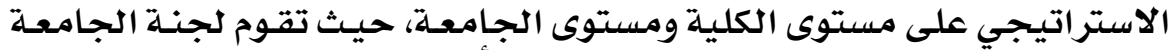

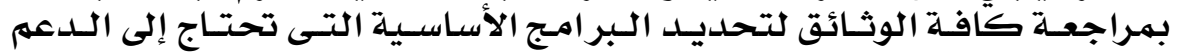

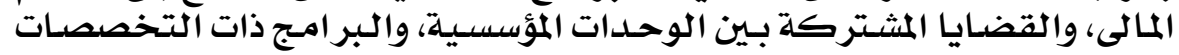

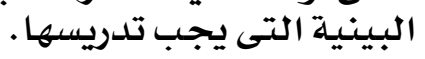

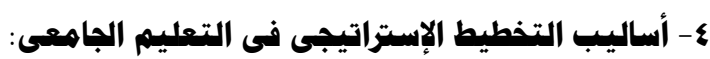

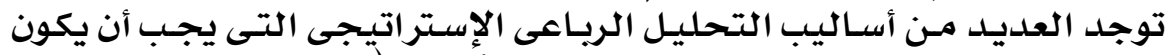

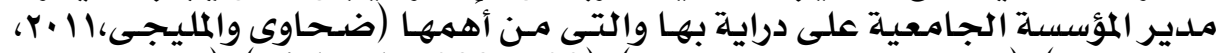

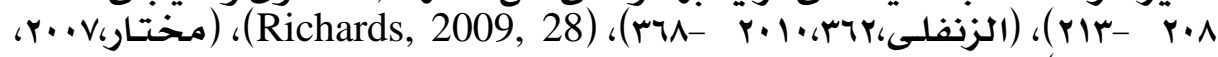
$:(r) \cdot-r \cdot T$

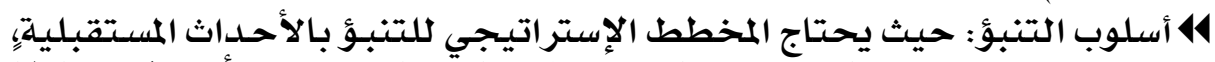

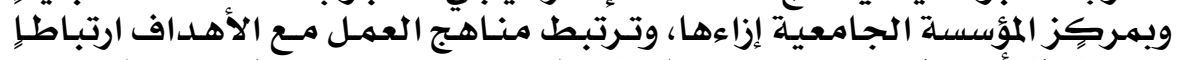

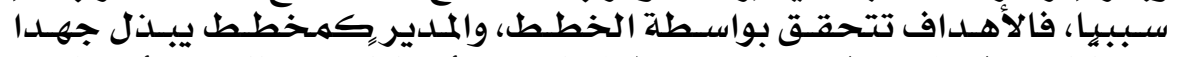

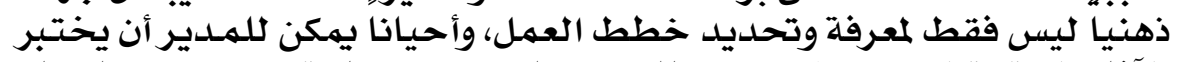

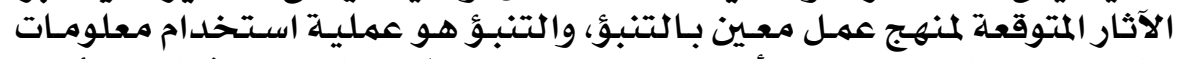

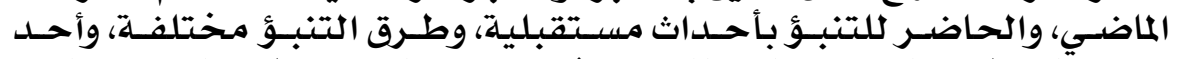

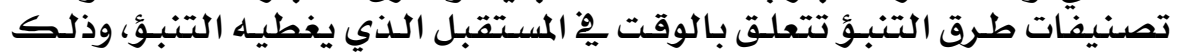

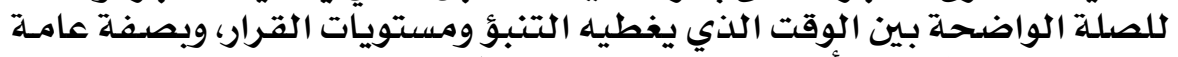

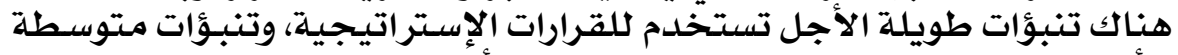

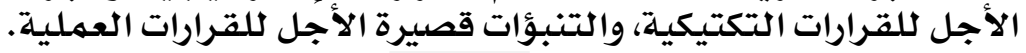

\section{$\varepsilon \vee V$}




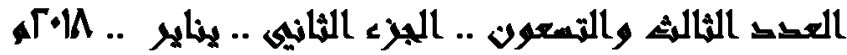

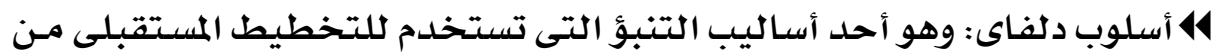

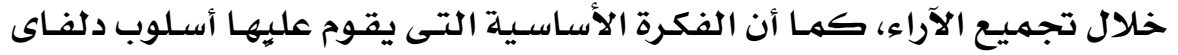

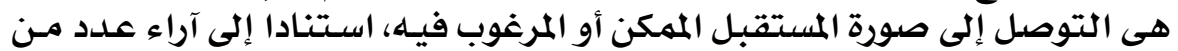

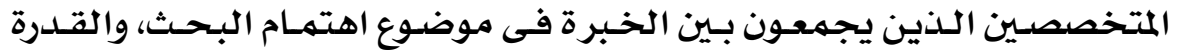

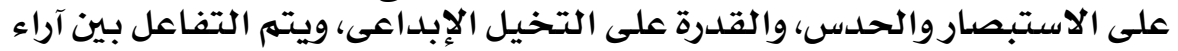

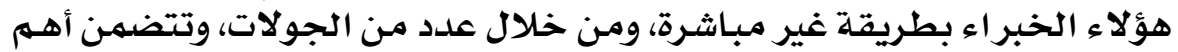

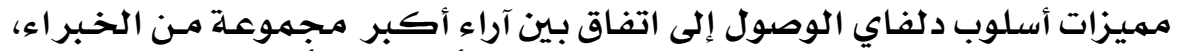

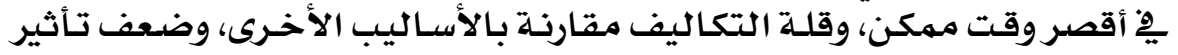

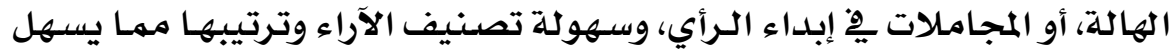

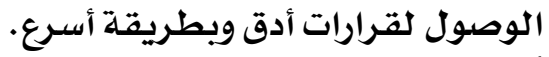

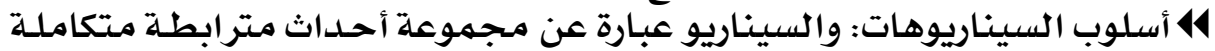

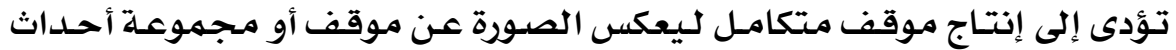

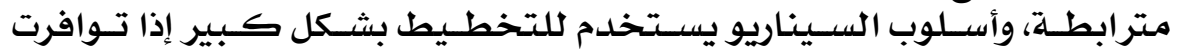

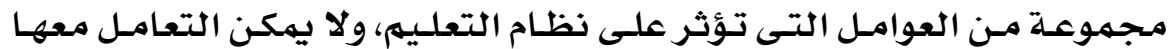

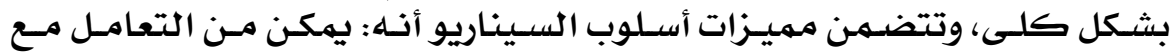

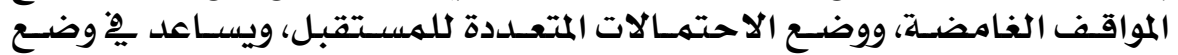

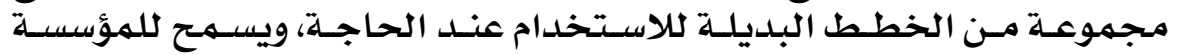

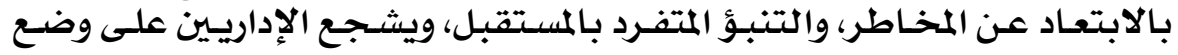

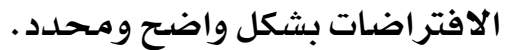

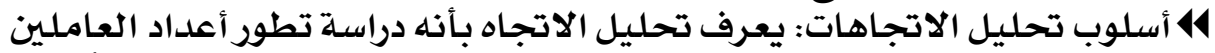

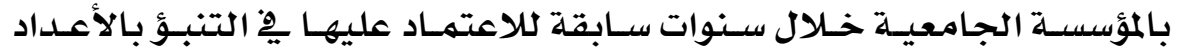

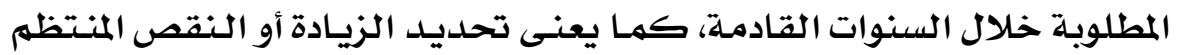

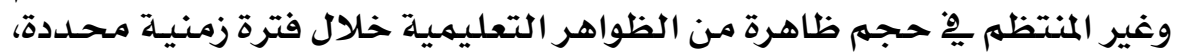

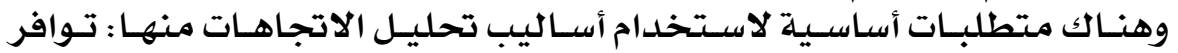

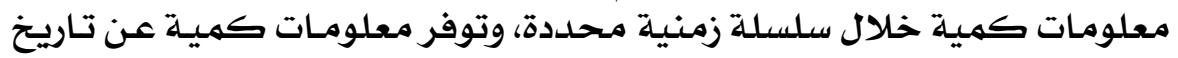

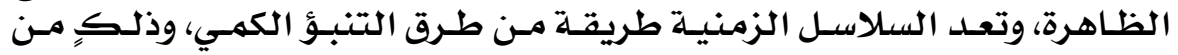

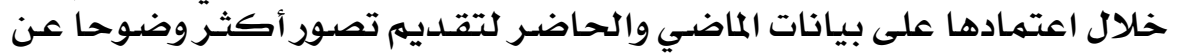

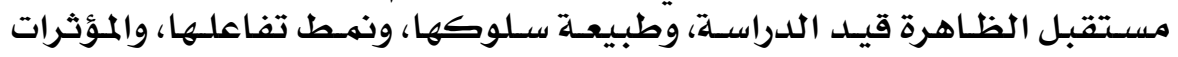
التي تؤثر فيها التيا

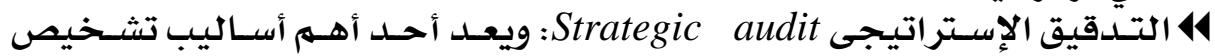

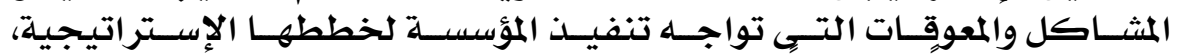

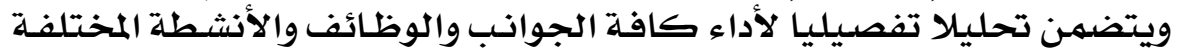

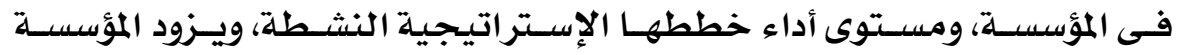

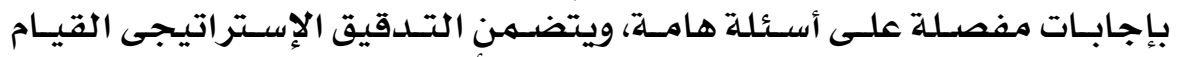

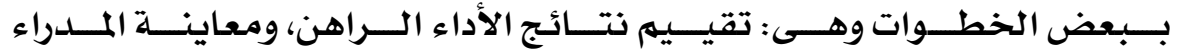

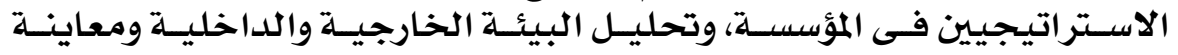

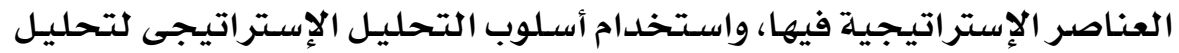




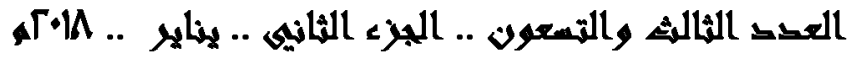

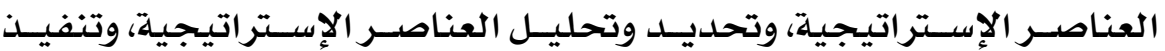

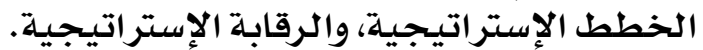

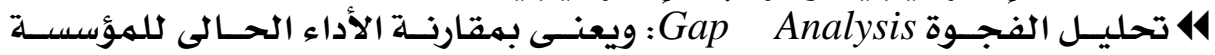

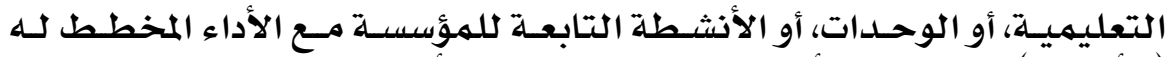

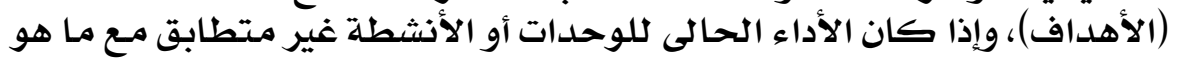

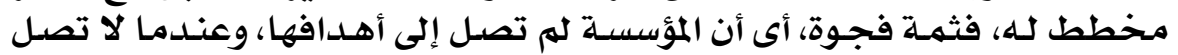

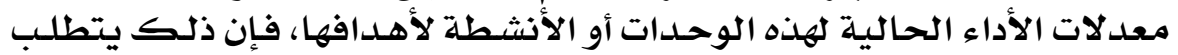

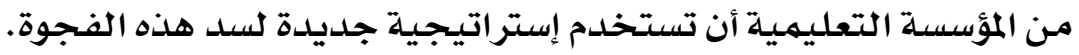

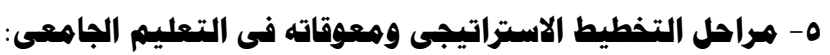

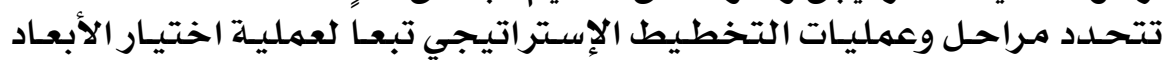

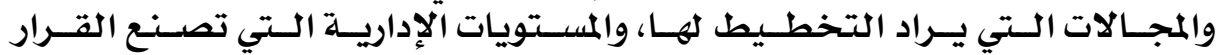

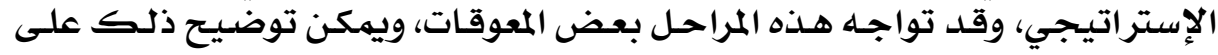

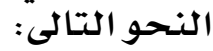

• هراحل التخطيط الاستراتيجى فى التعليم الجاهـى :

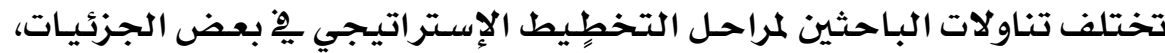

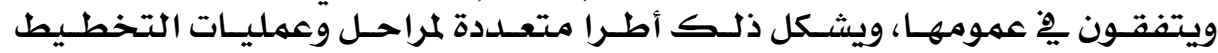

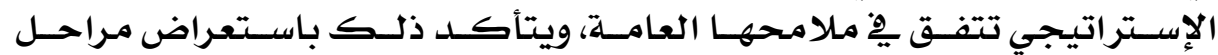

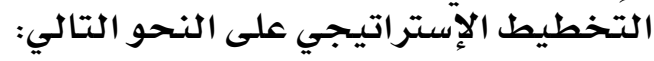

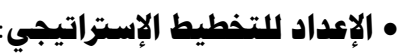

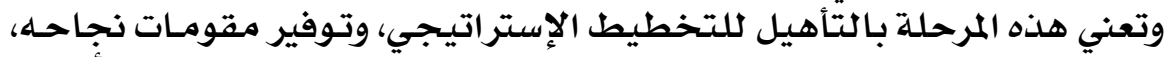

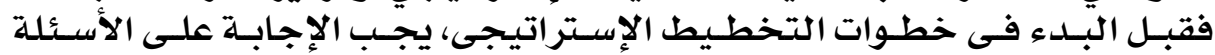

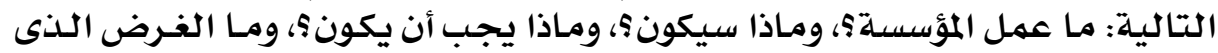

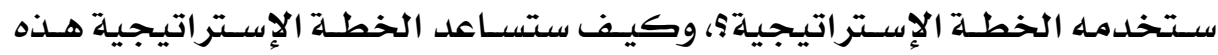

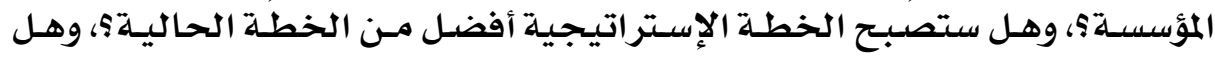

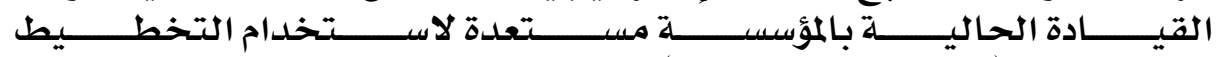
الإستراتيجى ؟ (Meinhart, 2004, 46).

• تصديد توجهات المؤسسة الجامعية المستقبلية:

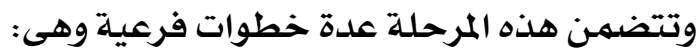

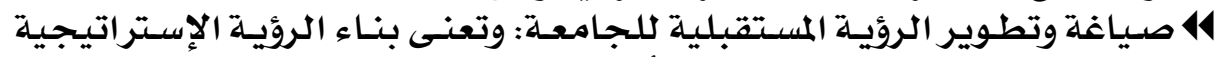

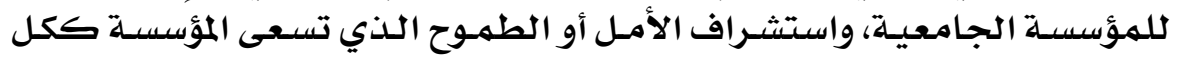

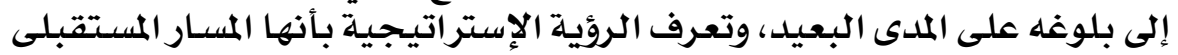

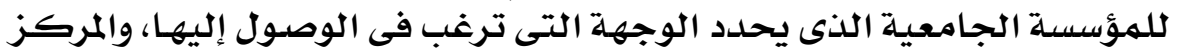

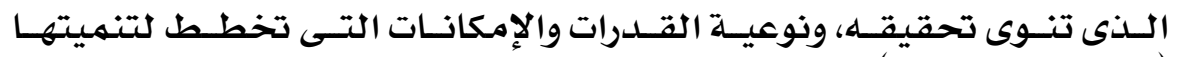
(Prusha,2006,11)

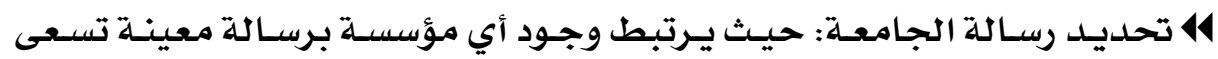

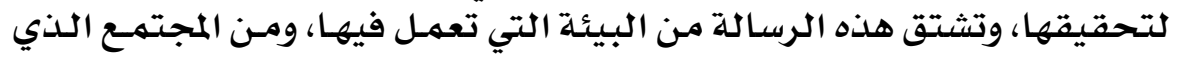

\section{$\varepsilon \vee q$}




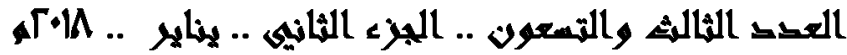

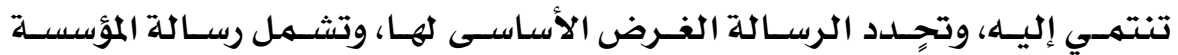

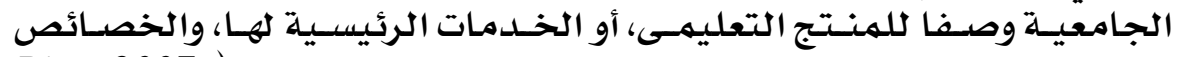

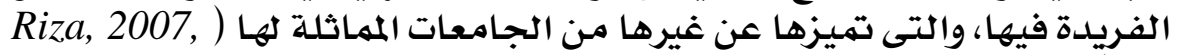
178

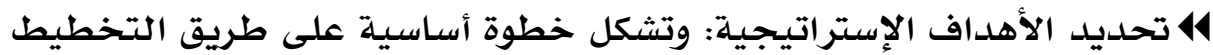

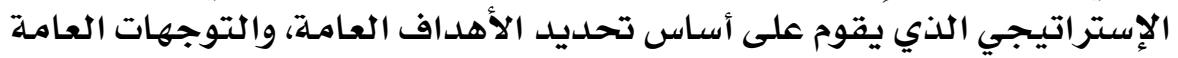

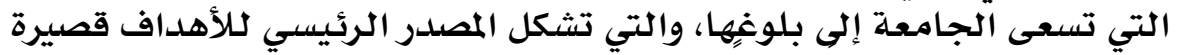

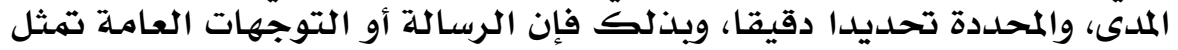

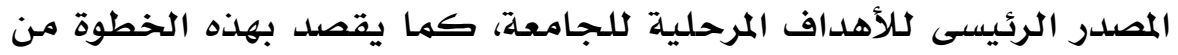

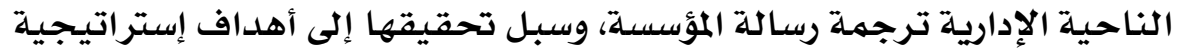

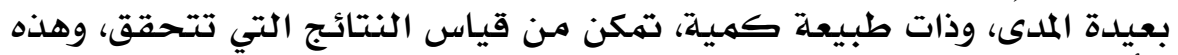

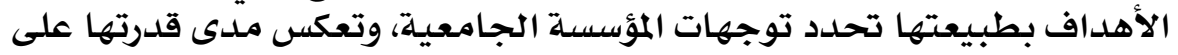
التفاعل مـع بيئتها.

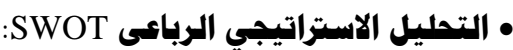

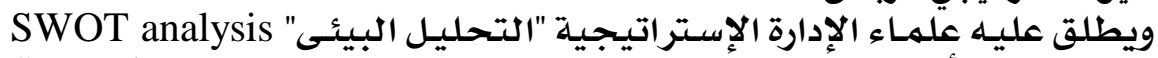

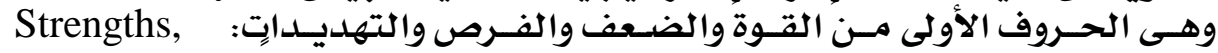
لأنه ، Weaknesses, Opportunities, Threats.

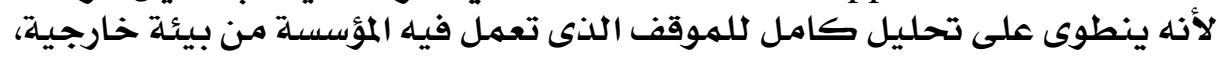

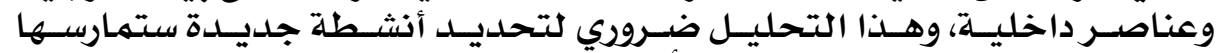

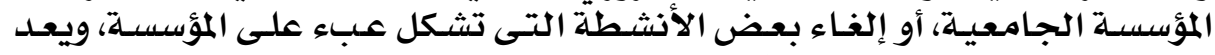

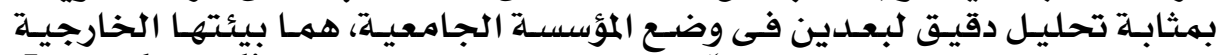

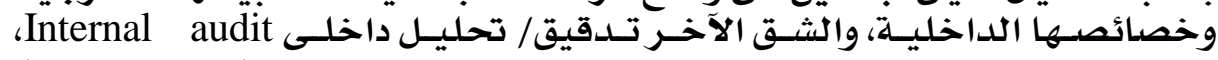

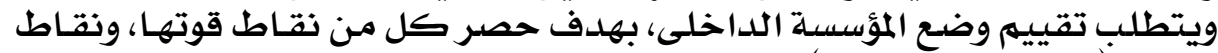
ضعفهان ) (Chang, 2008, 12)

• صياغة الخطة الاستراتيبية وتنفيذها:

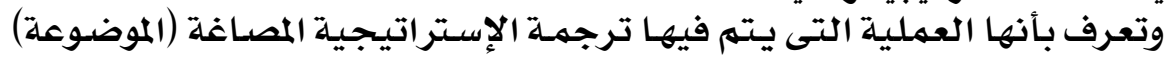

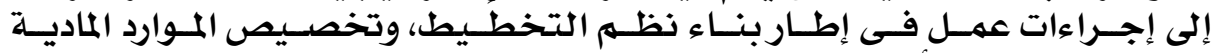

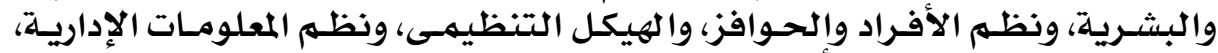

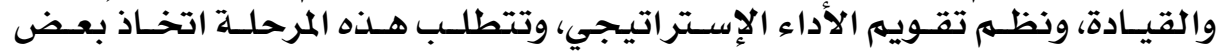

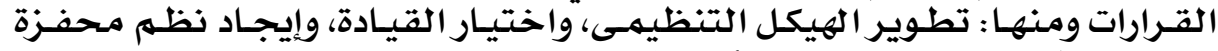

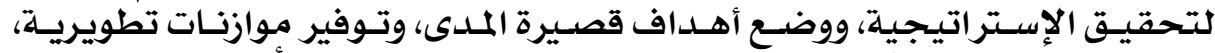

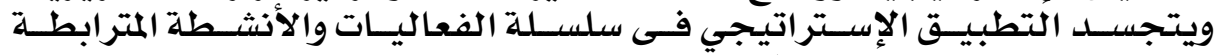

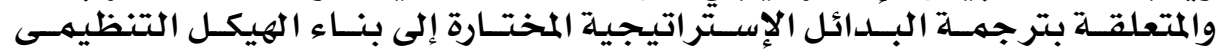

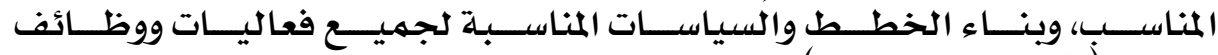

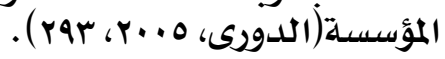

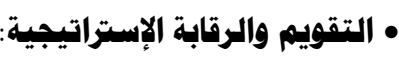

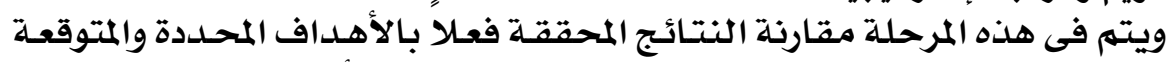

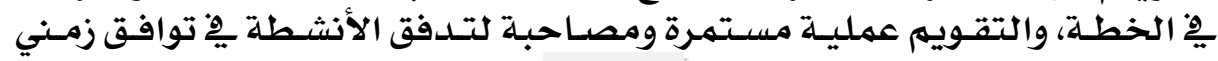

\section{$\varepsilon \Lambda$.}




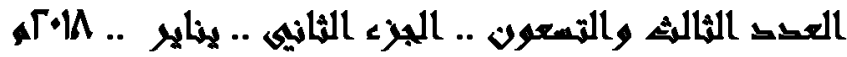

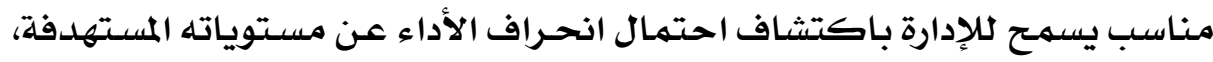

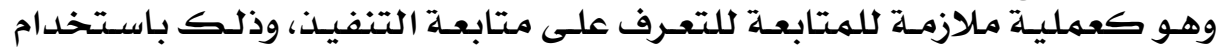

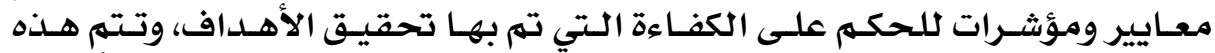

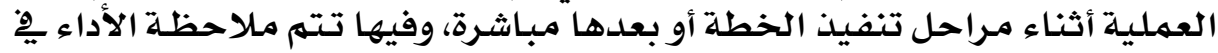

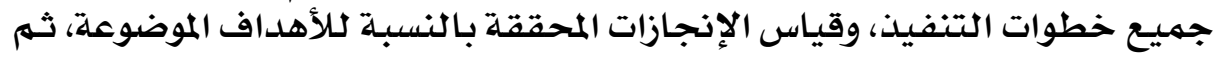

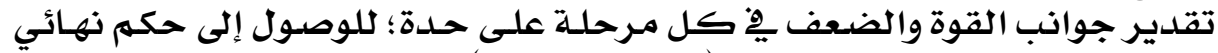

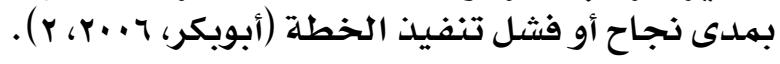

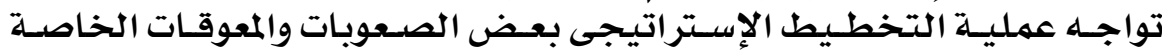

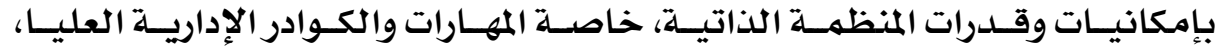

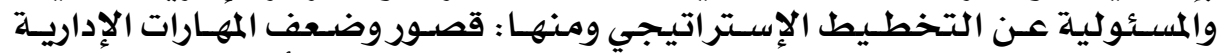

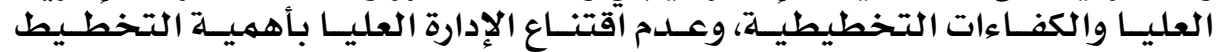

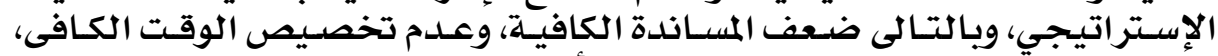

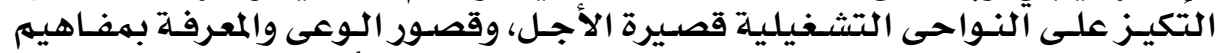

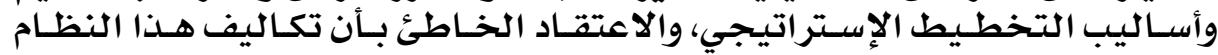

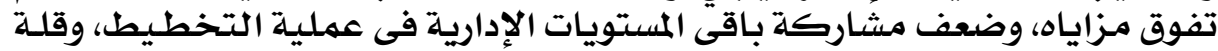

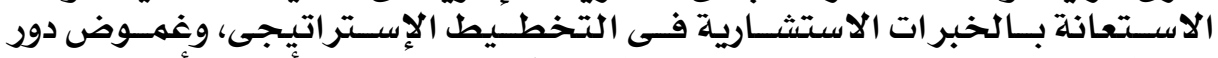

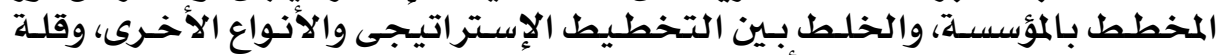

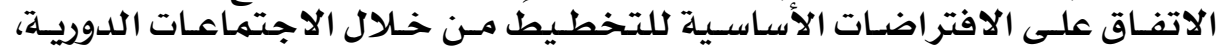

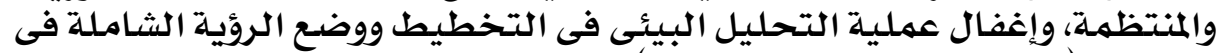

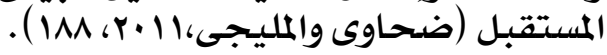

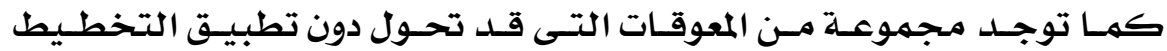

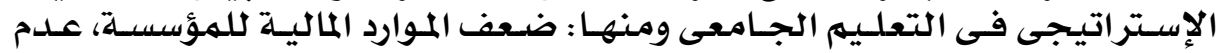

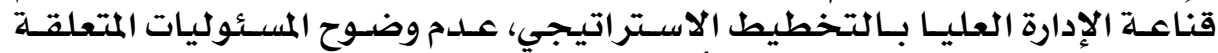

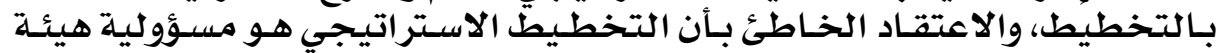

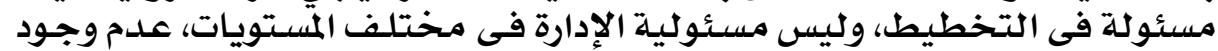

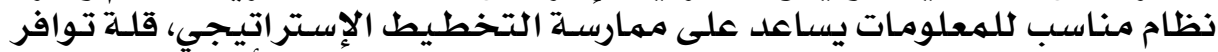

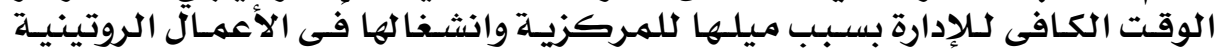

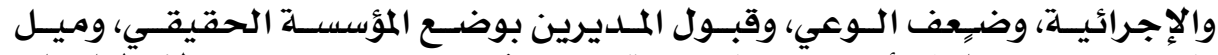

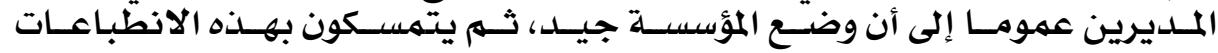

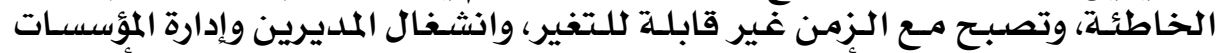

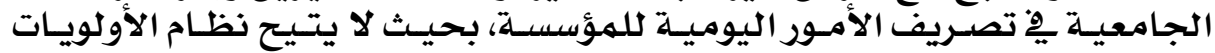

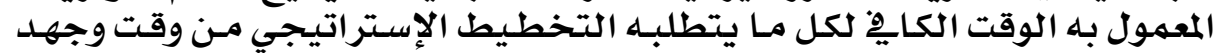

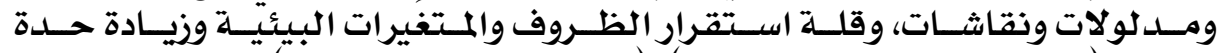

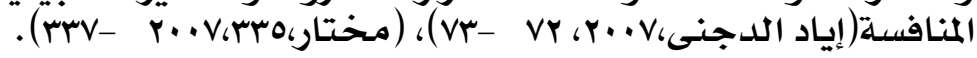

• ثانيا: هاهية الميرة التنافسية لإهاهمات:

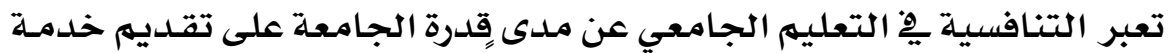

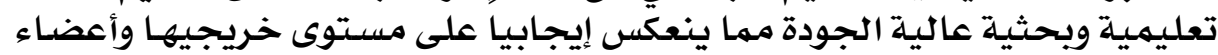




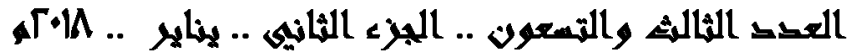

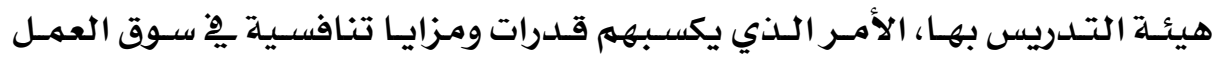

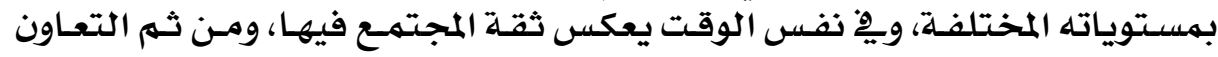

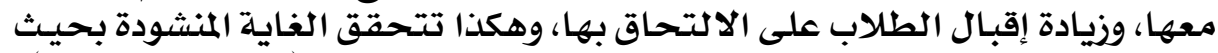

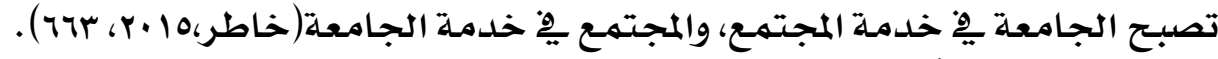

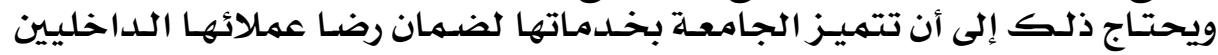

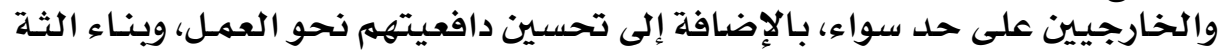

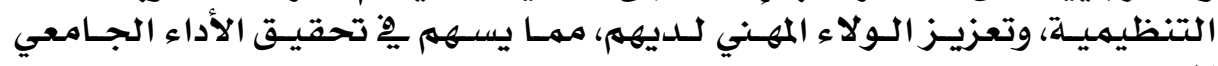

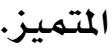

ويمكن تناول ماهية الميزة التنافسية للجامعات على النحو الآتي:

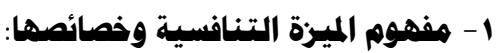

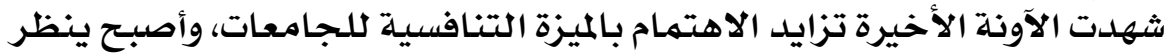

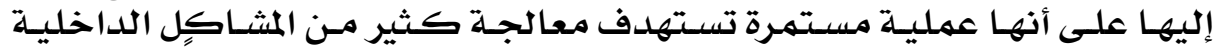

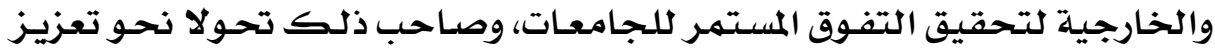

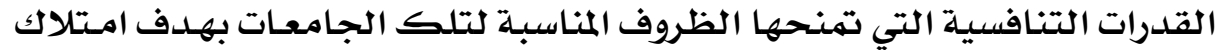

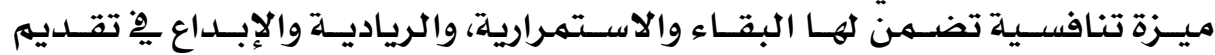

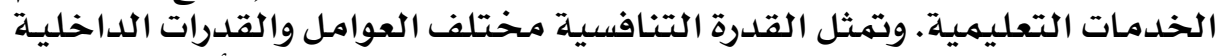

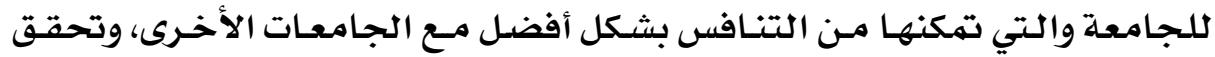

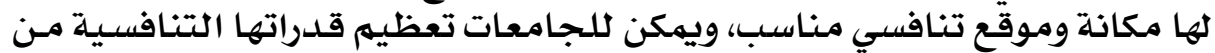

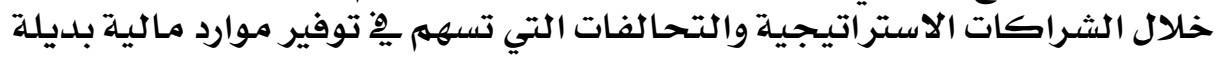

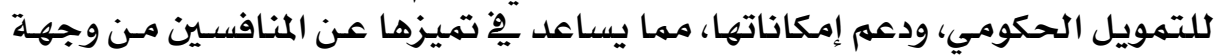
نظر عمالائها الداخليين ودين والخارجيين.

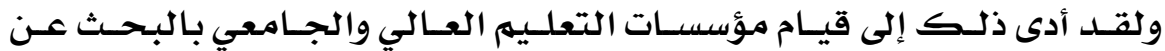

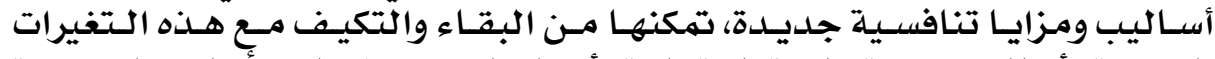

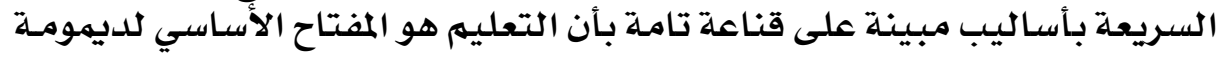

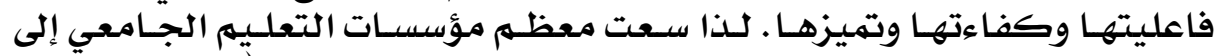

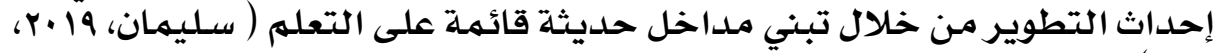

ويهكن استعراض مفهوم الميزة التنافسية وخصائصها على النحو الآتي:

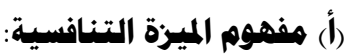

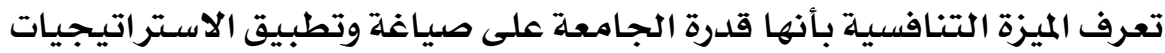

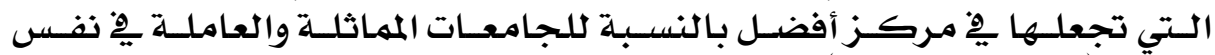

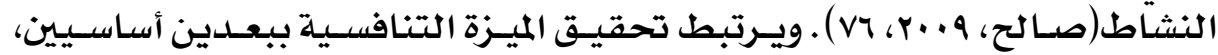

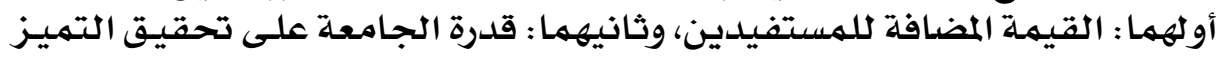

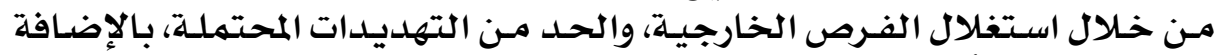

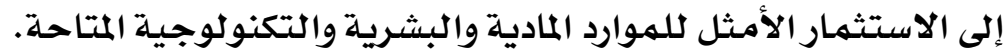




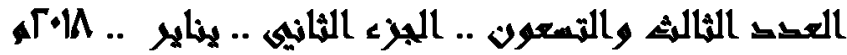

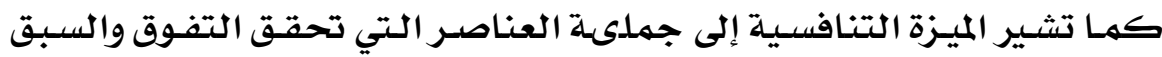

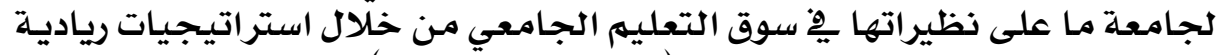

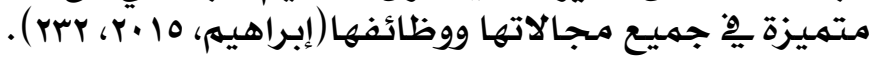

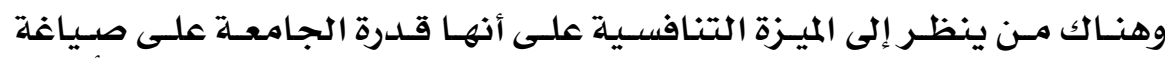

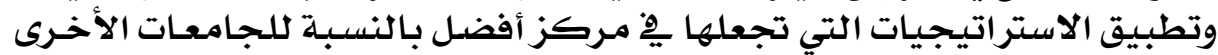

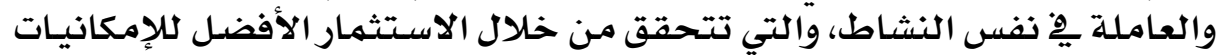

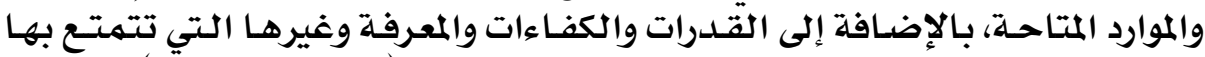

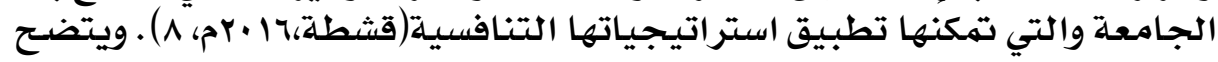

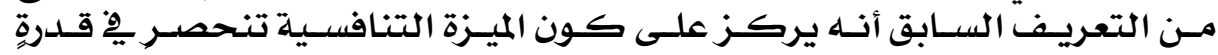

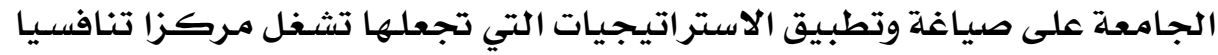
أفضل مقارنة بنظرائها.

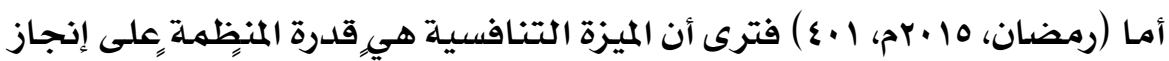

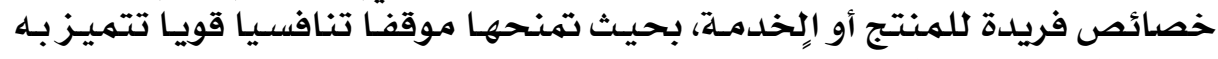

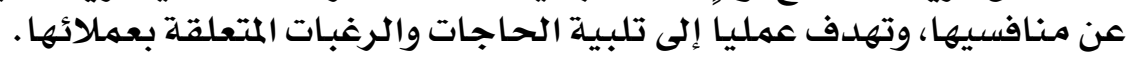

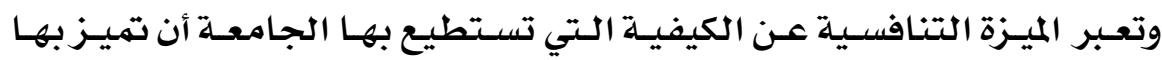

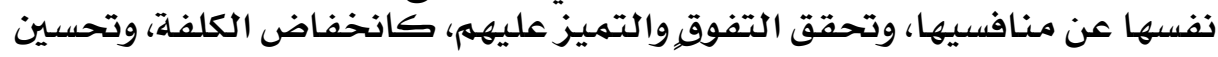

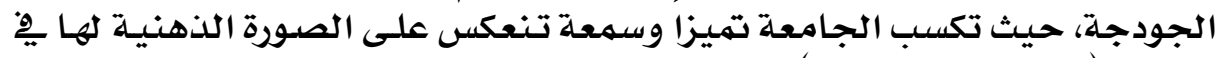

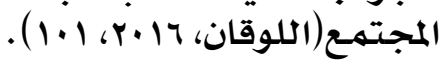

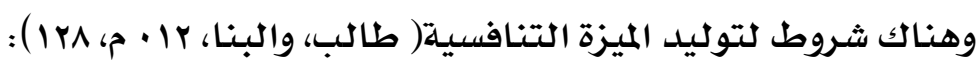

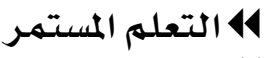

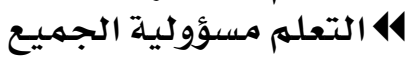
414 تيسير مصادر التعلم والحصولة الجميع على المعرفة.

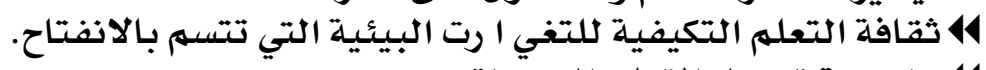

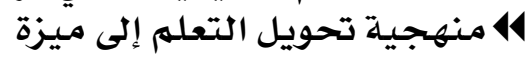
414 إقامة معايير لقياس ومتابعة التعلم باستمرار.

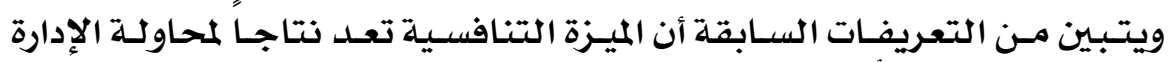

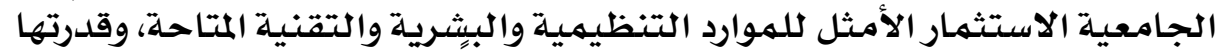

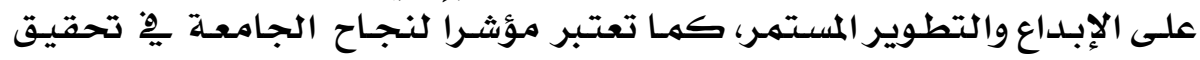

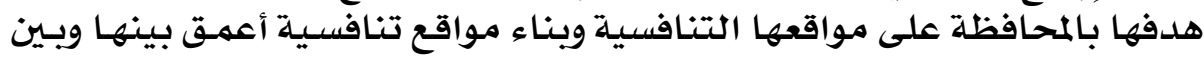

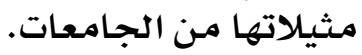

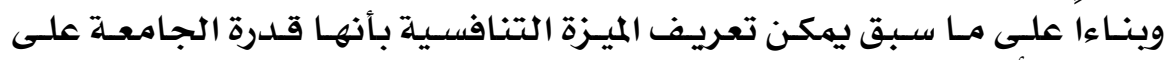

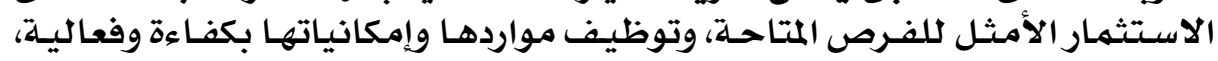

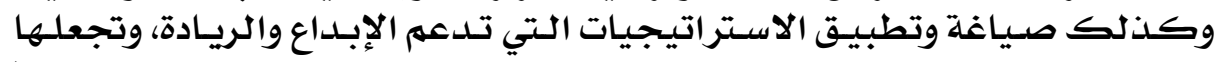

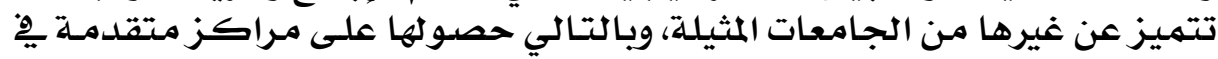
التصنيف العالمي للجامعات. 


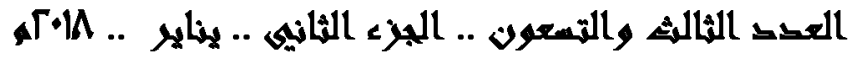

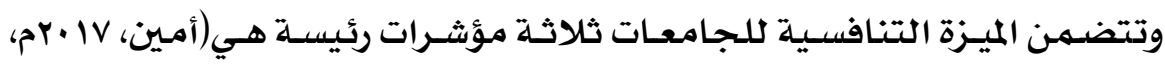

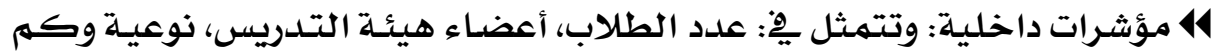
البحوث والدراسات، والخريجين، والجئية والجهاز الإداري.

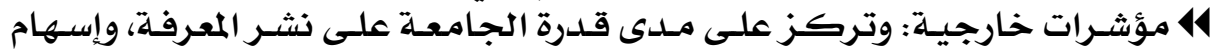

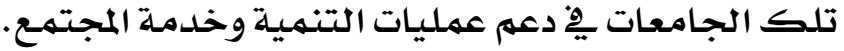

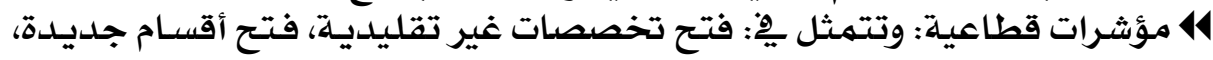

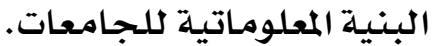

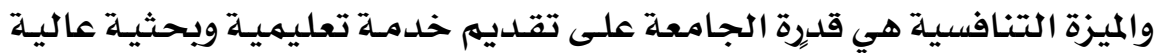

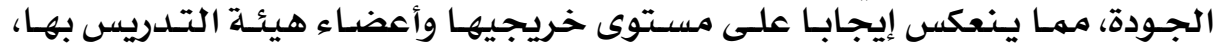

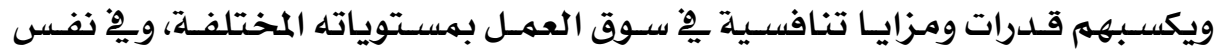

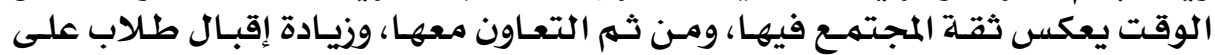

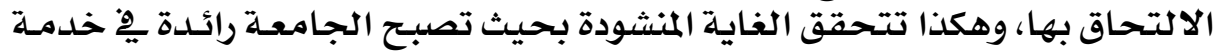

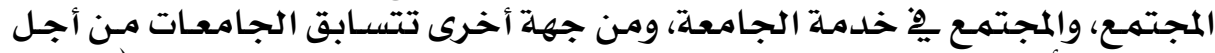

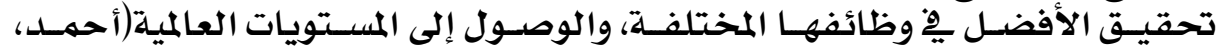

.)(111،r.10

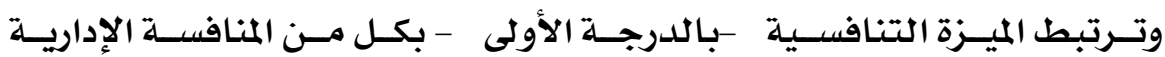

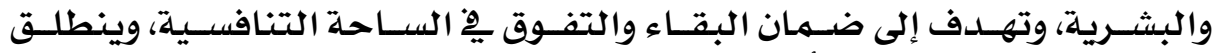

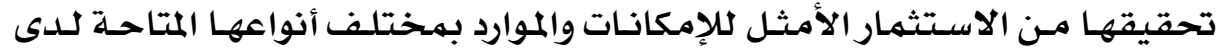

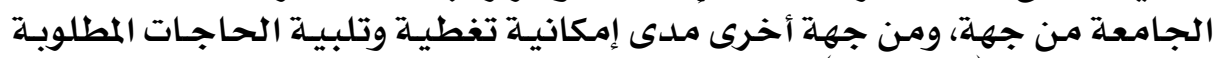

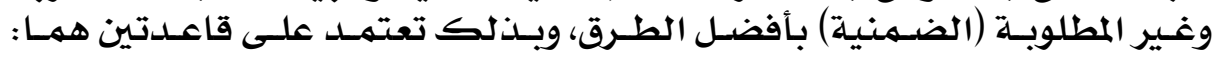
استراتيجية جديدة والإبداع.

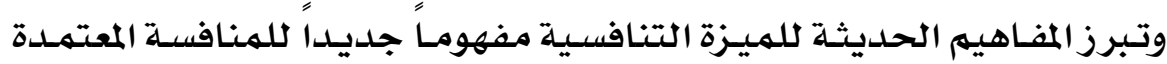
على الزمن والتي تقوم على:

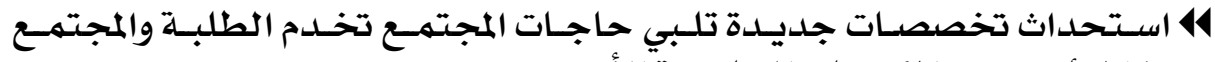

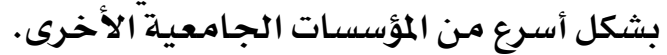

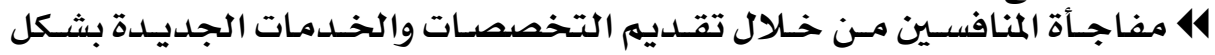

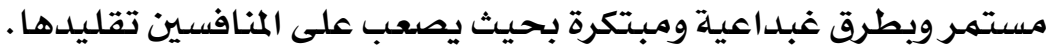

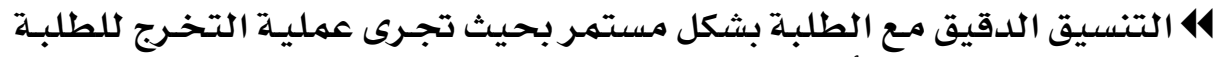
مِّ وقتها المحدد دون تأخير. مما سبق يمكن استخلاص الآتية:

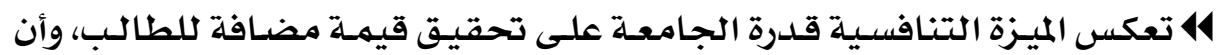

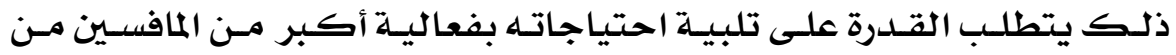
خلال تبني استراتيجية ترتكز على التميز.

\section{$\varepsilon \wedge \varepsilon$}




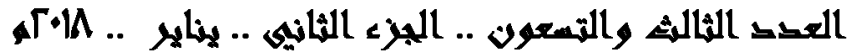

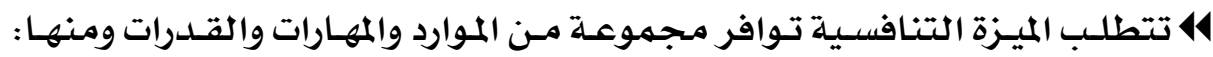

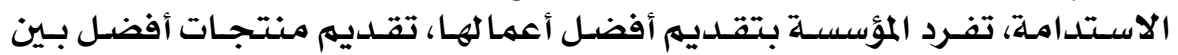
مثيلاتها.

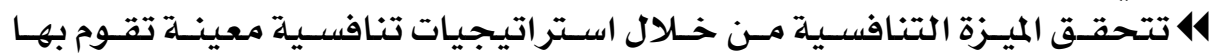

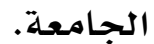

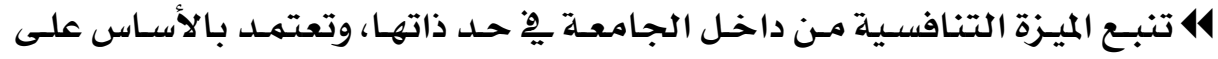
عمليـة الإبلداع.

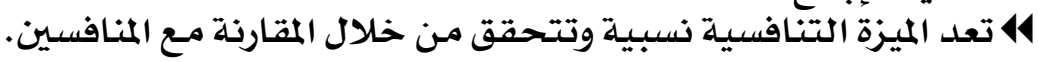

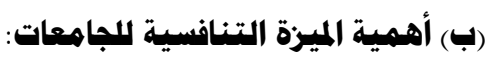

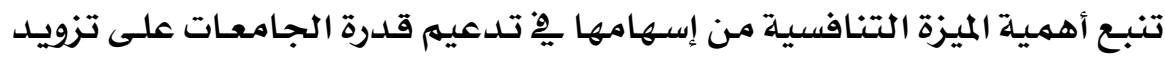

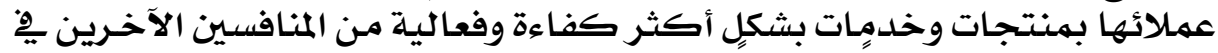

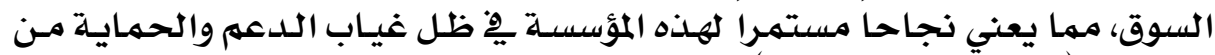

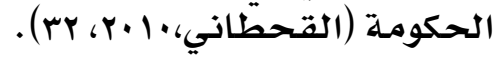

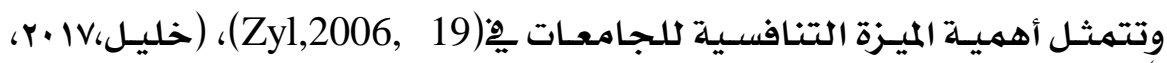
: (Ir

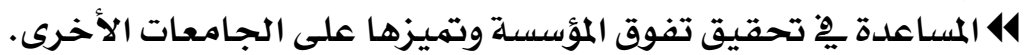

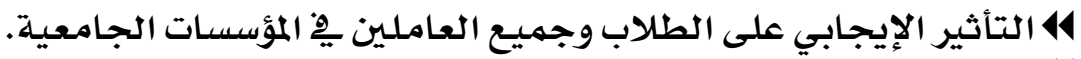

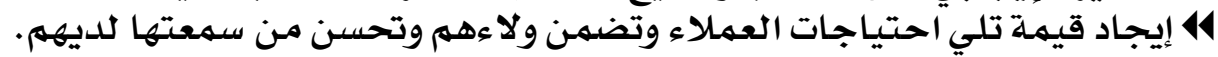

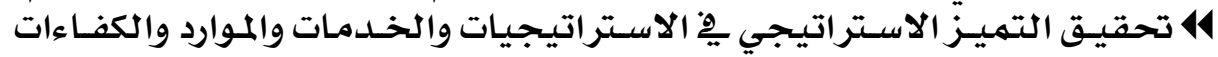
على المنافسين.

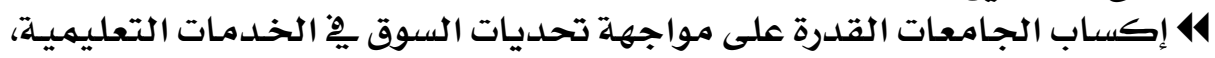

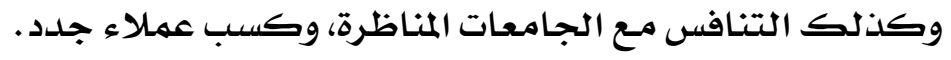

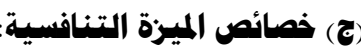

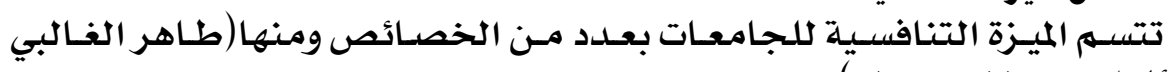

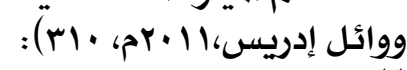

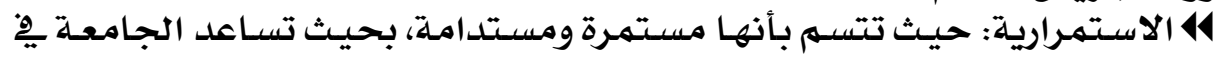

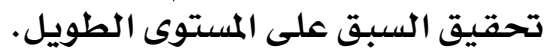

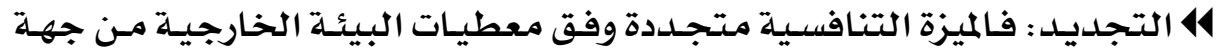

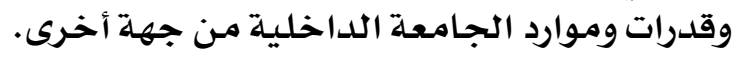

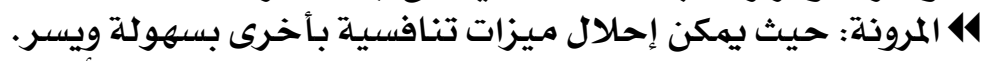

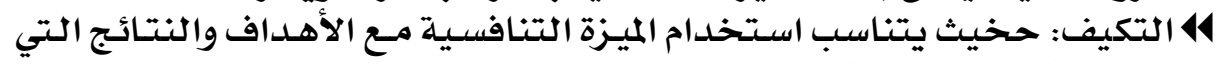

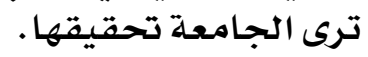

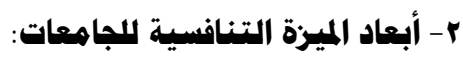

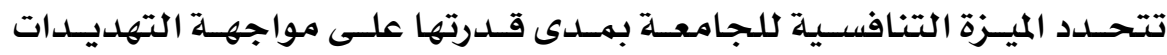

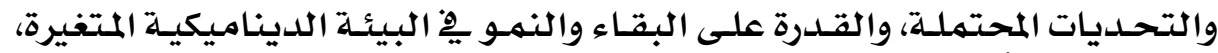

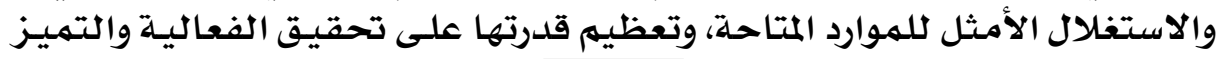

\section{$\varepsilon \wedge \theta$}




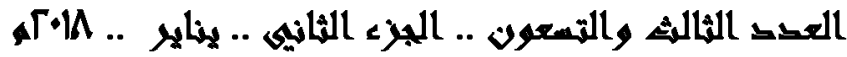

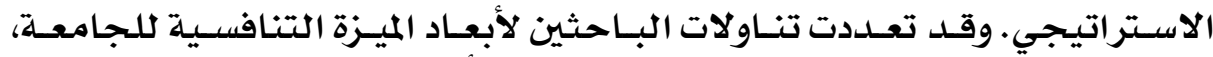

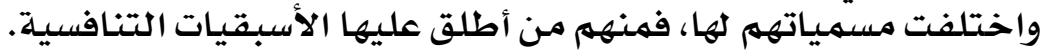

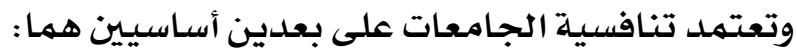

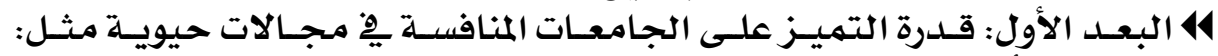

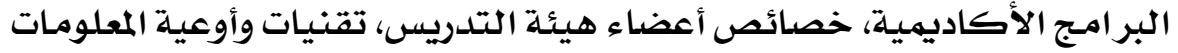

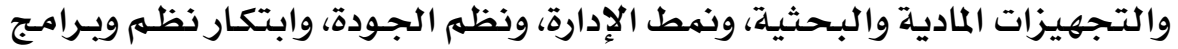

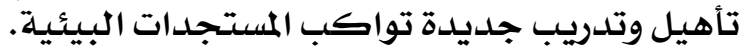

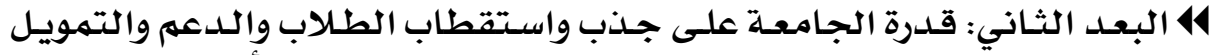

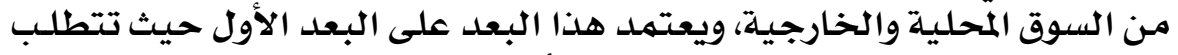

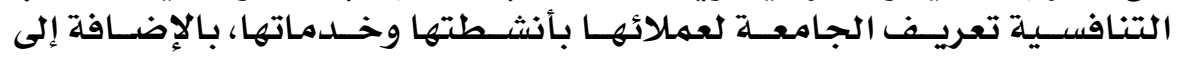

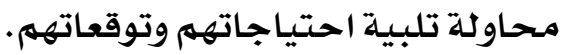

وتتضمن أبعاد الميزة التنافسية مانيكا يأتي:

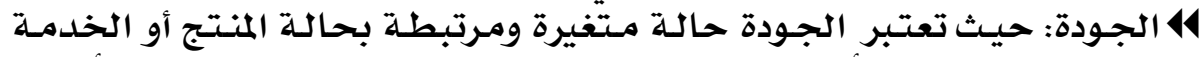

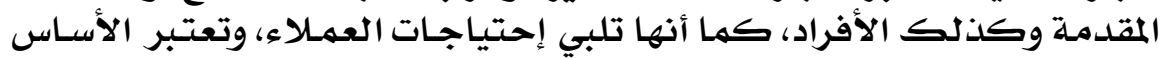

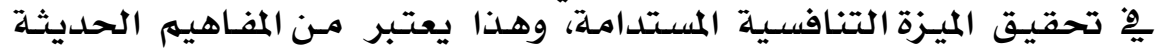

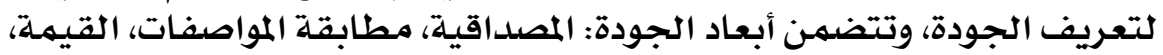

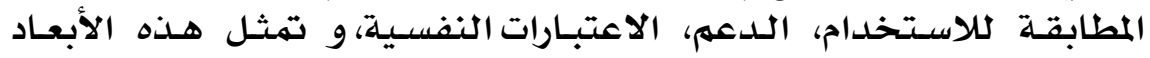

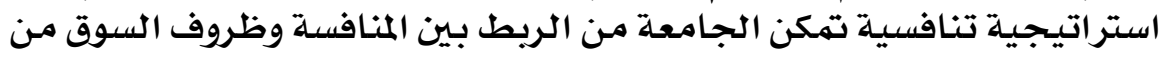

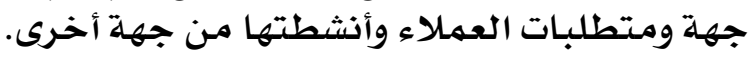

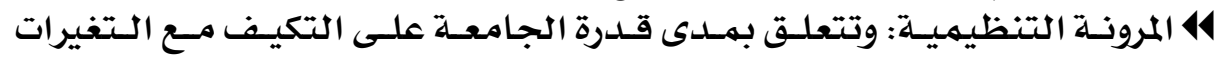

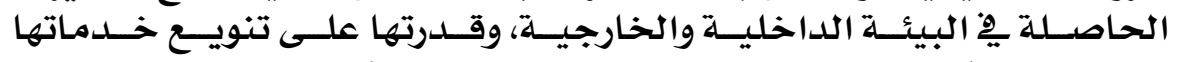

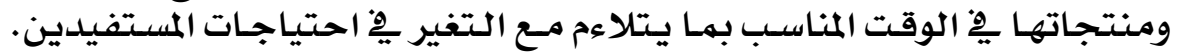

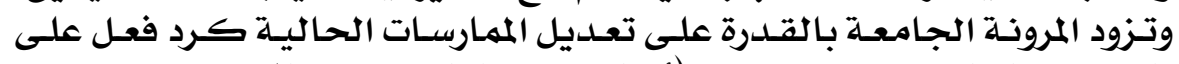

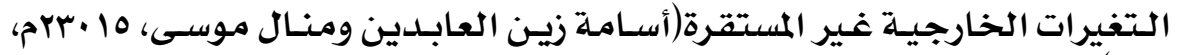

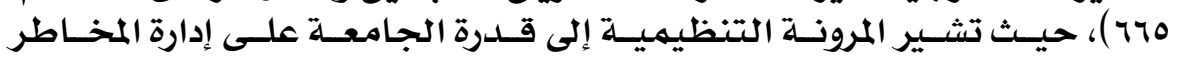

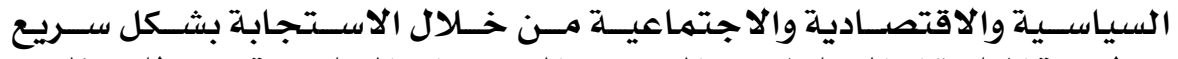

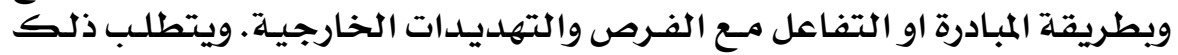

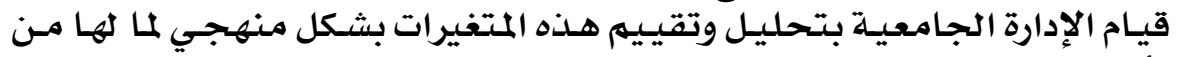

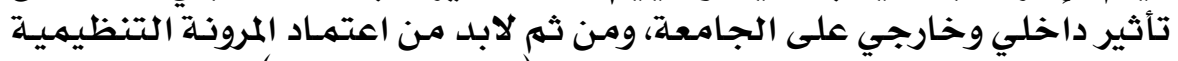

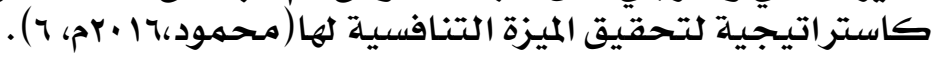

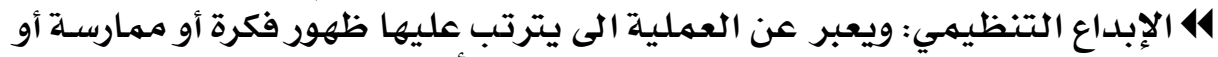

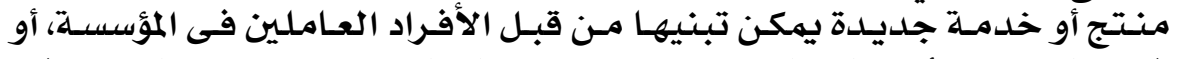

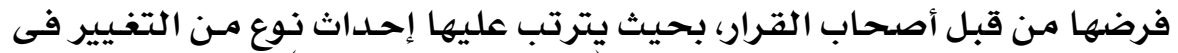

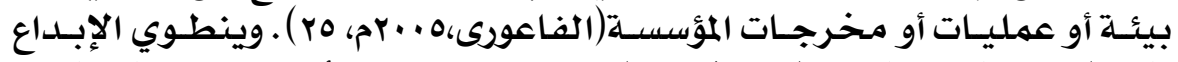

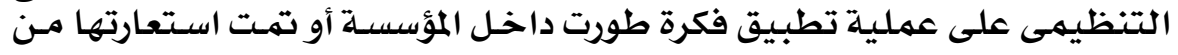

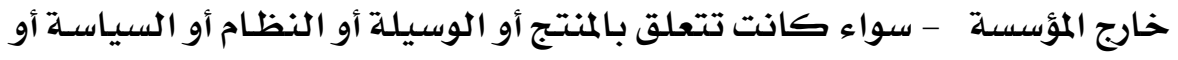

\section{$\varepsilon \wedge \uparrow$}




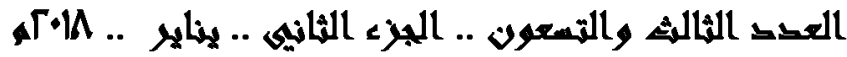

البر نامـج أو الخدمـة، والتى هى جديـلـة بـالنسـبـة للمؤسســة حينهـا تم تطبيقهـا.

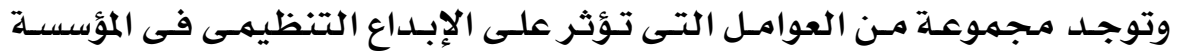

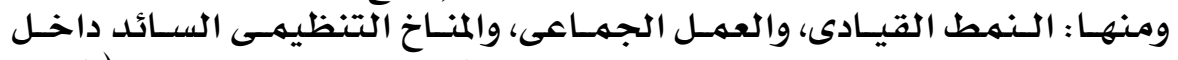

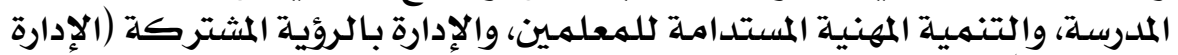

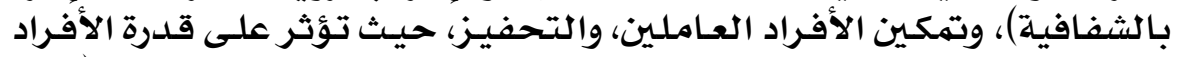

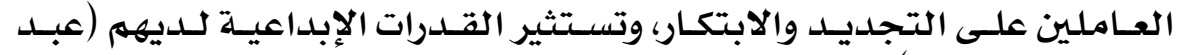

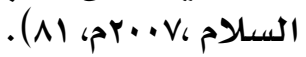

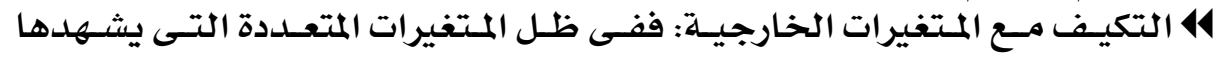

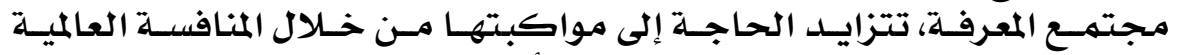

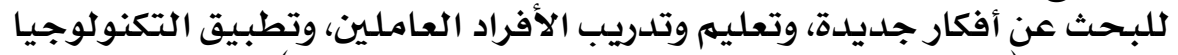

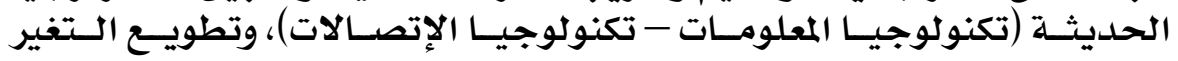

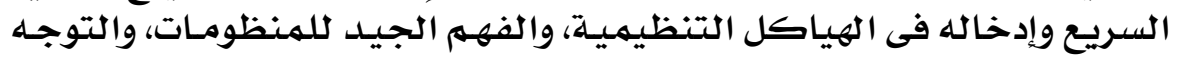

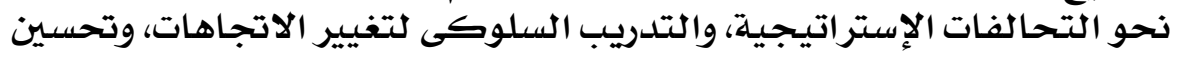

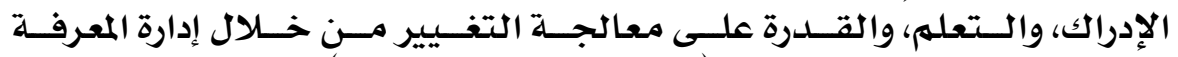

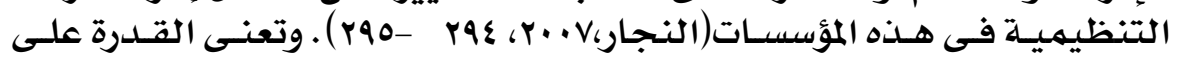

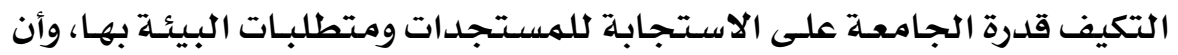

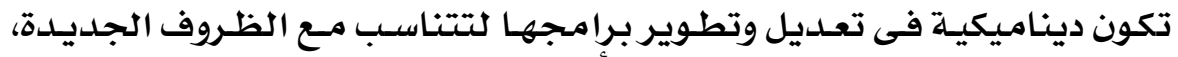

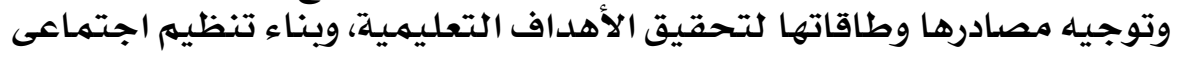

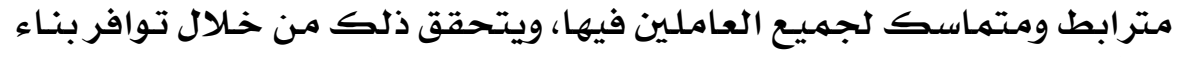

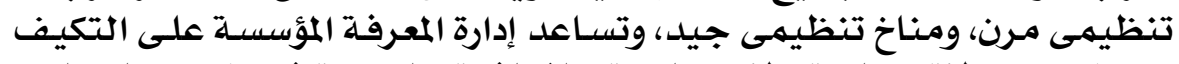

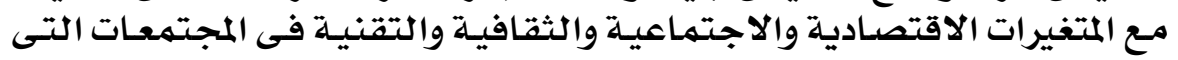

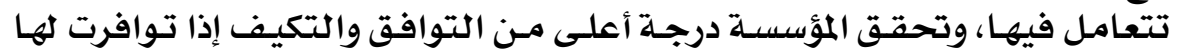

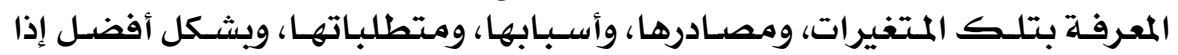

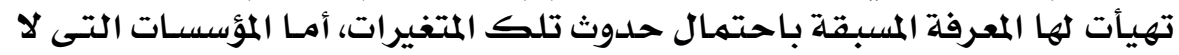

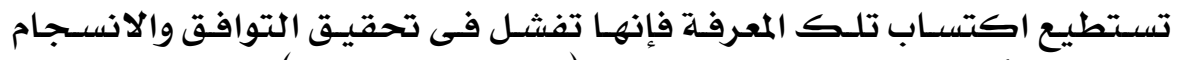

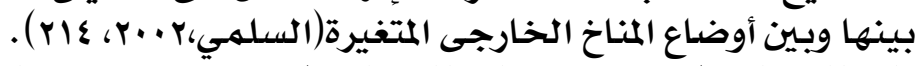

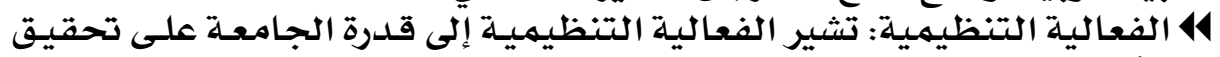

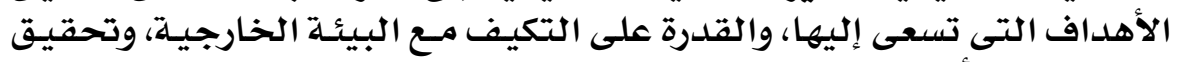

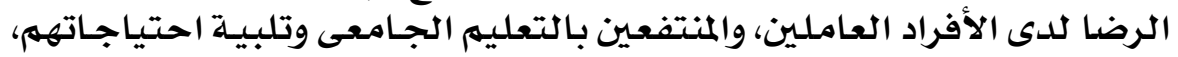

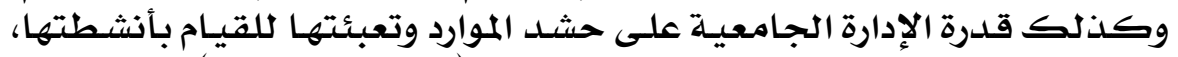

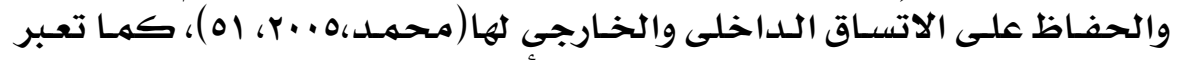

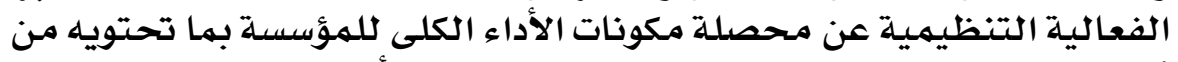

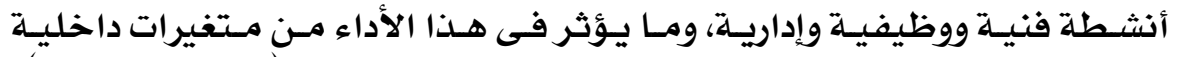

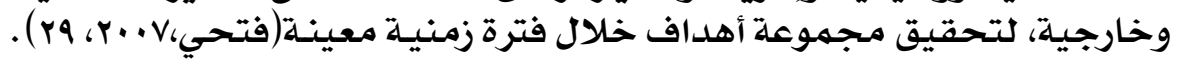

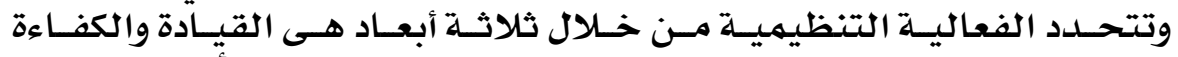

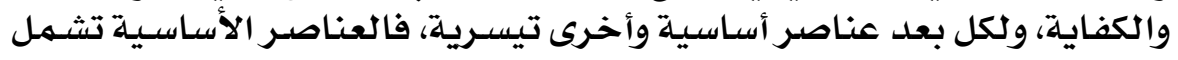

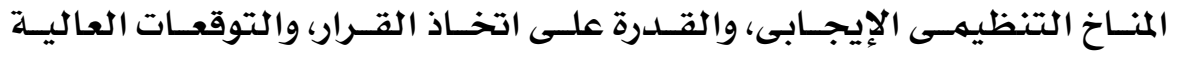




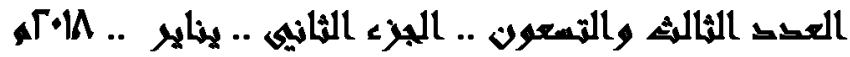

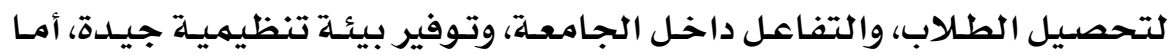

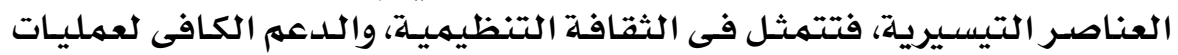

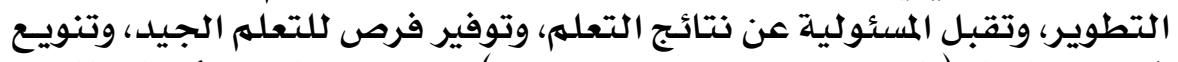

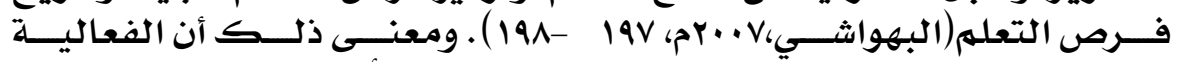

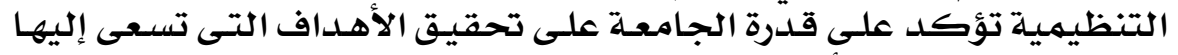

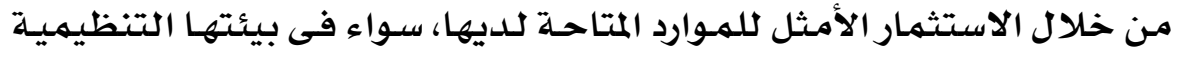

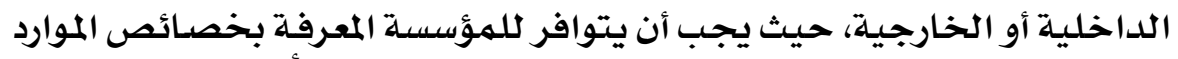

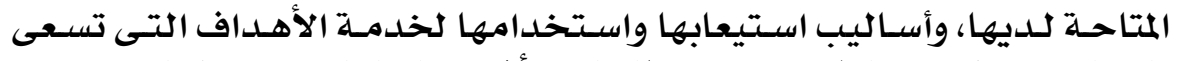

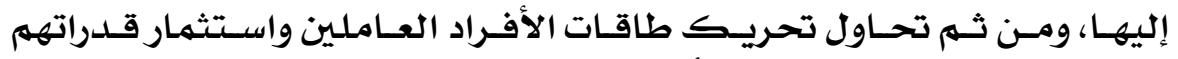

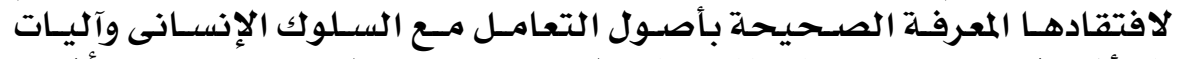

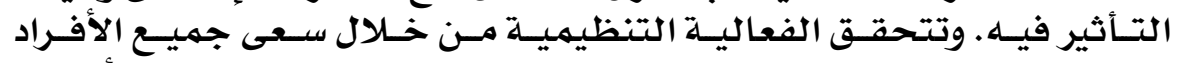

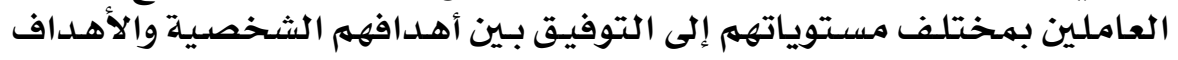

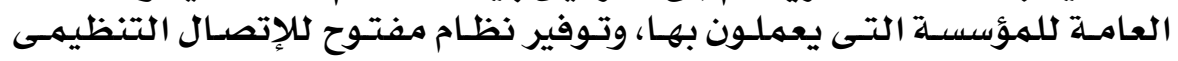

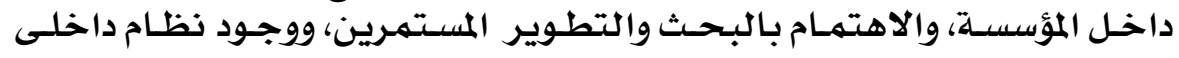

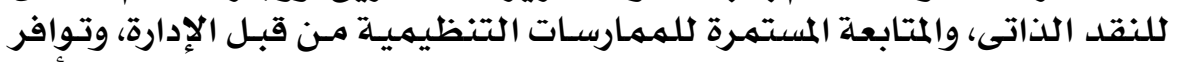

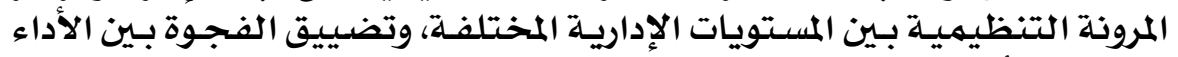

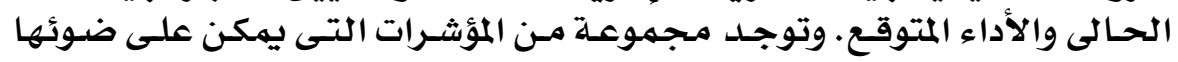

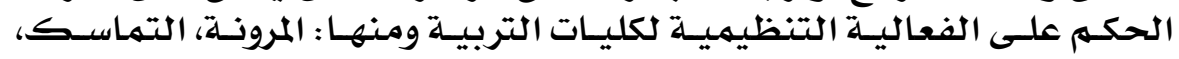

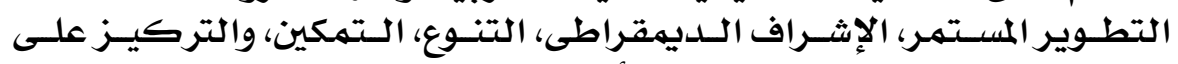

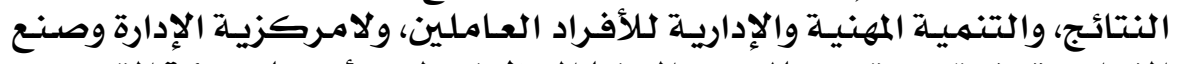

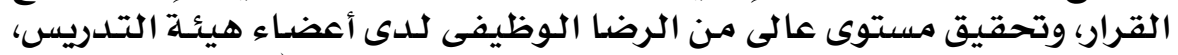

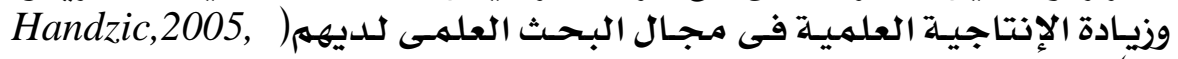

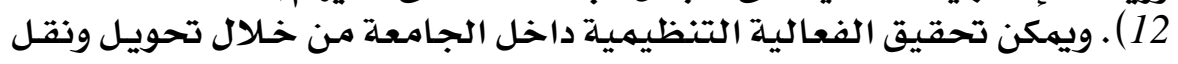

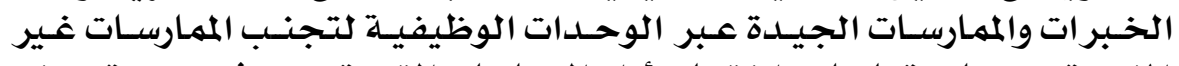

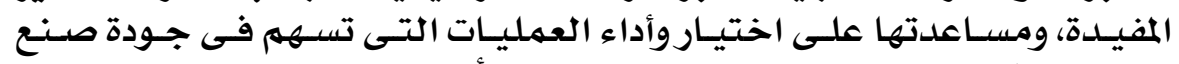

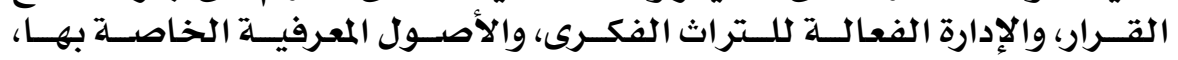

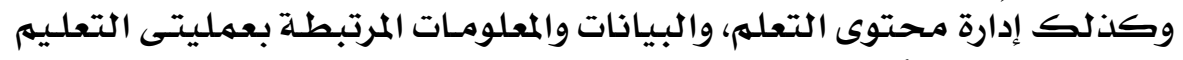

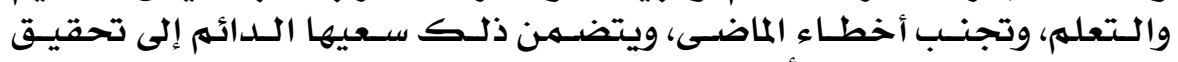

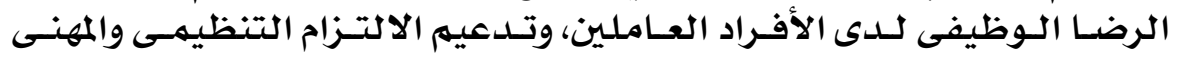

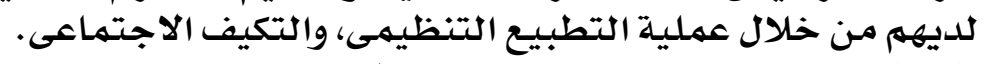

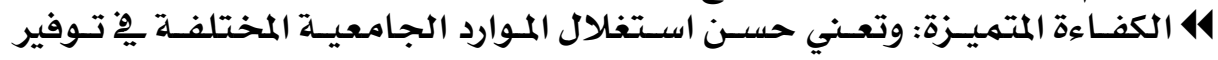

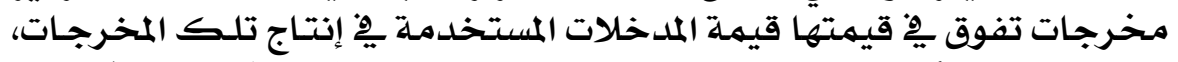

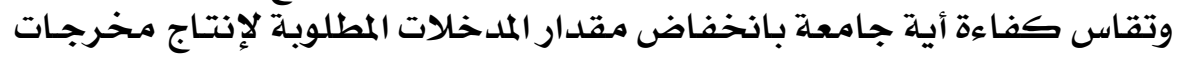

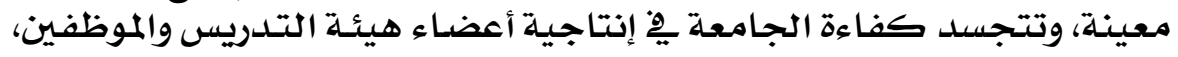

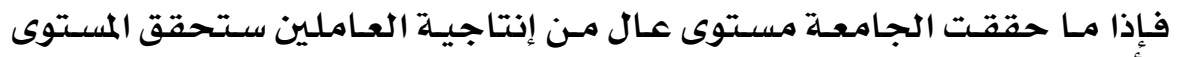

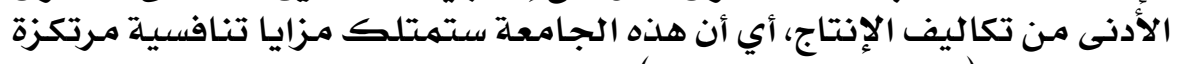

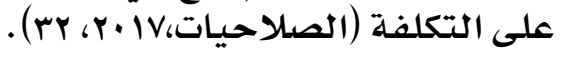

\section{$\varepsilon \wedge \wedge$}




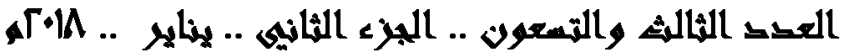

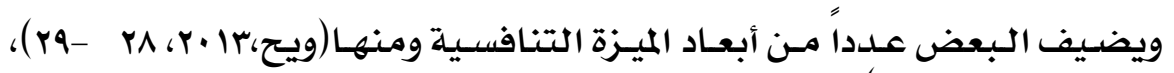

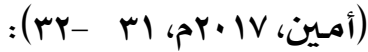
له التركيز على الطلاب: أي تحقيق القدرة على الحفـاظ على الطلاب الحساليين،

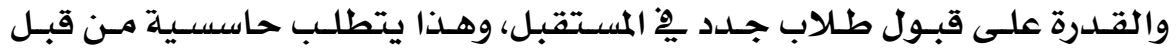

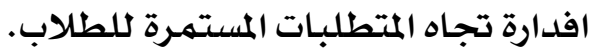

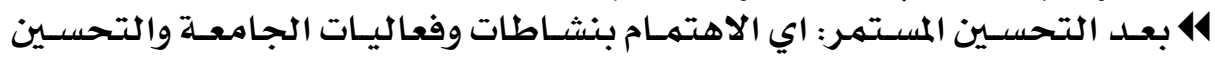

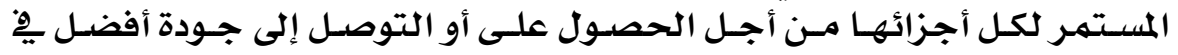

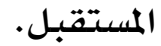

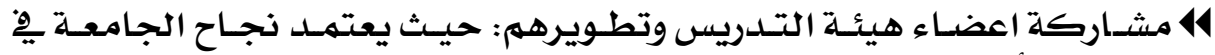

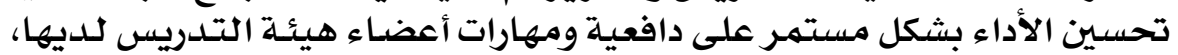

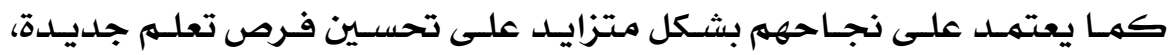
وتطبيق مهارات نوعية. له الإدارة بالحقائق: حيث تقوم الميزة التنافسية على بيانات وحقائق تلزم مـن أجل

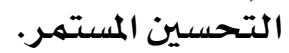

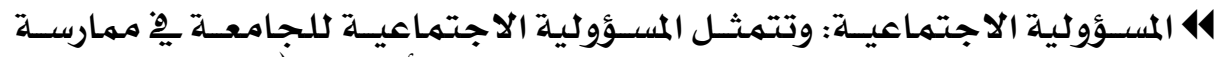

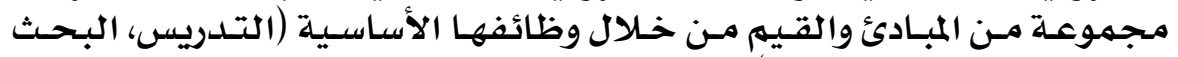

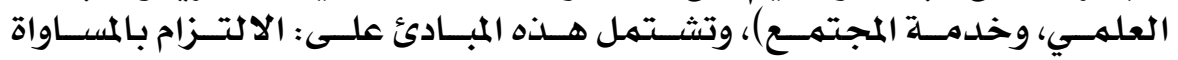

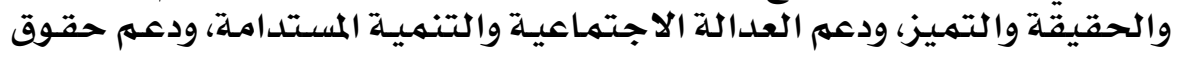
الإلنسان.

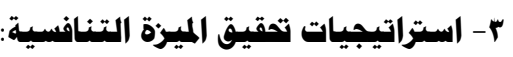
تتضمن استراتيجيات تحقيق الميزة التينة التنافسية ما يأتي:

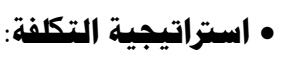
تلعب التكاليف دوراً مهماً مِِ تحقيق الميزة التنافسية، فالجامعـة المتميزة تعهل

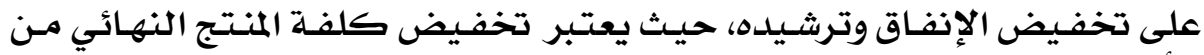

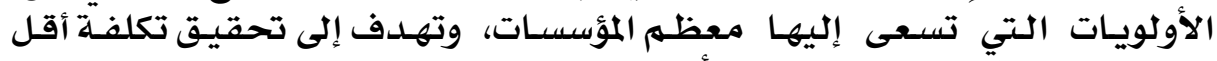

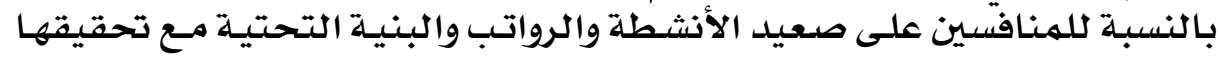

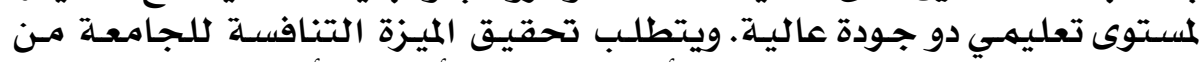

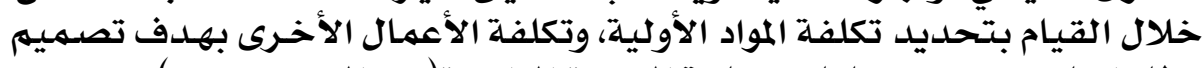

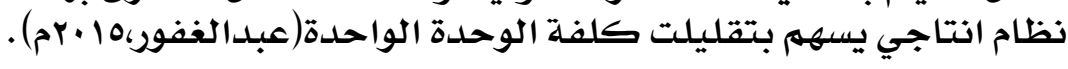

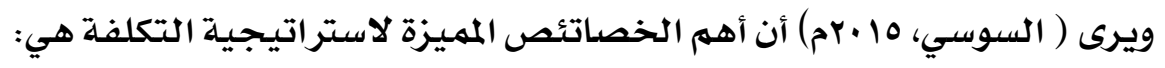

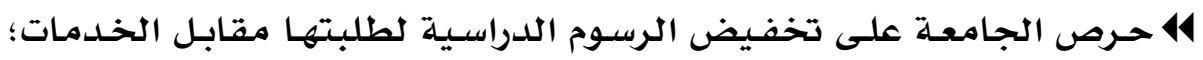
للحماية من المنافسين. 14 سعي الإدارة إلى تحقيق التنافس مـع الجامعات الأخرى بتكاليف مخفضـة يو.

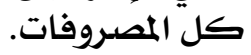

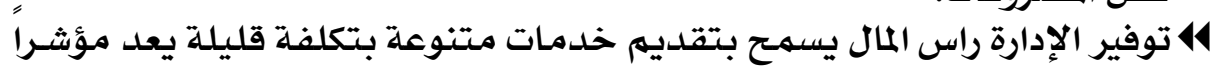

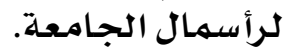

\section{$\varepsilon \wedge q$}




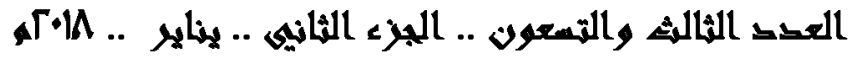

\الكاليف الدراسـة المخفضة تشكل قوة تفاوضيـة للكلية مـع الطلبـة؛ لأن أسـعارها مخفضشة.

\section{• استراتيمية التهميرز:}

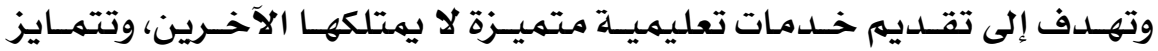

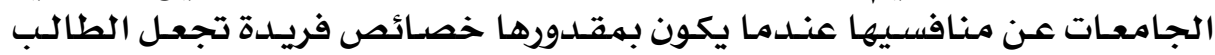

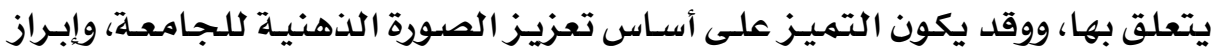

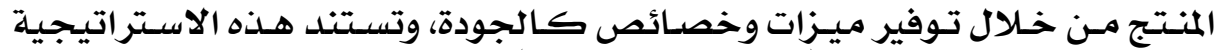

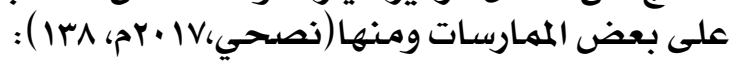

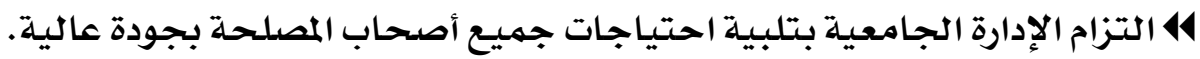

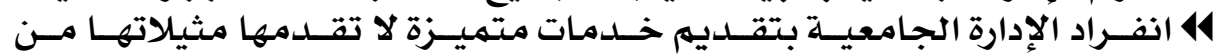

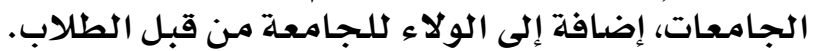

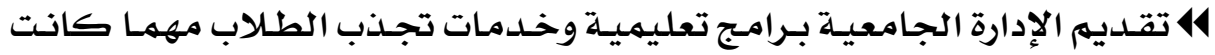
التكلفة. 14 تشـجيـع الإدارة الجـامعيـة على المهارسـات التطويريـة والإبـداعيـة لـدى العـاملين بها لاكتشاف الكفاءة العالية الدادية لديهم.

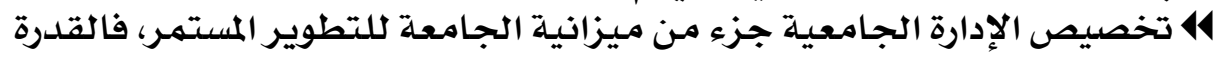

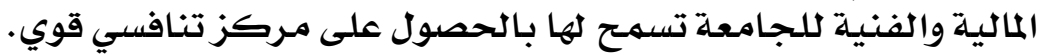

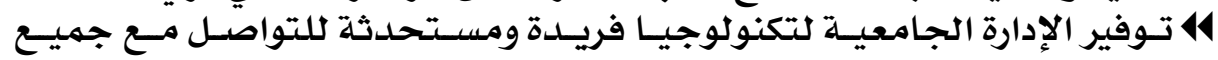

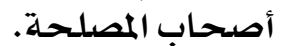

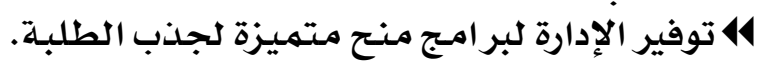

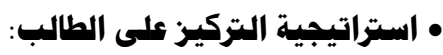

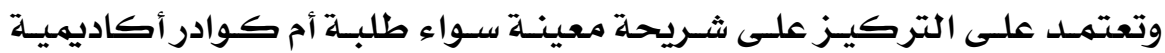

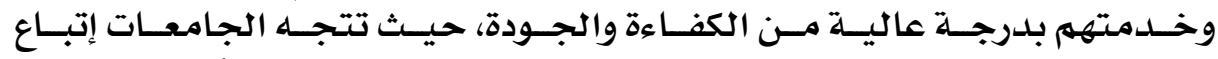

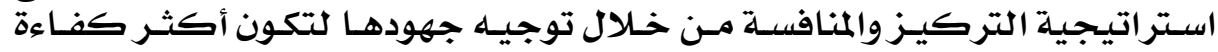

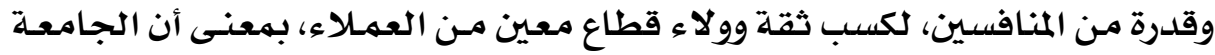

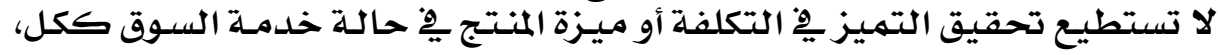

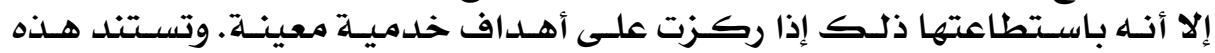

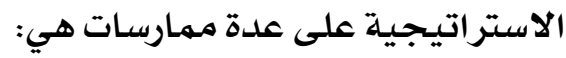

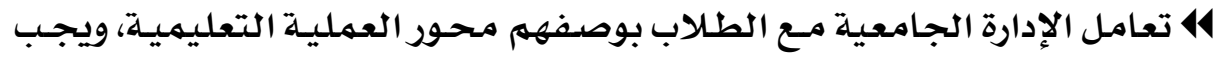

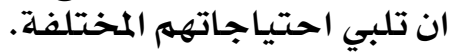

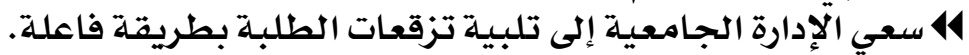

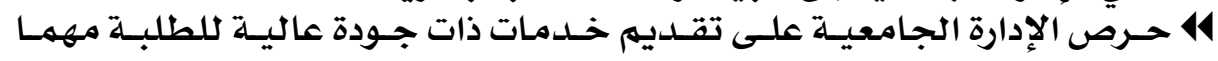
كانت التكاليف.

14 محاولة الإدارة الجامعيـة تطوير العلادقة بيـن الطلبـة والعاملـين بشكل مستهـر.

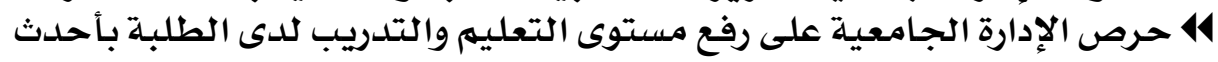
الطرق.

\section{\&9.}




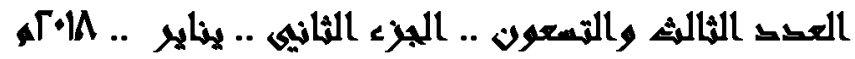

• استراتيجية سرعة الاستجابة:

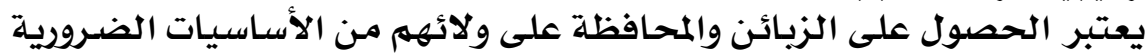

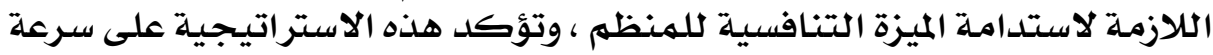

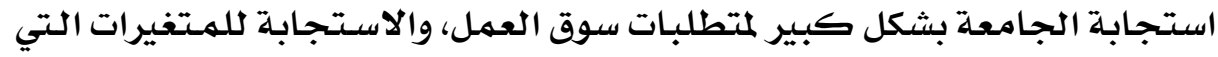

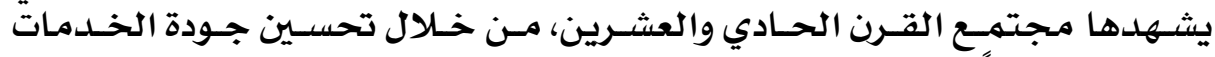

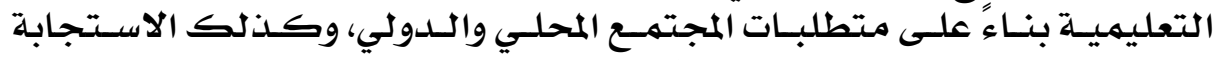

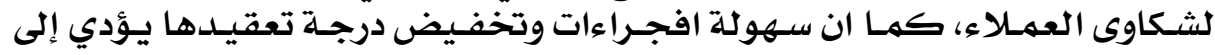

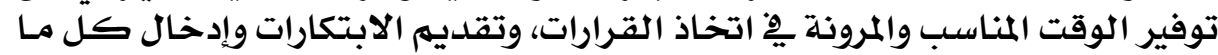

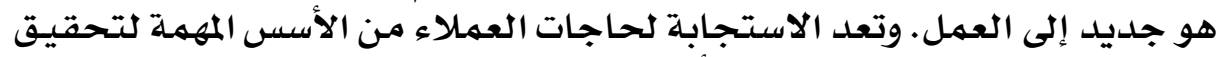

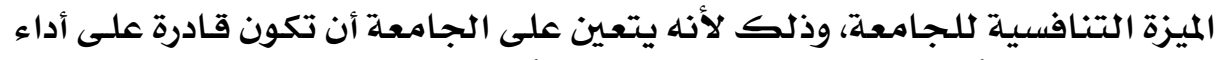

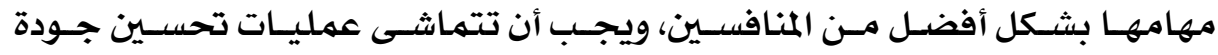

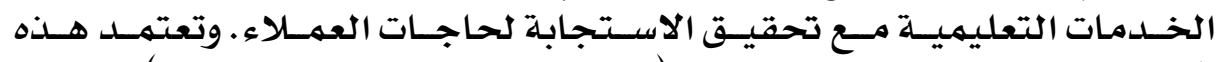

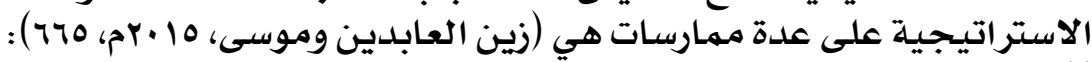

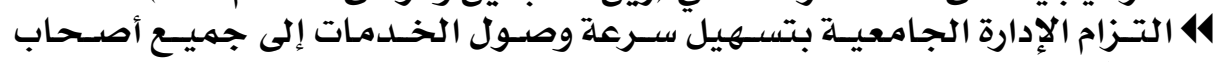

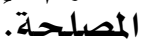

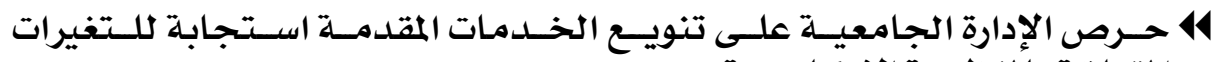

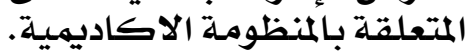

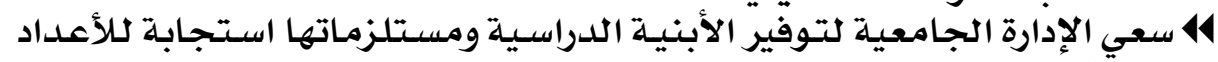
المقبوّية.

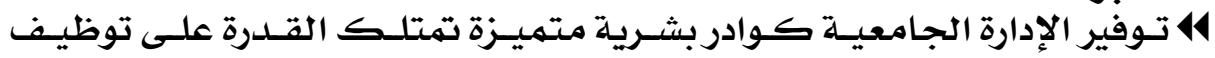

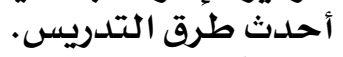

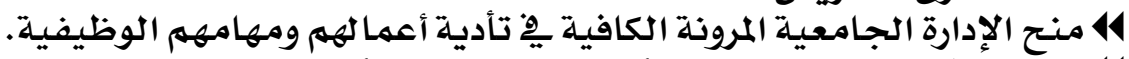

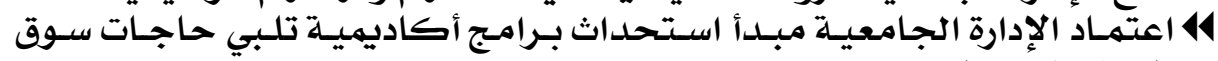

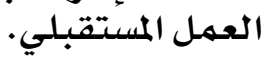

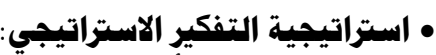

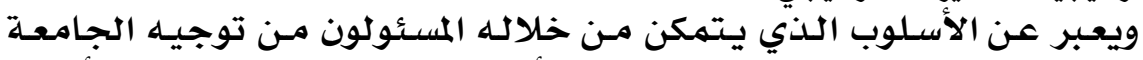

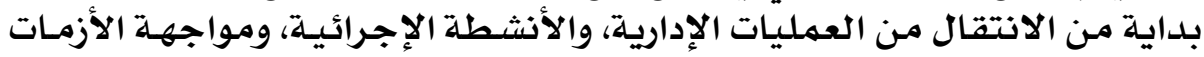

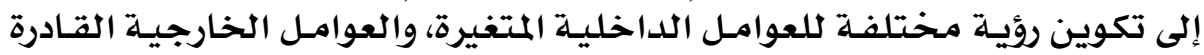

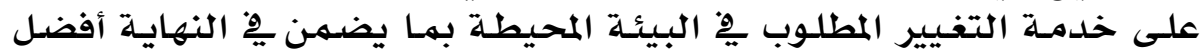

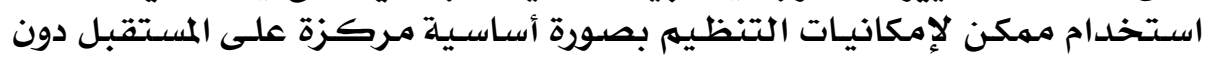

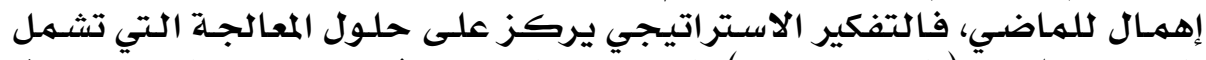

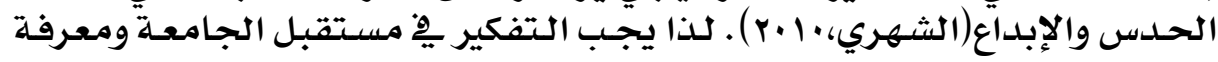

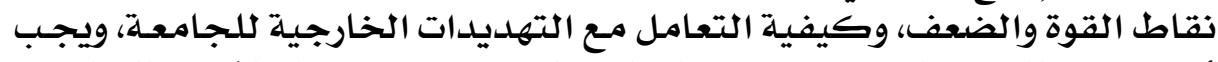

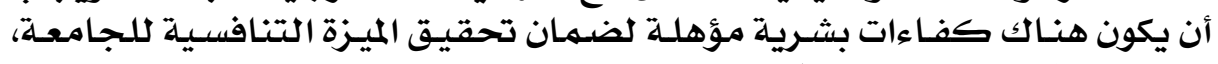

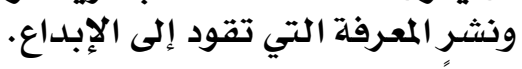

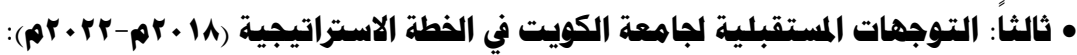

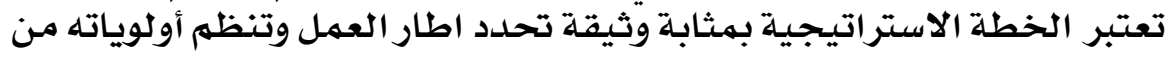

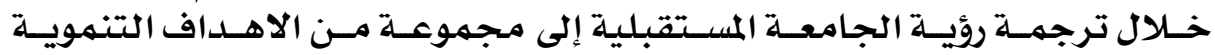

\section{$\{91$}




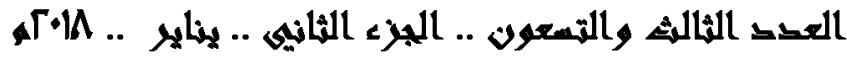

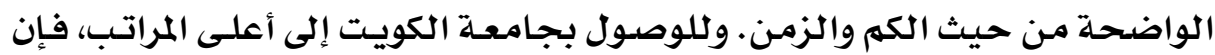

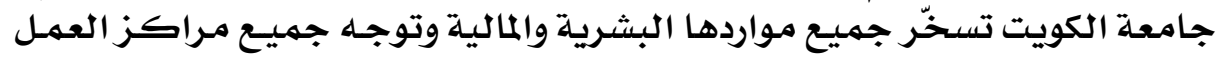

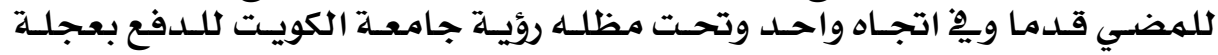

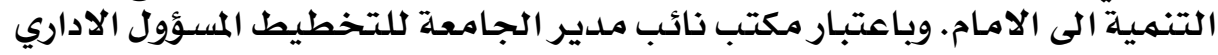

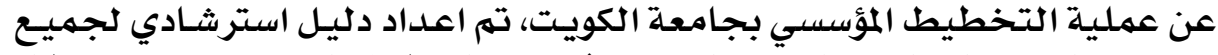

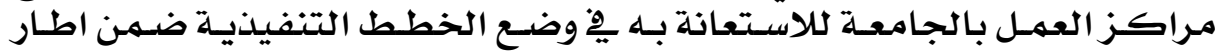
موحل لتسهيل عملية التقييهم والمتابعة حتى يتم الوصول الى الغاية المنشودة.

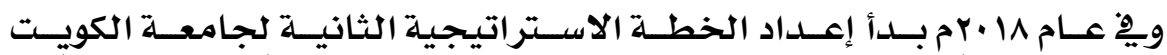
2 )

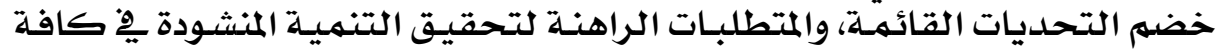

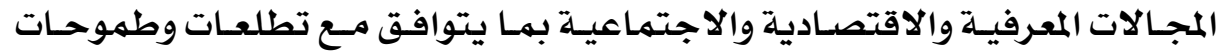

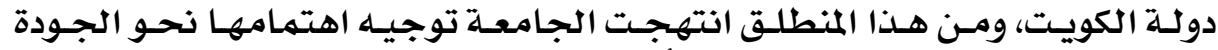

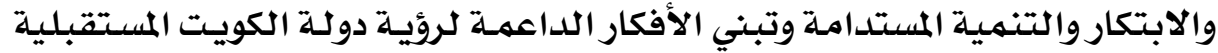

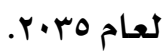

وبهشـاركة اسـتراتيـجية مسن كافـة منتسـبي الأسـرة الجـامعيـة، تم رسـم الإطسار

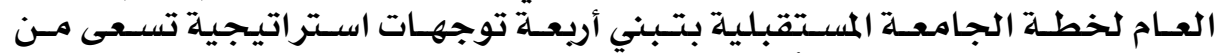

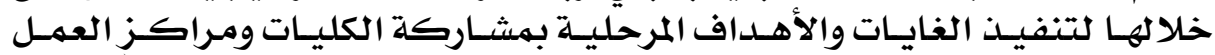

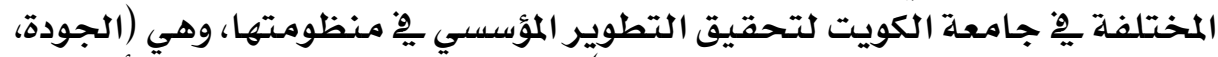

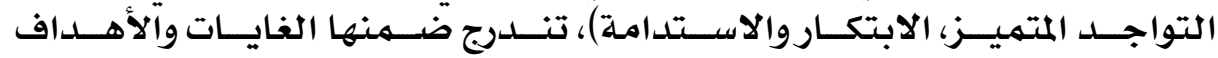

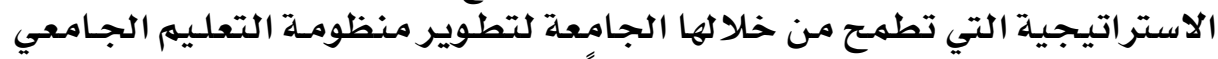

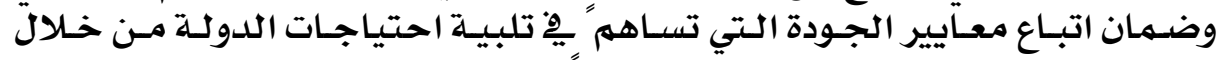

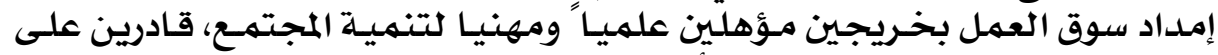

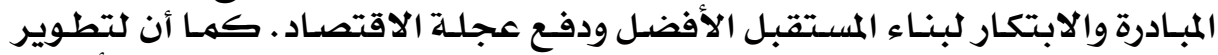

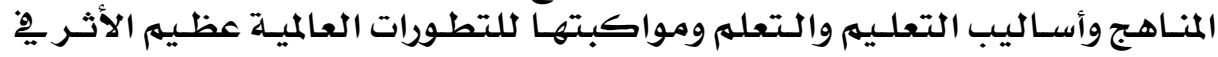

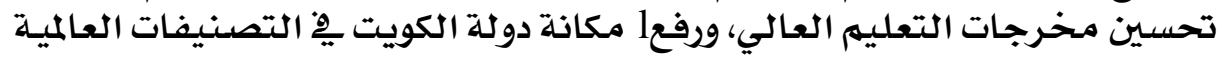

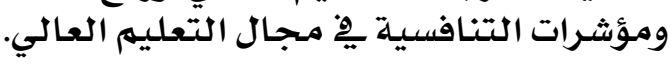

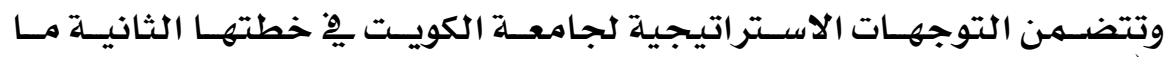

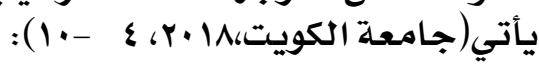

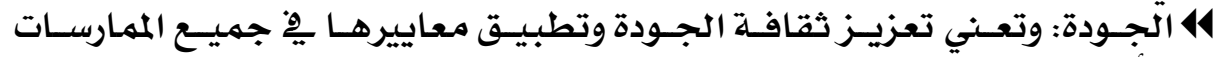

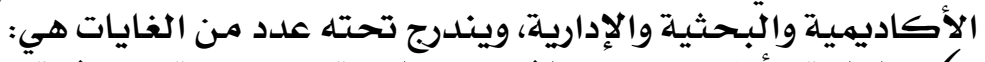

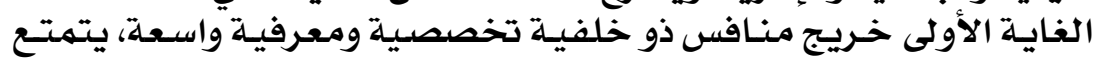

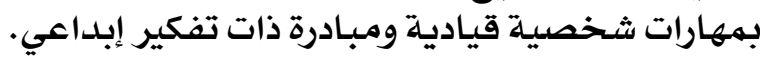

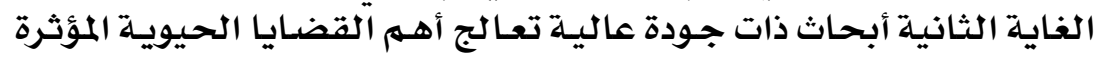
محليا ودوليا.

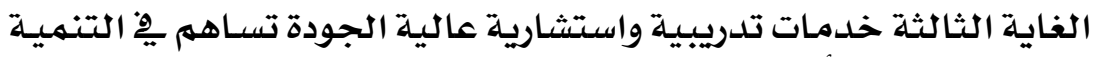

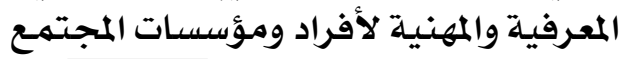

\section{\& 9 Y}




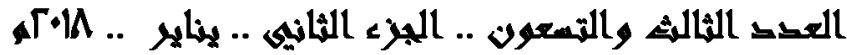

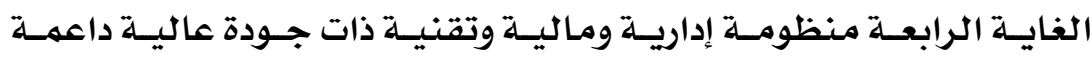

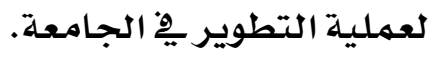

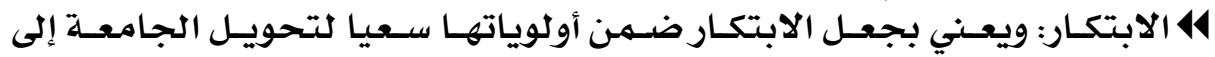

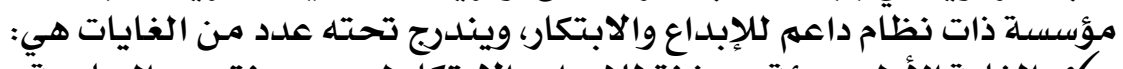

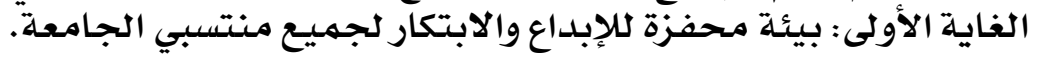

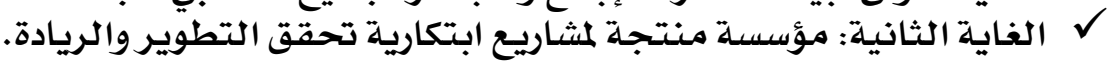

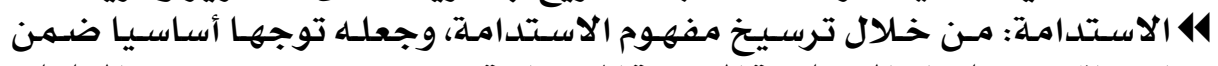

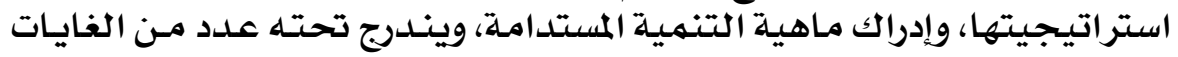

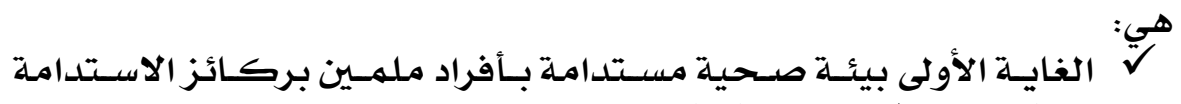

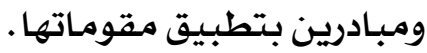

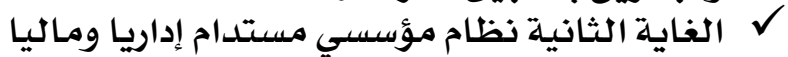

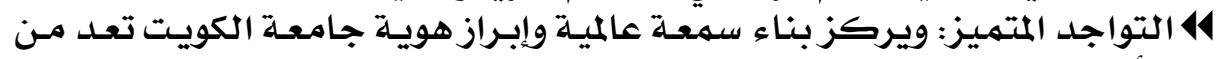

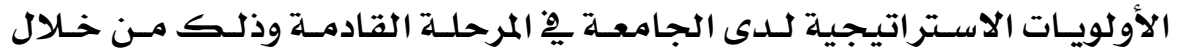

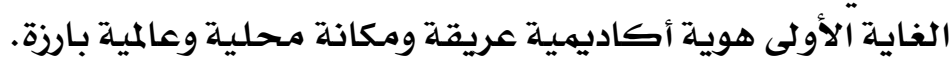

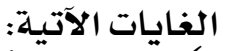

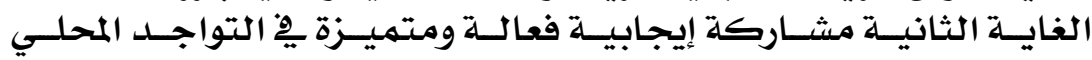
والعالمي.

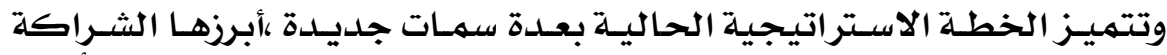

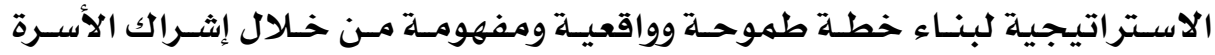

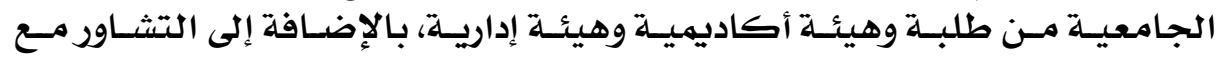

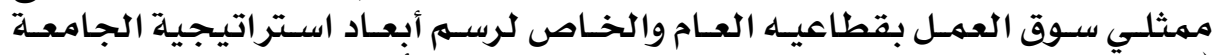

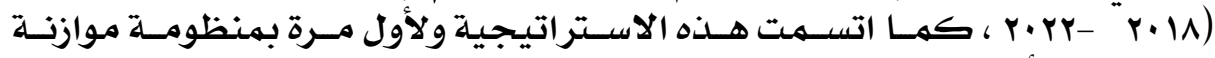

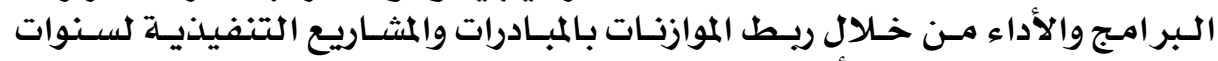

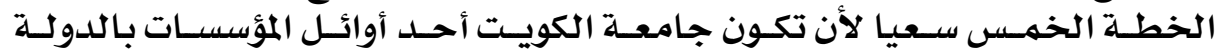

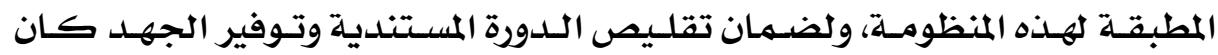

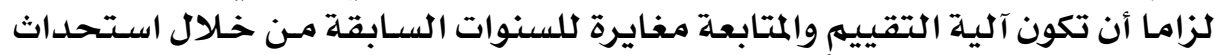

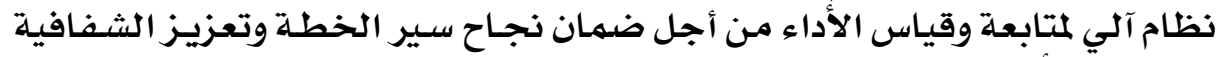

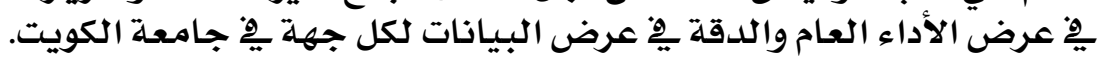

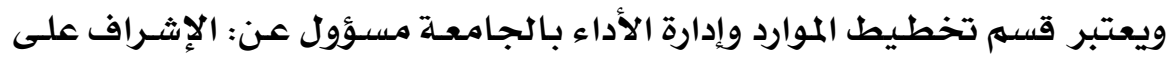

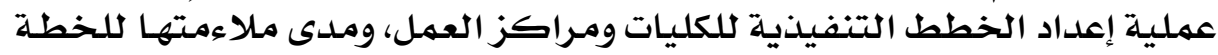

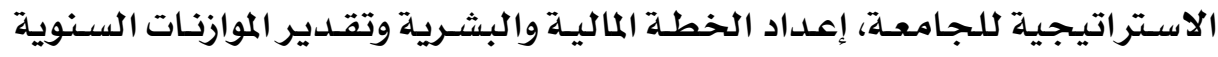

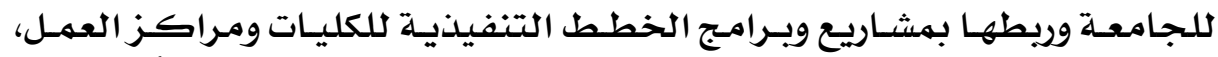

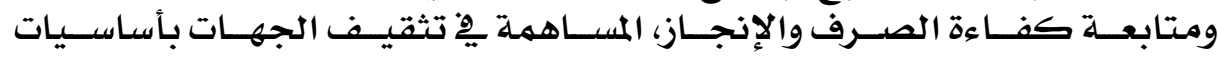

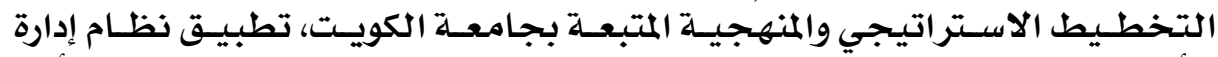

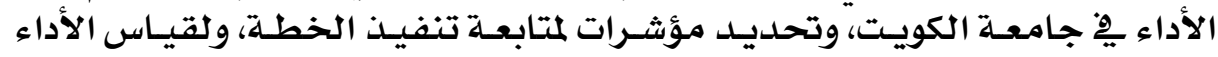




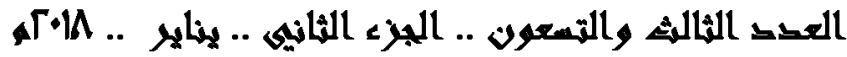

الفعلي للكليـات ومـراكز العهل وفقـا لـلأهـداف الاسـتراتيـجيـة، تحليـل ودراسـة أهـم

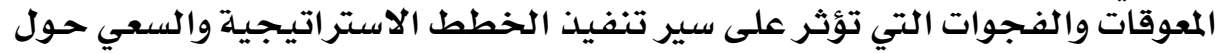

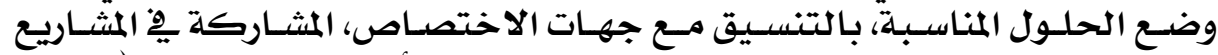

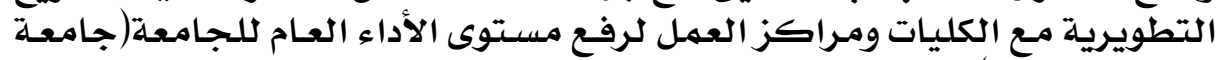

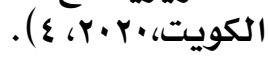

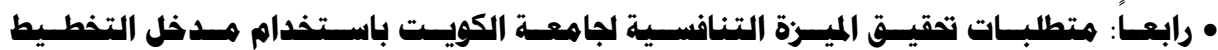

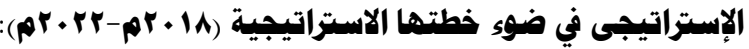

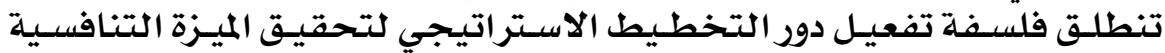

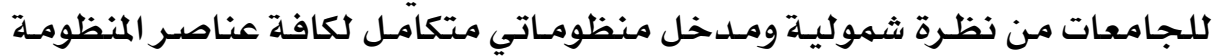

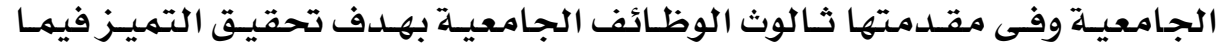

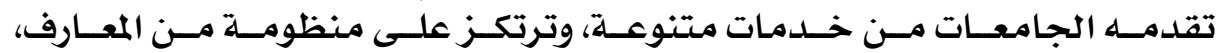

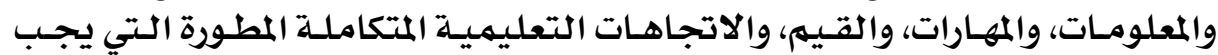

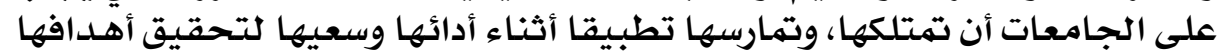

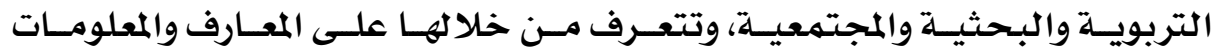

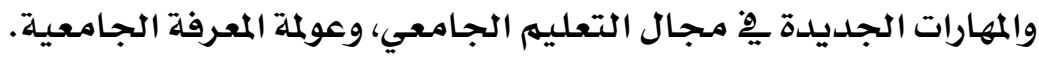

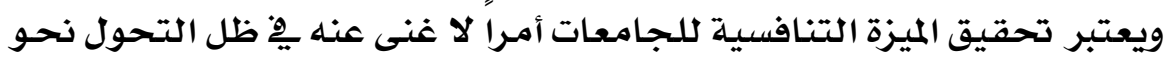

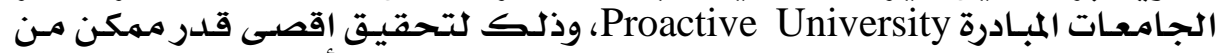

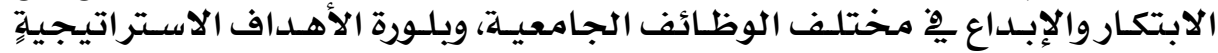

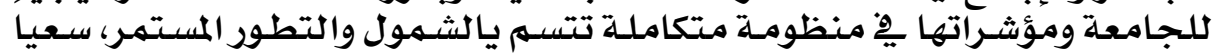

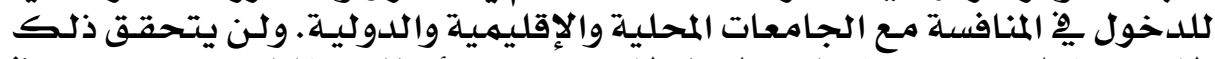

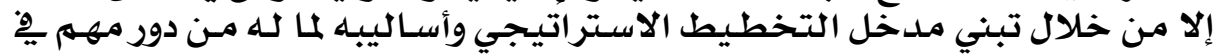

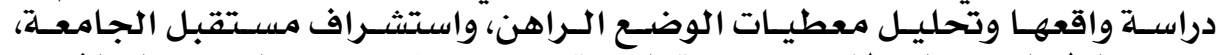

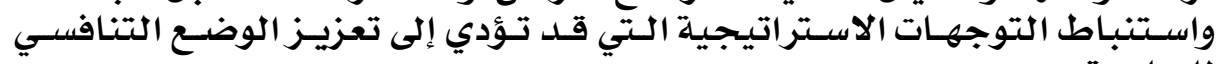
للمجامعـة.

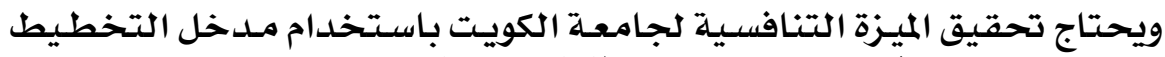

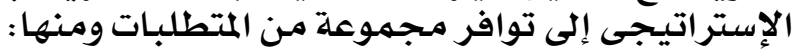

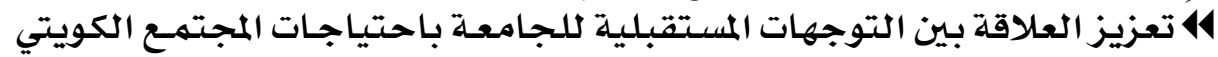

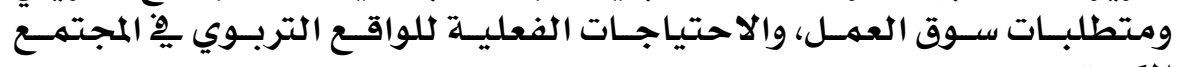
الكويتي. وانمين.

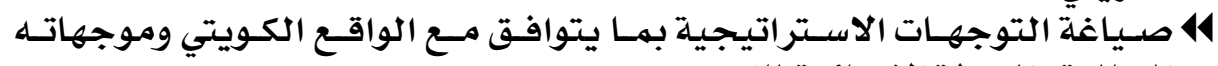

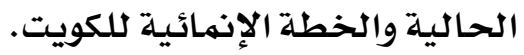

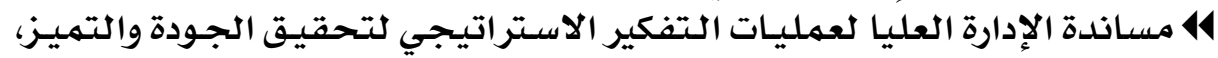

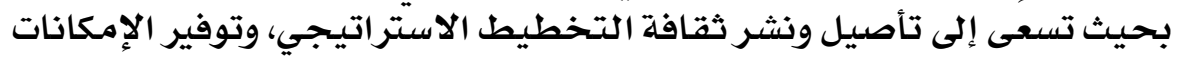

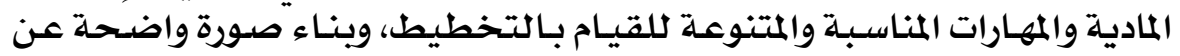

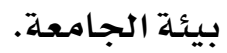

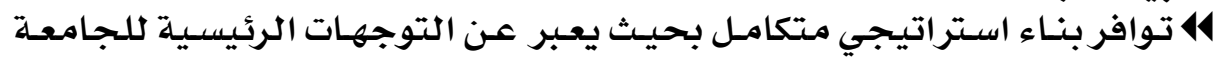

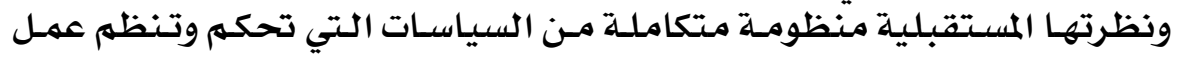

\section{$\varepsilon 9 \varepsilon$}




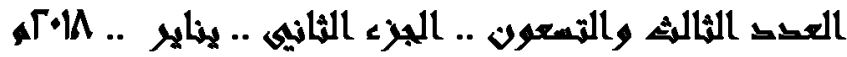

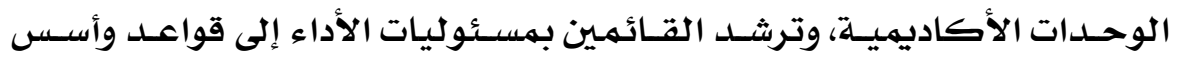

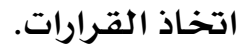

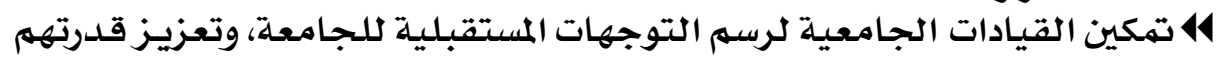

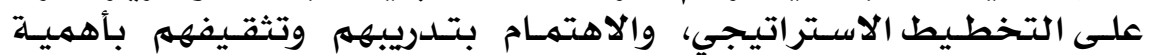

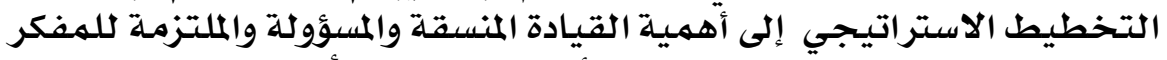

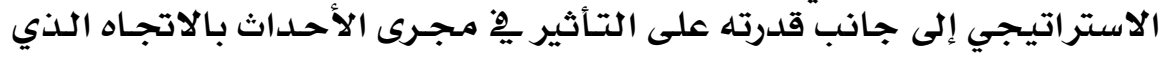

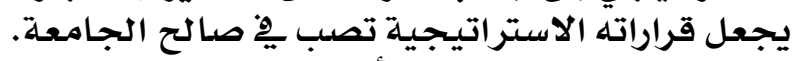

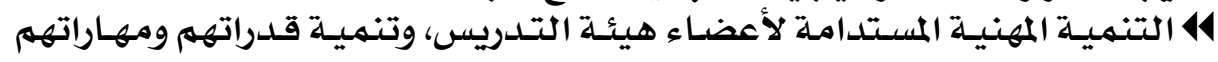

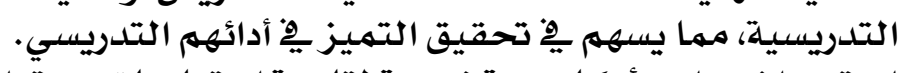

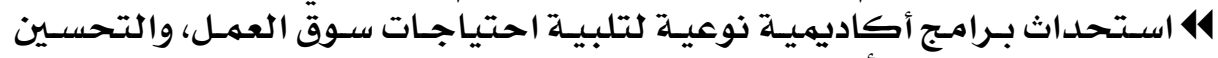

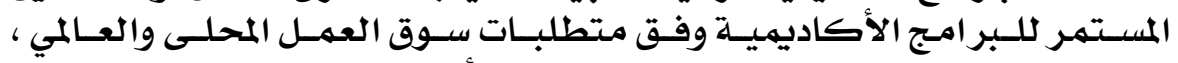

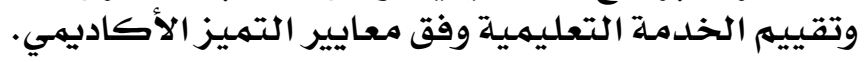

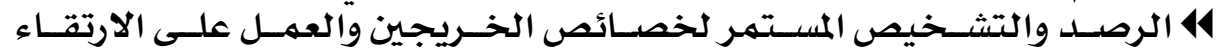

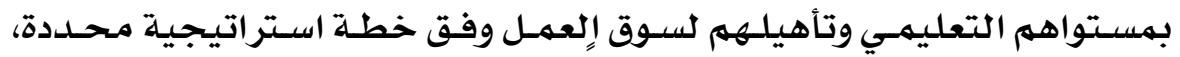

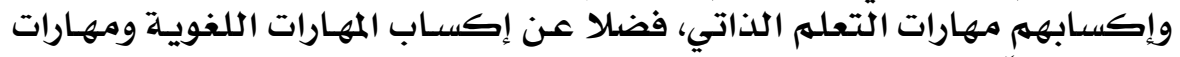
الحاسبب الآلي.

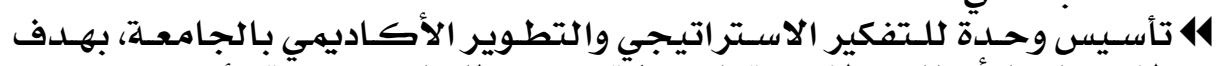

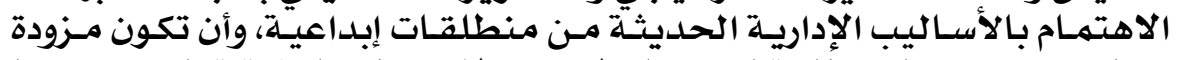

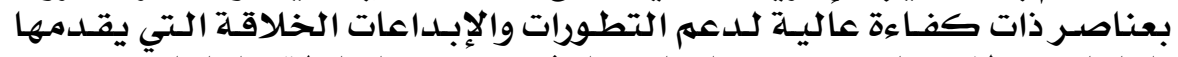

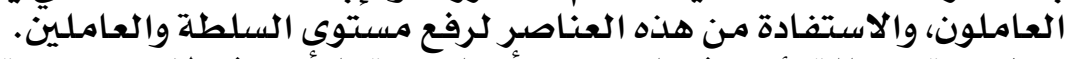

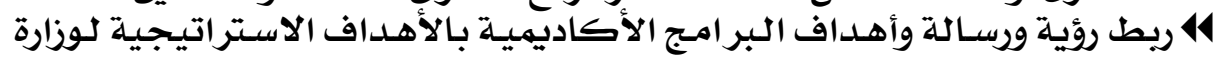

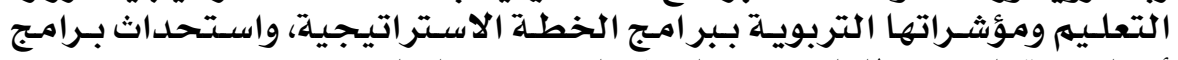

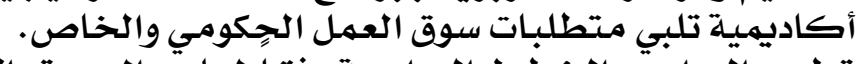

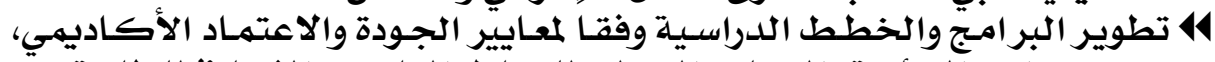

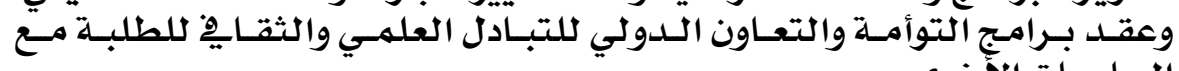

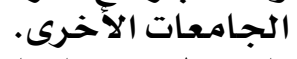

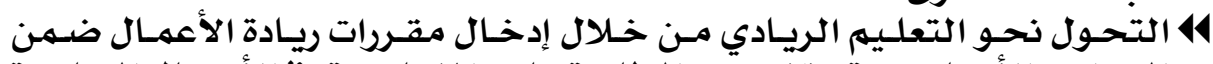

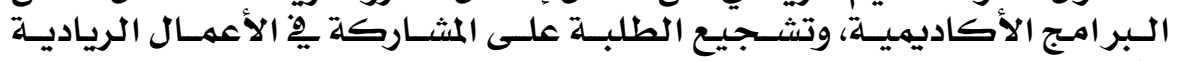
والإبداعية.

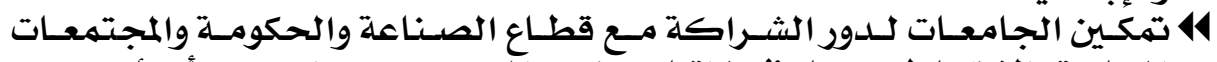

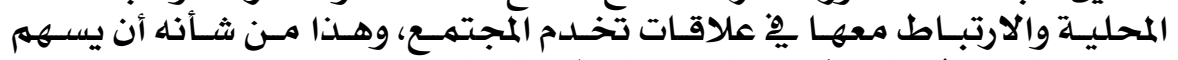

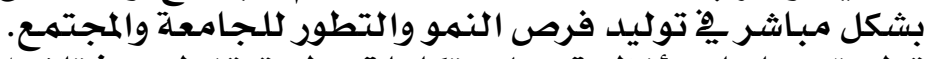

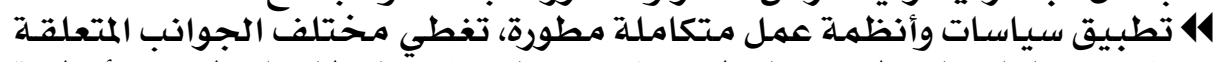

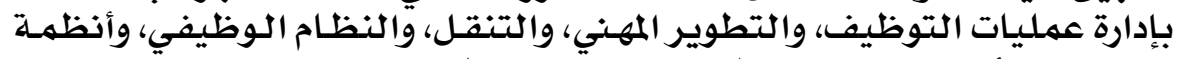

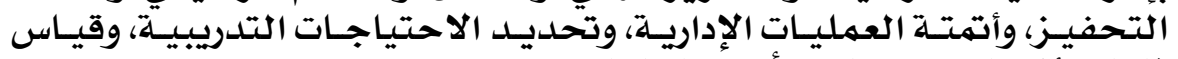

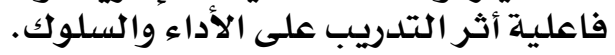

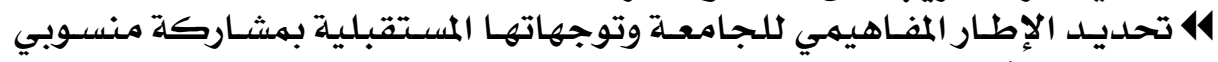

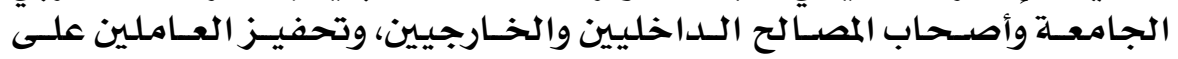

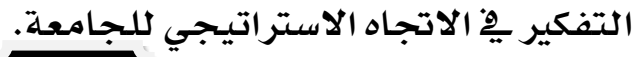




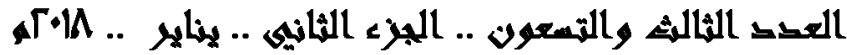

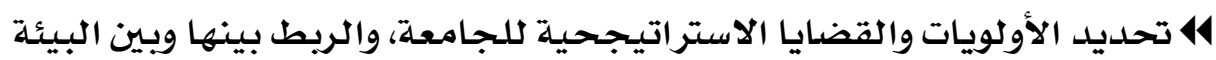

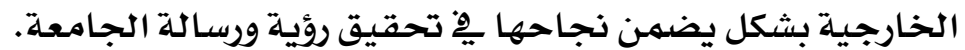

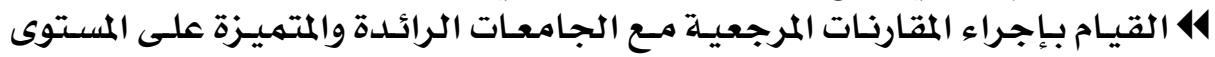

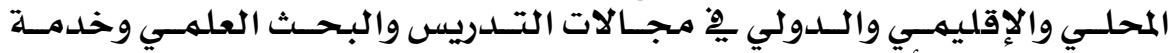

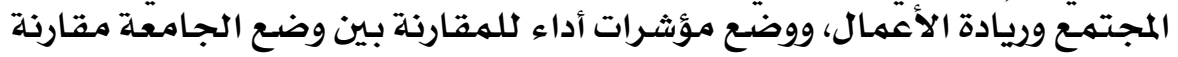

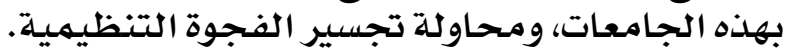

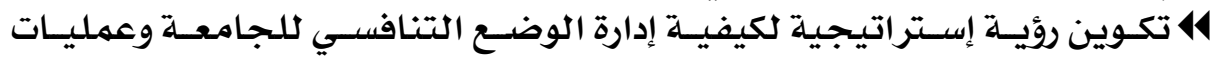

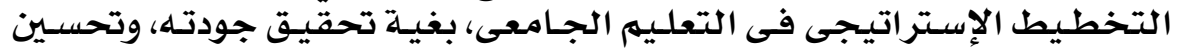

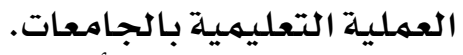

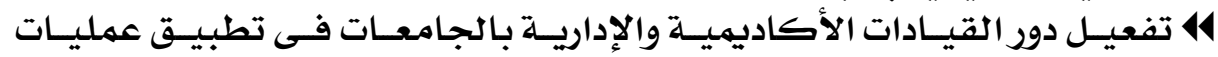

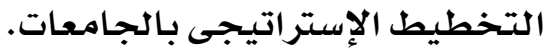

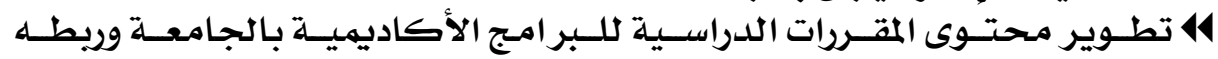

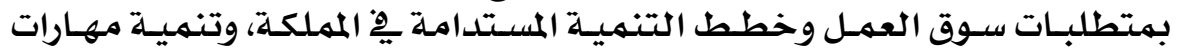

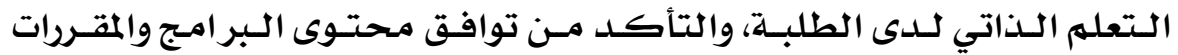

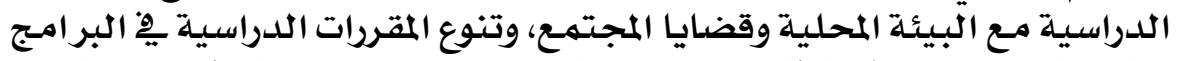

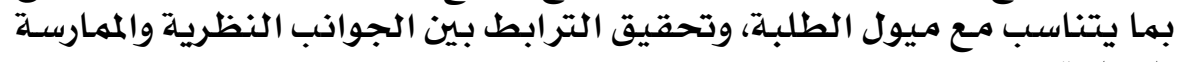

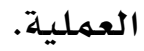

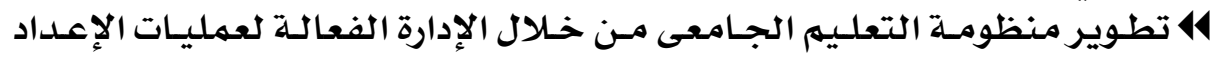

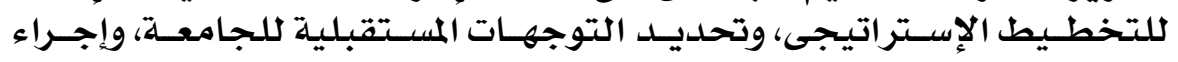

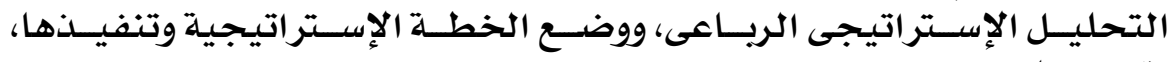
وتقييهـا.

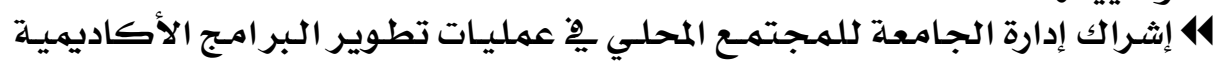

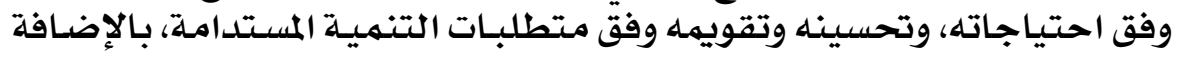

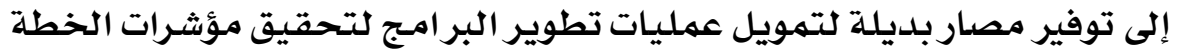

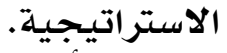
14 تطوير الأطر التنظيمية والتشريعية مـن أجل تحقيق الاستقلالية الإدارية

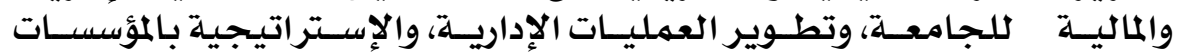

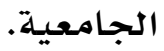

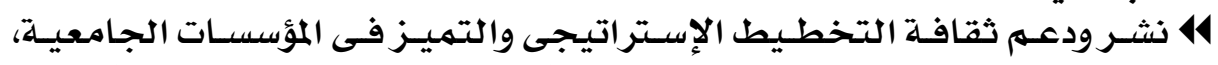

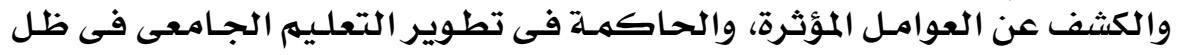

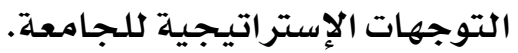

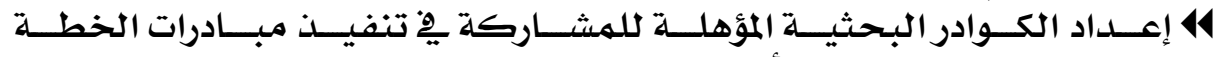

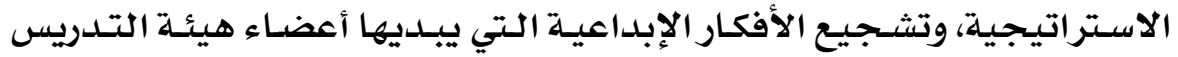

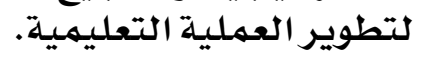

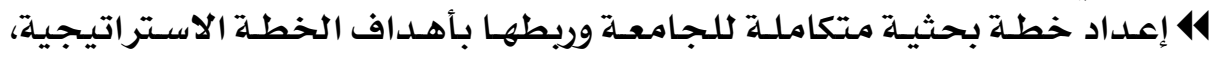

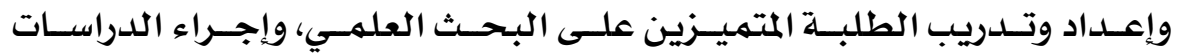
واطلاعهم على التجارب التطبيقية يِّ المجالات المختلفة.

\section{$\varepsilon 97$}




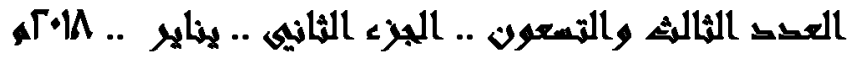

14 تطوير الخطة بصورة شمولية ومـرنة تحقق التوازن بين توقعات الأطراف المعنيـة

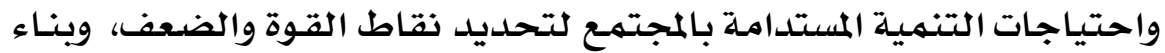

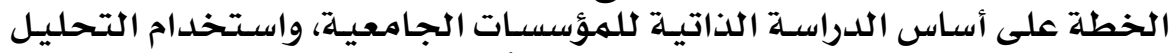

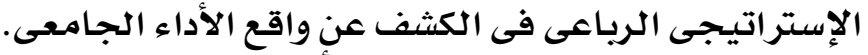

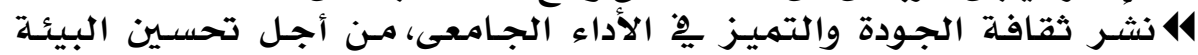

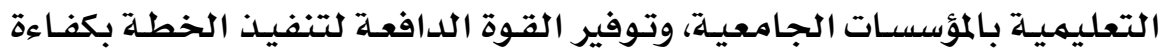
وفاعلية.

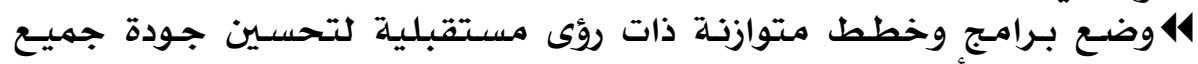

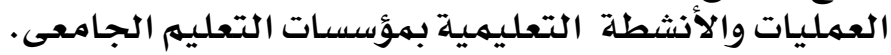

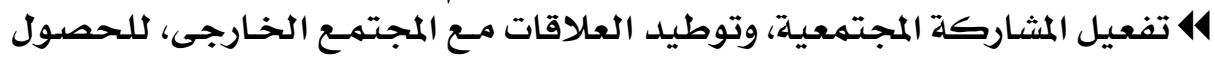

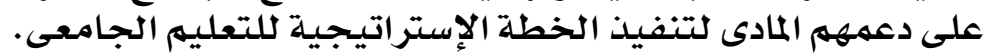

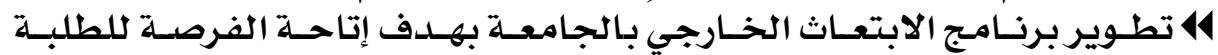

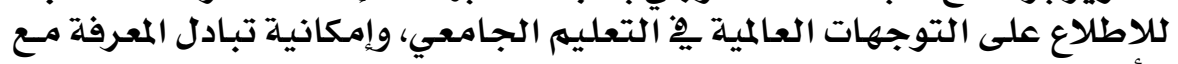

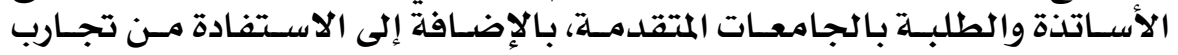

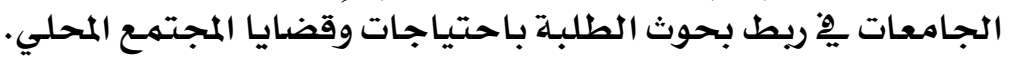

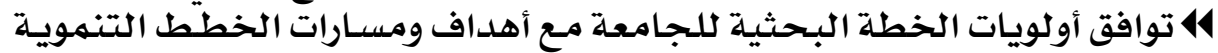

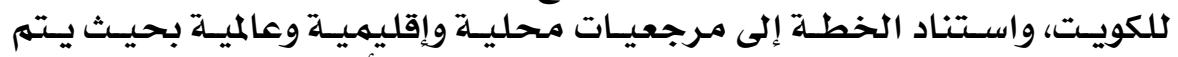

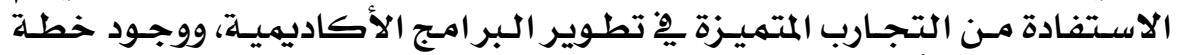

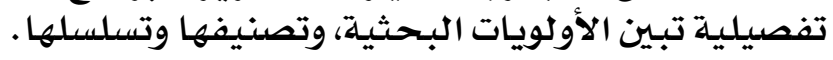

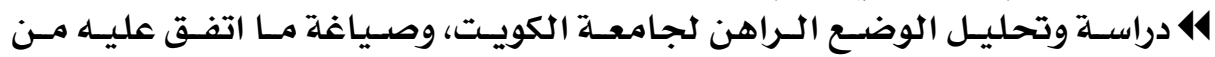

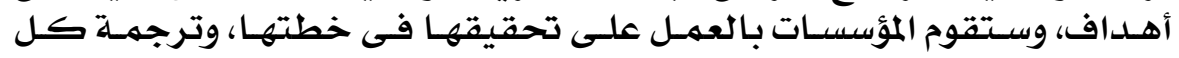

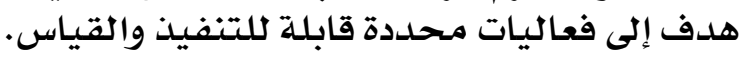

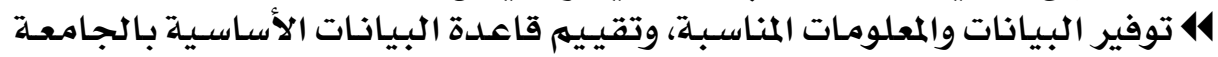

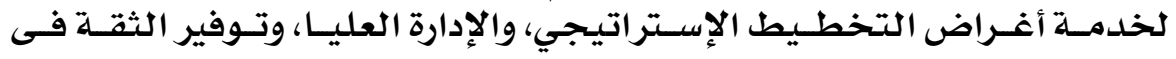

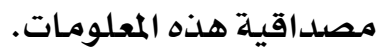

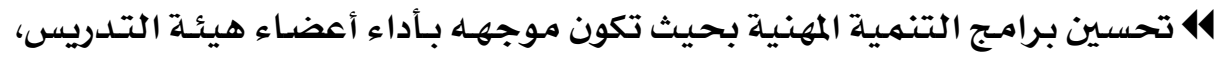

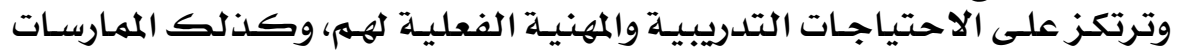

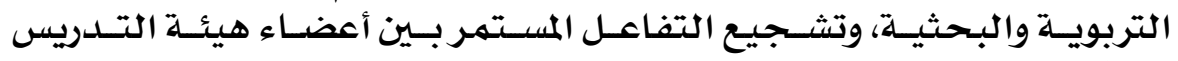

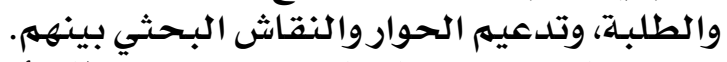

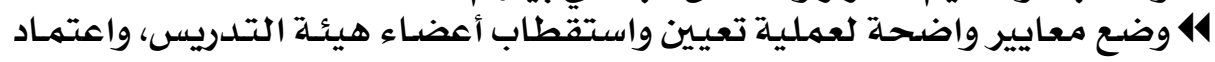

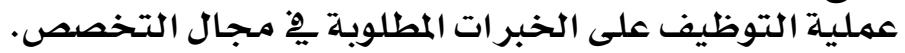

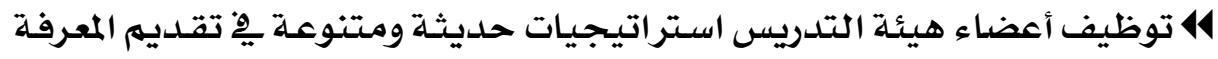

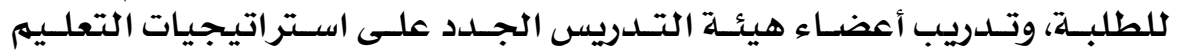

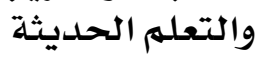

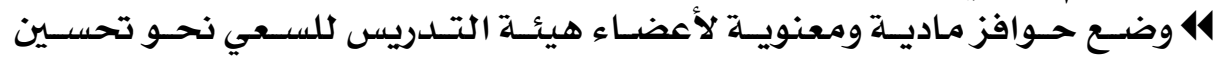

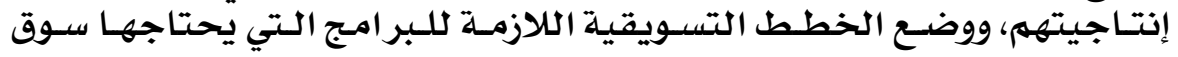

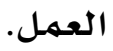




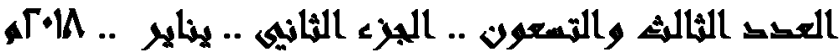

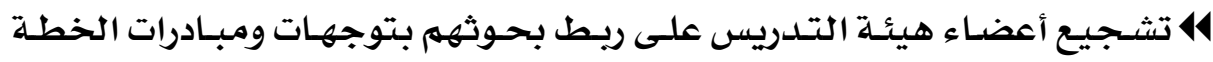

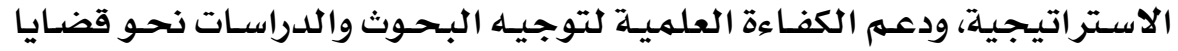

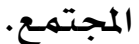

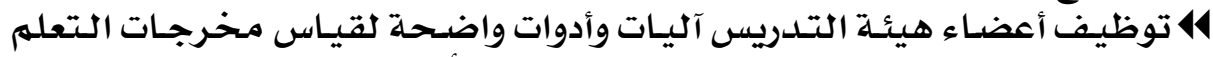

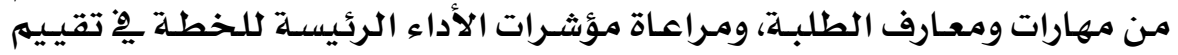

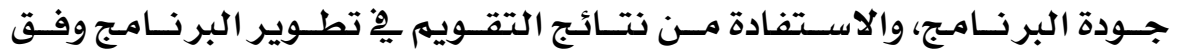

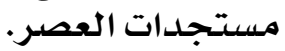

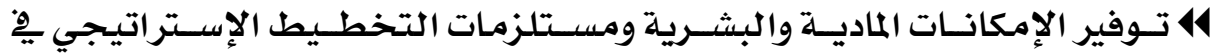
الجمامعات.

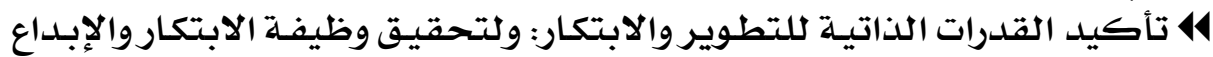

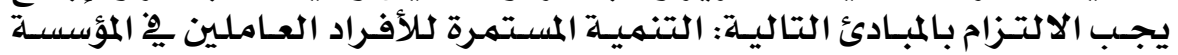

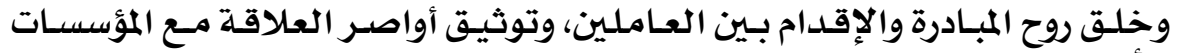

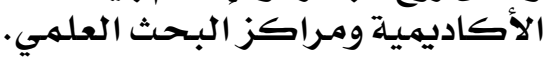

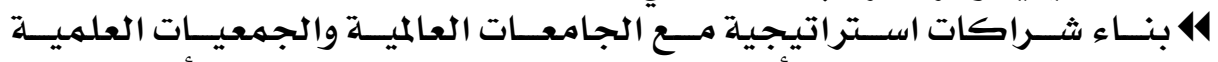

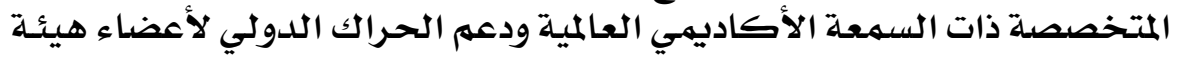

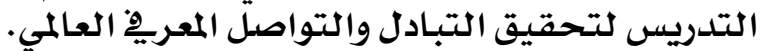

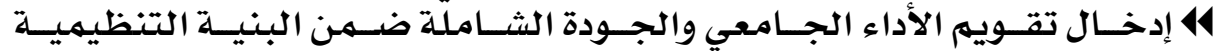

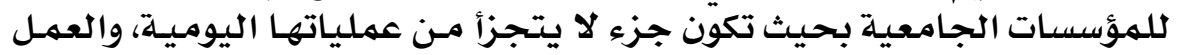

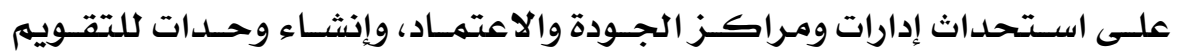

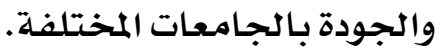

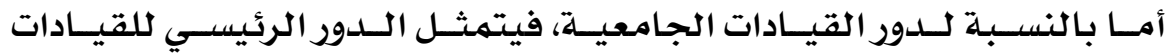

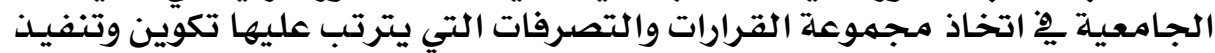

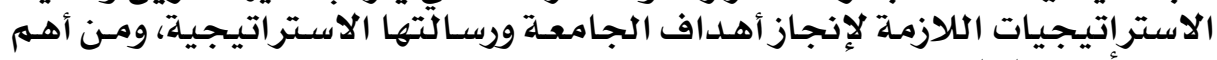

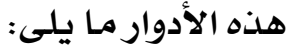

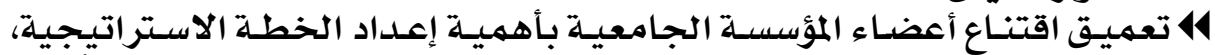

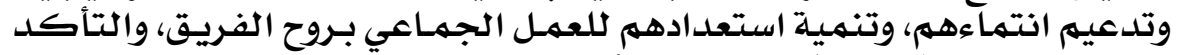

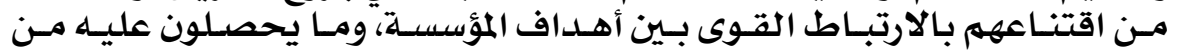

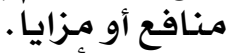

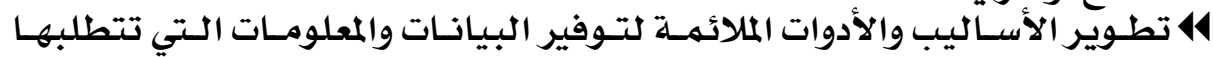

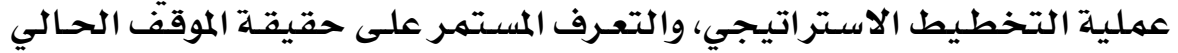

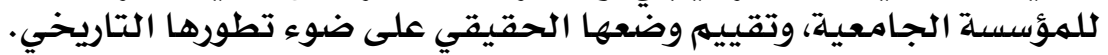

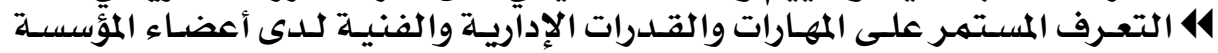

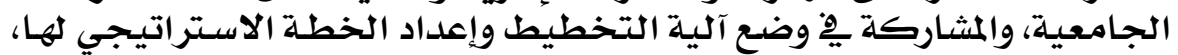

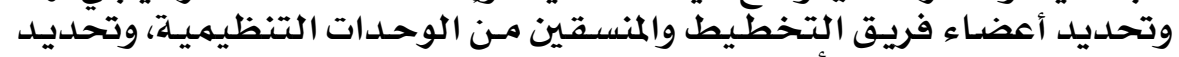

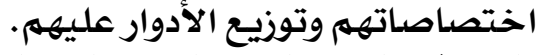

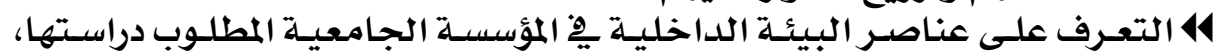

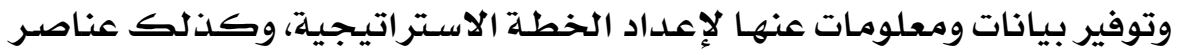
البيئة الخخارجية ونية. 


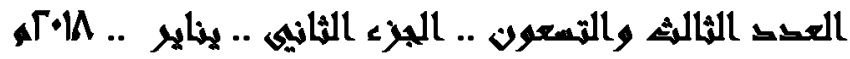

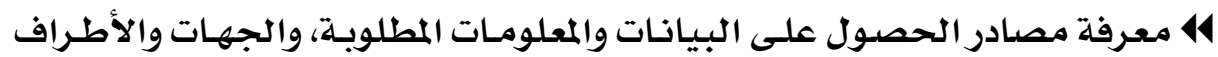

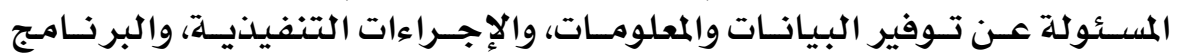

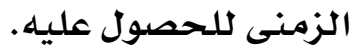

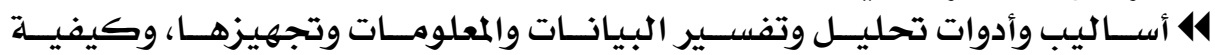

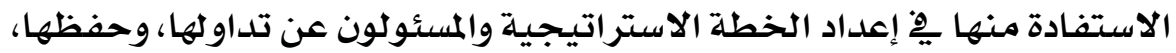

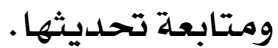

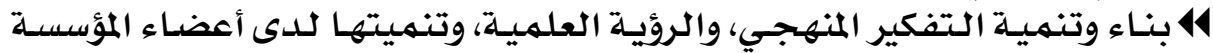

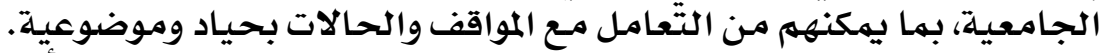

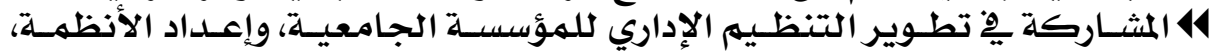

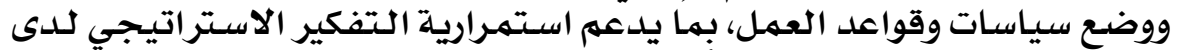

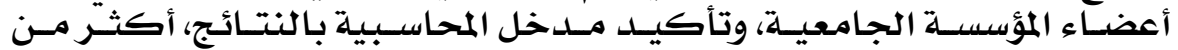

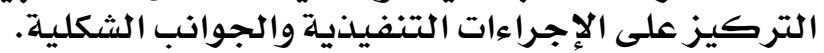

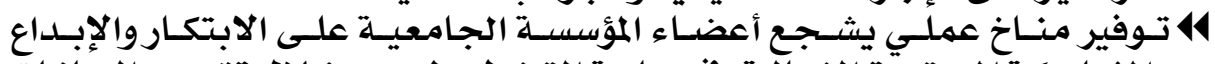

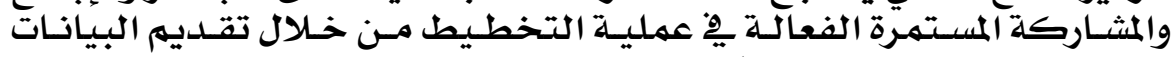

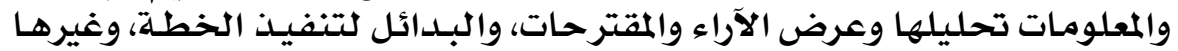

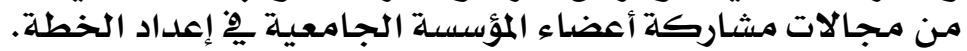

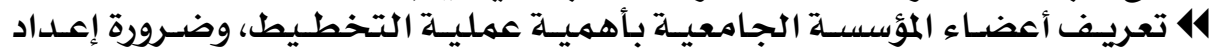

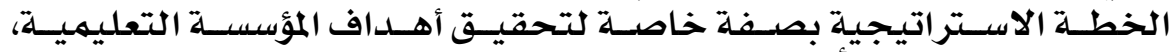

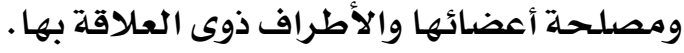

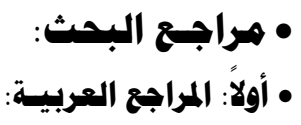

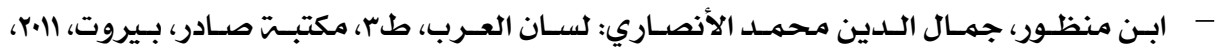

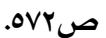
أبوبكر، مصطفى: إدارة الموارد البشريت مدخل لتحقيق الميزة التنافسيت، الدار الجامعيتة

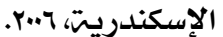

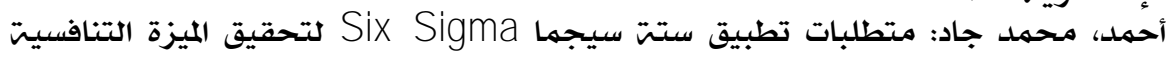

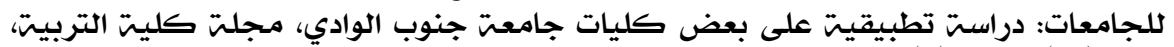

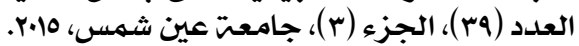

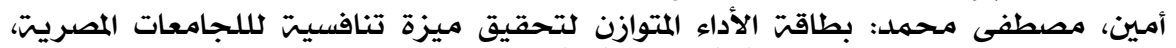

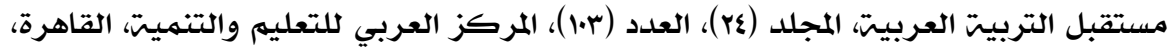
r. IV

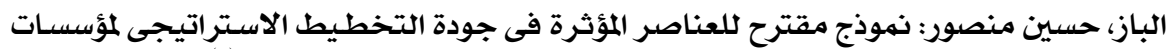

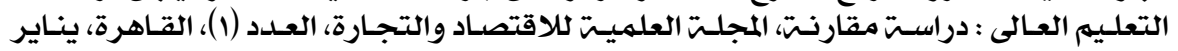

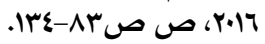

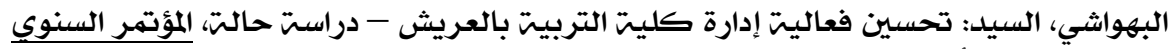

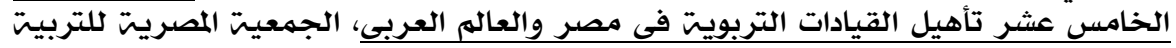

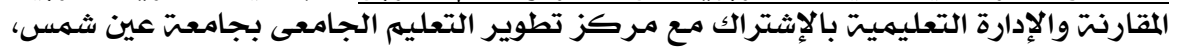

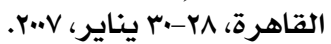

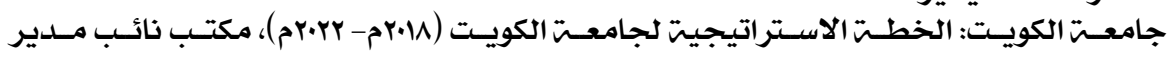

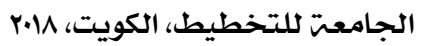




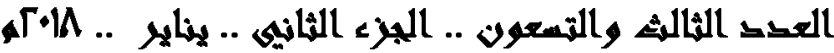

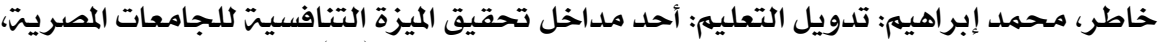

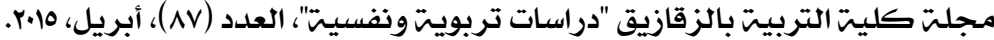

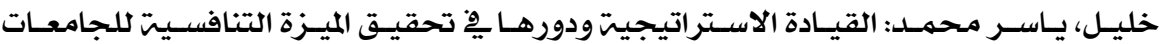

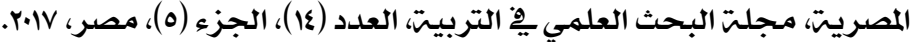

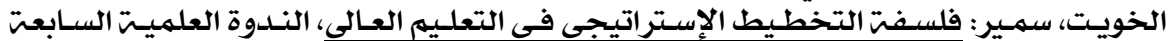

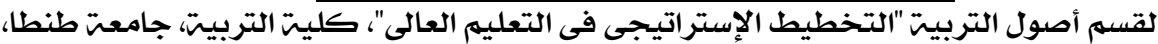

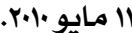

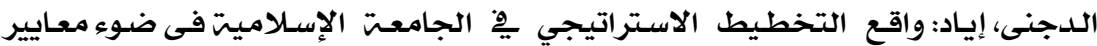

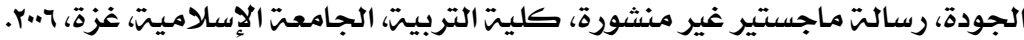
الدورى، زكريا: الإدارة الاستراتيجيت مفاهيهم وعمليات وحالات دراسيتة، دار اليازوري العلميتيت للنشر،

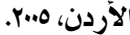

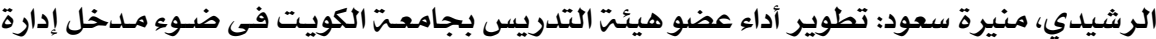

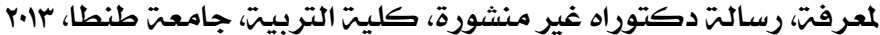

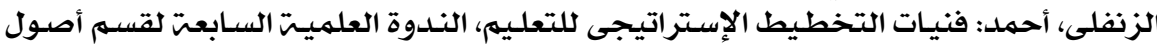

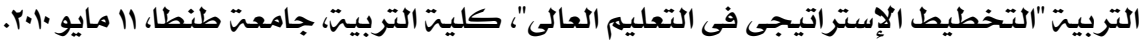

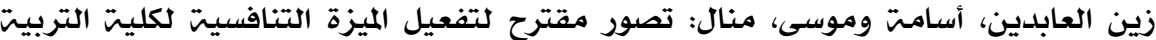

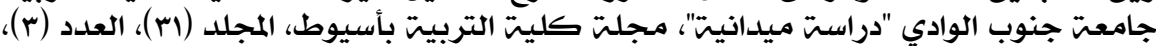

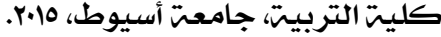

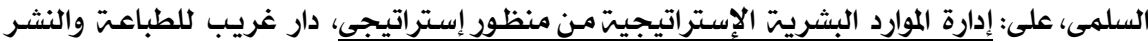

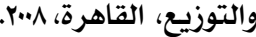

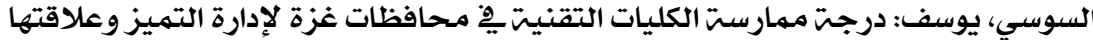

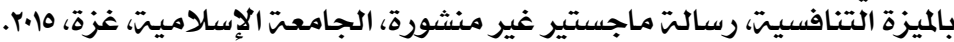

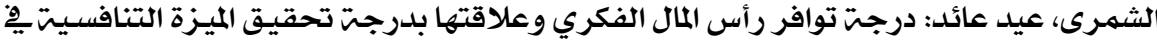

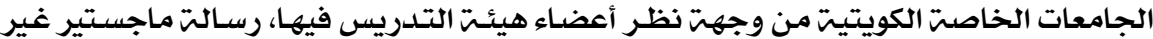

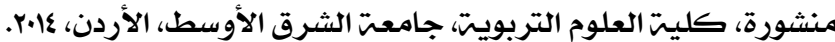

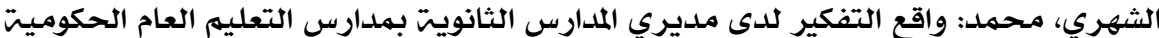

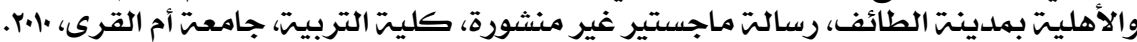

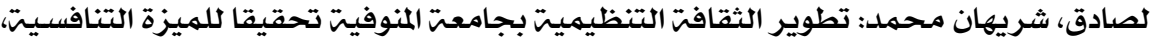

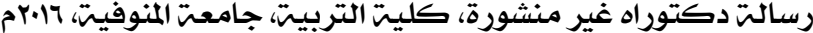

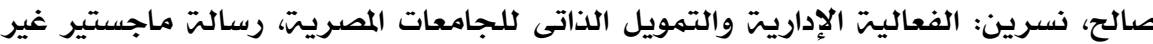

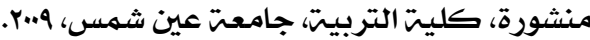

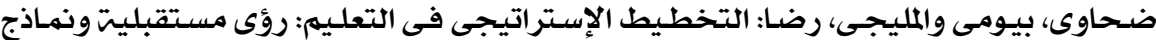

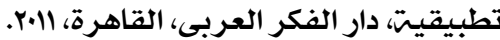

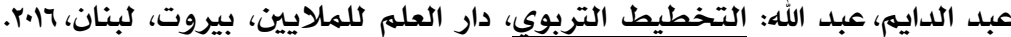

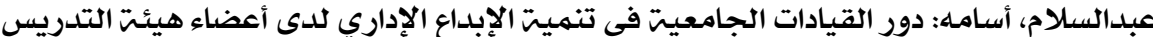

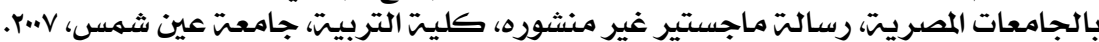

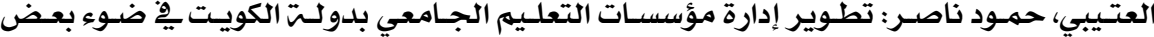

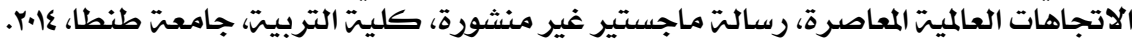

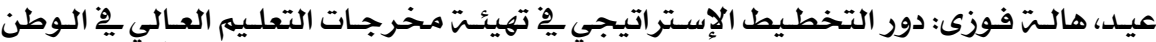

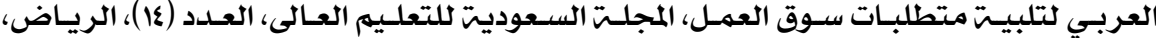

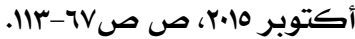
والغالبي، طاهر وإدريس، والب، وائل: الإدارة الاستراتيجيت من منظور متكامل، دار وائل للنشر

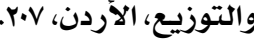




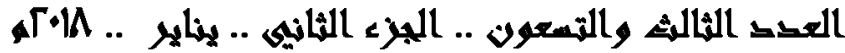

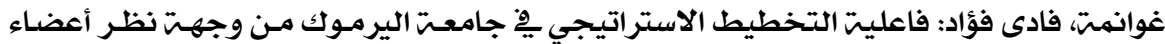

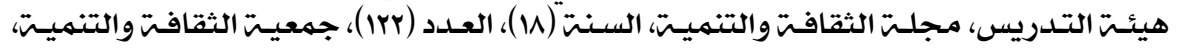

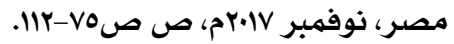

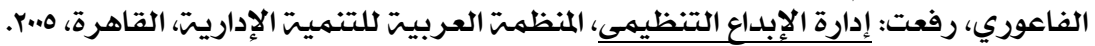

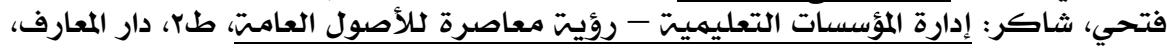

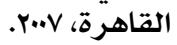

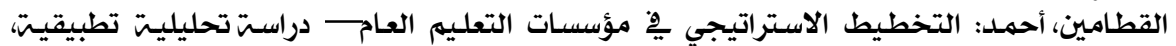

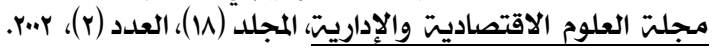

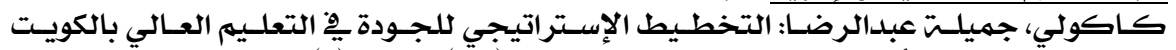

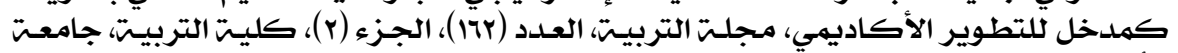

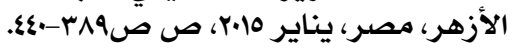

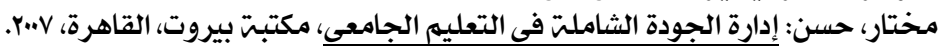

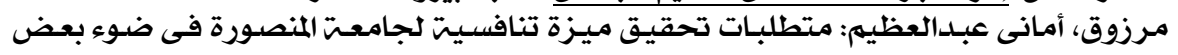

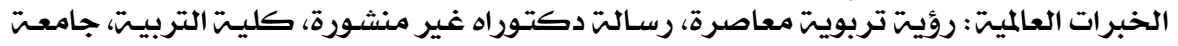

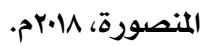

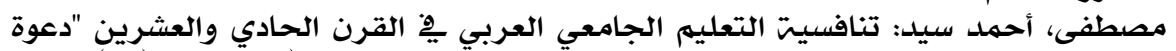

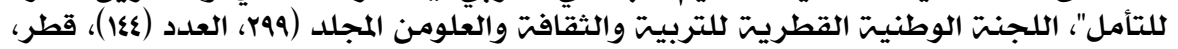

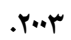

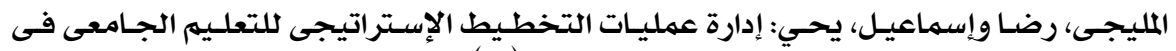

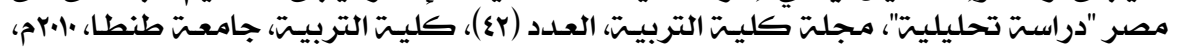

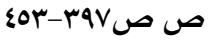

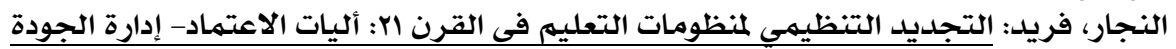

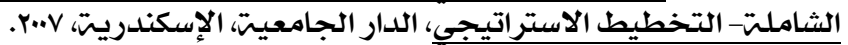

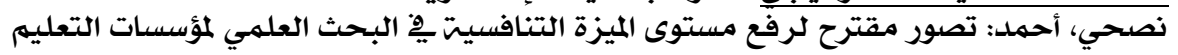

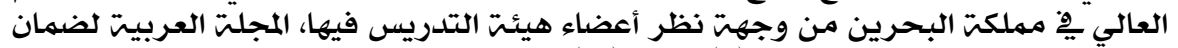

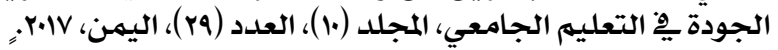

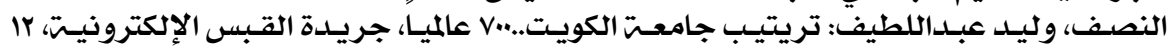

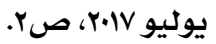

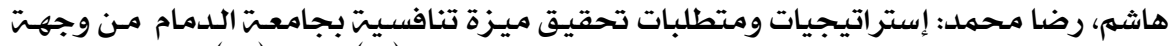

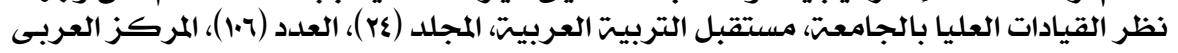

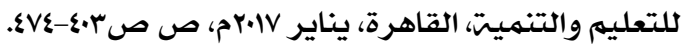

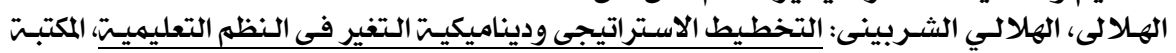

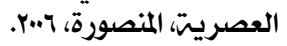

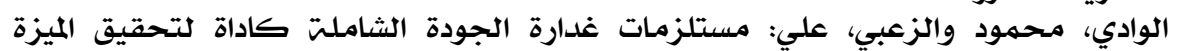

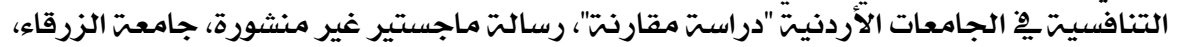

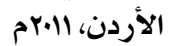

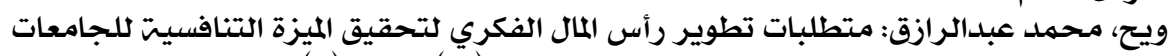

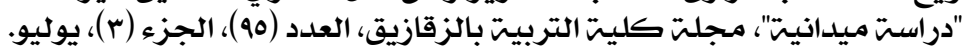

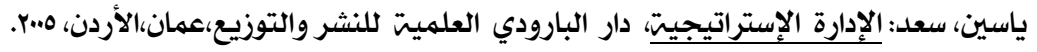

- Al-Daihani, Sultan: The Impact of Servant Leadership on Strategic Planning; A Field Study, The Educational Journal, Vol.31, Issue.123, Part (1), Kuwait University, June 2017, pp.11-37. 
- Bisaria, G.: Achieving Competitive Advantage by Private Management Colleges or Private Universities International Journal of Social Science and Interdisciplinary Research ، Vol. 2, No. 3, 2013, pp. 90-105.

- Burgess, E.: Stakeholders Perception of Strategic Planning in Higher Education; A Comparative Case Study of Two Institutions, PhD Dissertation, Graduate Faculty of the University of North Dakota, 2008

- Campell, V.: the perceived Impact of Strategic Planning on Professional Development in Berks County and Chester County Public School, Widener University, Dissertation Abstracts International, Vol. (64), No. (4), Issue (68), 2003.

- Campell, V.: the perceived Impact of Strategic Planning on Professional Development in Berks County and Chester County Public School, Widener University, Dissertation Abstracts International, Vol. (64), No. (4), Issue (68), 2003.

- Chang, G.: Strategic Planning in Education: Some Concepts and Methods, international Institute for Educational Planning, UNESCO, Paris, 2008.

- Davis, B.: From School Development plans to a Strategic Planning Framework, Diss, Abs. Int.. Vol. 56, No. 10, April 1996.

- Dooris, M.: Two Decades of Strategic Planning. Planning for Higher Education, Vol. 31, No.2, 2002.

- Fischer, B.: The Relationship between Leadership, Strategic Planning, and Capital Structure of Cardinal Stretch University, PhD Dissertation, College of Education and Leadership, Cardinal Stretch University , 2007

- Foon, S.: Capabilities Differentials As Sources of Sustainable Competitive Advantage: An Empirical Study on Malaysian Private Colleges/Institutions, PhD Thesis ،University of South Australia, Australia, 2005.

- Handzic, M.(2005): Knowledge Management through the Technology Glass, World Scientific Publishing Company, New Jersey, 2005

- Johnson, J.: Strategic Planning in the Millard Public Schools (1989-2003), $\mathrm{PhD}$ Dissertation, University of Nebraska, 2004.

- Khan, Hina \& Matlay, Harry (2009): Implementing Service Excellence In Higher Education. Education \& Training, Vol. 51 Issue: $8 / 9,769-780$.

- L u x t o n, A. \& et al: Strategic Planning in Higher Education, Education Department of the General Conference of Seventh-day Adventists, General Conference Department of Education, 2005

- Mashhadi, K. \& et al: A Quality-Oriented Approach toward Strategic Positioning in Higher Education Institutions, International Journal of Social Sciences, Vol. 2, No.4, 2007. 
- Meinhart, R.: Strategic Planning through Organization Lens, PhD Dissertation, George Washington University, 2004.

- Pearson, Andrew(2010): The Strategist's Choice: Competitive Strategy And The Question Of How To Compete, UBS Unique Business Strategies, P1.

- Porter, M. (2013): Competitiv Advantage: Creating \& Sustaining

- Prusha, T.: Strategic Planning in Community College Information Technology, A Delphi Study Model Program, PhD Dissertation, Iowa State University, 2006.

- Richards, C.: A New Paradigm: Strategies for Succession Planning in Higher Education, PhD Dissertation, Capella University, 2009

- Riza, A.: Strategic Planning at the State's Education Institutions Serving Open and Distance Education; Which are f Non-Profit Concern, Turkish Online Journal of Distance Education-TOJDE, Vol. 8, No. 1, January 2007

- Schueler, L.: How A University President inspires and maintains a Shared Vision during a Strategic Planning Process and Its Implementation, PhD Dissertation, Faculty of the Rossier School of Education, University of Southern California, 2007.

- Stevens, R.: Strategic Planning in Education, Open University Press, London, 2004.

- Suarez, A., Moreira, R.S., Carrapatoso,E.(2006): The Role Of Usability In The Competitiveness Of Higher Education Institutions, Papers Of Iadis International Conference : Applied Computing, San Sebastian, Spain, 25-28 February 2006, P314.

- Superior Performance, Free Press, New York.

- Williams, T.: Strategic Planning Leadership in Illinois Community Colleges; Who is Leading the Process, PhD Dissertation, University of Illinois, March 2009.

\section{潾喽溇溇}

